\author{
Universidade de São Paulo \\ Instituto de Física
}

\title{
Investigação da relação entre coeficientes termodifusivos em colóides magnéticos a base de água
}

(Versão corrigida)

\section{André Luiz Sehnem}

Orientador: Prof. Dr. Antônio Martins Figueiredo Neto

Tese de doutorado apresentada ao Instituto de Física como requisito parcial para a obtenção do título de Doutor em Ciências.

Banca Examinadora:

Prof. Dr. Antônio Martins Figueiredo Neto (IFUSP)

Prof. Dr. André de Pinho Vieira (IFUSP)

Prof. Dr. Paulo Alberto Nussenzveig (IFUSP)

Prof. Dr. Sérgio Carlos Zílio (IFSC-USP)

Prof. Dr. Luiz Roberto Evangelista (UEM) 


\section{FICHA CATALOGRÁFICA}

\section{Preparada pelo Serviço de Biblioteca e Informação}

do Instituto de Física da Universidade de São Paulo

\section{Sehnem, André Luiz}

Investigação da relação entre coeficientes termodifusivos em colóides magnéticos a base de água. São Paulo, 2018.

Tese (Doutorado) - Universidade de São Paulo. Instituto de Física. Depto. de Física Experimental.

Orientador: Prof. Dr. Antônio Martins Figueiredo Neto Área de Concentração: Fluidos Complexos.

Unitermos: 1. Termodifusão; 2. Colóides magnéticos; 3. Coeficiente Soret; 4. Coeficiente Seebeck; 5 . Termoeletricidade. 


\section{Agradecimentos}

Ao Prof. Dr. Antônio Martins Figueiredo Neto, pela oportunidade oferecida de realizar este trabalho e sua disposição para orientação.

À Lucimara Domingues de Oliveira, sempre ao meu lado dividindo alegrias e angústias.

Aos professores do Grupo de Fluidos Complexos da UnB, $\operatorname{Prof}^{\mathrm{a}} \operatorname{Dr}^{\mathrm{a}}$ Renata Aquino e Prof. Dr. Alex. F. C. Campos, pela colaboração no trabalho.

À Profa. Dra. Simone Wiegand, pela colaboração e ajuda com a pesquisa durante o estágio de Doutorado-Sanduíche em Forschungszentrum Jülich, Alemanha.

À Profa. Dra. Elizabeth P. G. Arêas do IQUSP, por permitir o uso de seu laboratório para parte da pesquisa.

Aos membros do Grupo de Fluidos Complexos.

Às agências de fomento, Cnpq e CAPES. 


\section{Resumo}

O presente trabalho investiga o fenômeno termodifusivo em dispersões coloidais de nanopartículas magnéticas de óxidos de ferro em água (ferrofluidos), com a formação de dupla camada elétrica em torno das partículas. A estabilidade da partícula em solução é controlada pela concentração de íons. Ao estabelecer uma diferença de temperatura através da amostra líquida, ocorre o efeito de termodifusão (efeito Soret) das partículas e de íons em solução. Este efeito é o movimento das partículas para o lado frio ou quente do gradiente de temperatura. O acúmulo para um dos lados do gradiente de temperatura depende das características da solução. O efeito Soret de ferrofluidos em soluções ácidas e básicas é descrito a partir da determinação experimental das grandezas físicas envolvidas na difusão das partículas. O coeficiente Soret $S_{T}$ e o coeficiente de difusão são determinados em experimentos ópticos de lente de matéria, utilizando o aparato experimental de Varredura-Z, e de espalhamento Rayleigh forçado para termodifusão. Para investigar a resposta dos íons ao gradiente de temperatura, são realizadas medidas do potencial termoelétrico em uma célula termoelétrica, gerado a partir da difusão das cargas dispersas no líquido. O potencial superficial das partículas também é investigado experimentalmente, para descrever a interação das partículas com o campo termoelétrico. Os experimentos são realizados em função da temperatura da amostra e usados para descrever os resultados $S_{T}(T)$ das partículas, a partir de equações dos principais modelos teóricos. Os resultados mostram as diferenças e semelhanças do efeito Soret das nanopartículas em soluções ácidas e básicas, e que em ambos os casos a termodifusão de nanopartículas reflete o comportamento termodifusivo dos íons dispersos em solução. 


\begin{abstract}
This work investigates the thermal diffusion phenomena in colloidal dispersions of iron oxide magnetic nanoparticles dispersed in water (ferrofluid). The particles are stable in water due to electrical double layer around the particles, controlled by the ionic concentration. A temperature gradient throughout the ferrofluid sample causes the thermodiffusion (Soret effect) of dispersed particles and ions. This effect is the movement of particles to the cold or hot side of the temperature gradient. The particles migration for a given side depends on the characteristics of the sample. The Soret effect of ferrofluids in acidic and basic solutions is described by the experimental measurements of the physical parameters associated to particles diffusion. The Soret coefficient $S_{T}$ and the mass diffusion coefficient are measured in the matter lens experiment in the Z-scan experimental setup, and by the use of Thermal Diffusion Forced Rayleigh Scattering experiments. Concerning the ionic response to the temperature gradient the thermoelectric field generated by charges diffusion is measured in a thermoelectric cell. The surface potential of the particles is also measured to describe its interactions with the thermoelectric field. These experiments are made as function of the temperature of the sample and the results are applied to describe the $S_{T}(T)$ of particles by the use of equations from the main theoretical models. The results show differences and resemblances of the Soret effect in acidic and basic nanoparticles solutions. In both kind of solutions the thermodiffusion of nanoparticles is mainly ruled by the thermodiffusion of ions dispersed in solution.
\end{abstract}




\section{Sumário}

1 Introdução 13

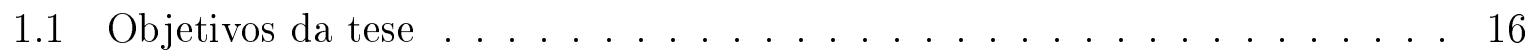

1.1.1 Efeito da temperatura . . . . . . . . . . . . 17

1.1.2 Efeitos específicos dos íons . . . . . . . . . . . . . 18

1.2 Organização da tese . . . . . . . . . . . . . . . . . . . . 19

2 Termodifusão em Dispersões Coloidais 23

2.1 Dispersão de nanopartículas em meio aquoso . . . . . . . . . . . . . . 24

2.1.1 Carga superficial e dupla camada eletrostática . . . . . . . . . . 24

2.1.2 Forças de van der Waals . . . . . . . . . . . . . . 28

2.1 .3 Interação magnética . . . . . . . . . . . . . . . . . 29

2.1.4 Teoria DLVO . . . . . . . . . . . . . . . 29

2.1.5 Potencial zeta . . . . . . . . . . . . . 30

2.2 Termodifusão em dispersões coloidais . . . . . . . . . . . . . . . . . 32

2.2.1 Fluxo de calor e de partículas ................ 32

2.2.2 Origem do efeito Soret em nanopartículas carregadas . . . . . . . 33

2.2.3 Contribuição da dupla camada eletrostática - modelo tipo capacitor 34

2.2.4 Campo termoelétrico . . . . . . . . . . . . 36

3 Materiais e Métodos $\quad 39$

3.1 Síntese e Caracterização das Nanopartículas . . . . . . . . . . . . . . 39

3.1.1 Síntese de ferrofluidos com nanopartículas de ferrite de cobalto . . . 39

3.1.2 Diluição de ferrofluidos em meios ácido e alcalino . . . . . . . . . . 41 
3.1.3 Microscopia Eletrônica de Transmissão e Espalhamento de raios X a Baixos Ângulos . . . . . . . . . . . . . . . . . . . 44 41

3.2 Potencial Zeta - Atenuação Eletroacústica . . . . . . . . . . . . . . . 44

3.2.1 Procedimento Experimental no espectrômetro acústico . . . . . . . 45

3.3 Potencial zeta e espalhamento dinâmico de luz . . . . . . . . . . . . . 47

3.4 Célula Termoelétrica - Medida do Coeficiente Seebeck . . . . . . . . . 48

3.4.1 Procedimento Experimental para medir o coeficiente Seebeck . . . . 51

3.4.2 Modelagem da célula termoelétrica. . . . . . . . . . . . . 52

3.5 Coeficiente Soret - Lente de Matéria . . . . . . . . . . . . 53

3.5.1 Difusão de calor e de massa em duas dimensões. . . . . . . . . . 54

3.5.2 Montagem Experimental - Varredura-Z . . . . . . . . . . 58

3.5.3 Procedimento experimental para determinar o coeficiente Soret. . . 58

3.5.4 Determinação dos coeficientes ópticos $d n / d \Phi$ e $d n / d T$. . . . . . 60

3.6 Coeficiente Soret - Experimento IRTDFRS . . . . . . . . . . . 60

3.6.1 Obtenção do Coeficiente Soret . . . . . . . . . . . . . . 62

$4 S_{T}(T)$ para ferrofluidos de solução ácida $\quad 65$

4.1 Resultados . . . . . . . . . . . . . . . . . 66

4.1.1 Lente Térmica e Lente de Matéria . . . . . . . . . . . 66

4.1 .2 Potencial zeta . . . . . . . . . . . . . 71

4.1.3 Campo termoelétrico - efeito Seebeck . . . . . . . . . . . . . 74

4.2 Análise teórica de $S_{T}(T) \ldots \ldots \ldots \ldots \ldots \ldots \ldots$

4.3 Conclusão - amostras em meio ácido . . . . . . . . . . . . . . . 79

5 Influência do Coeficiente $S_{T}^{\text {ion }}$ Sobre $S_{T} \quad 81$

5.1 Curvas experimentais de $\zeta^{\text {het }}(t)$ para soluções iônicas e de nanopartículas . 83

5.2 Coeficiente Soret de íons em função da concentração e temperatura . . . . 84

5.3 Descrição teórica proposta para o efeito Soret iônico . . . . . . . . . . . . 89

5.4 Coeficiente Soret de nanopartículas dispersas em soluções aquosas de hi-

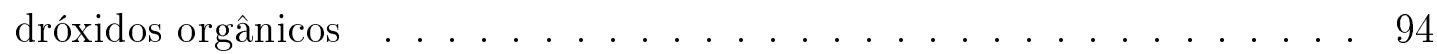


6 Relação entre $S$ e $S_{T}^{i o n}$ na célula termoelétrica

6.1 Resultados experimentais para soluções eletrolíticas . . . . . . . . . . . 105

6.1.1 Mudança rápida de $\Delta V(t)$, separação de cargas na camada difusa. . 106

6.1.2 Difusão de íons no bulk, descrição da mudança lenta de $\Delta V(t) \ldots$. 109

6.2 Coeficiente Seebeck na presença de nanopartículas . . . . . . . . . . 111

7 Conclusões e Perspectivas 


\section{Lista de Figuras}

1.1 Comportamento usual obtido para o coeficiente Soret em função da temperatura. Círculos representam resultados experimentais para nanopartículas de látex de poliestireno e quadrados são resultados para DNA plasmidial, ambos dispersos em água. As linhas contínuas são melhores ajustes para a equação 1.1. Figura adaptada de [1]. . . . . . . . . . . . . . . . 18

2.1 Modelo esquemático para a distribuição de íons em torno de uma partícula eletrostaticamente carregada e a distribuição do potencial eletrostático correspondente, sendo $r$ a distância à superfície da partícula. $\quad \ldots . . .26$

3.1 Esquema ilustrando o método de síntese de nanopartículas pelo método de coprecipitação. . . . . . . . . . . . . . . . . 40

3.2 (a) Imagem de MET de partículas de ferrofluido. (b) Distribuição de tamanhos obtida da análise de uma série de imagens e ajuste da distribuição

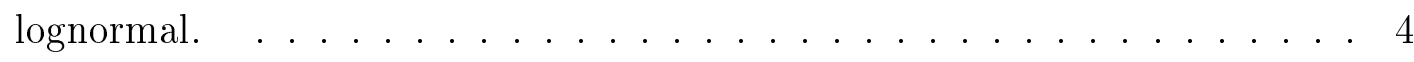

3.3 (a) Figura esquemática do experimento de SAXS. (b) Resultado característico da intensidade espalhada em função de $q$. . . . . . . . . . . . . . 43

3.4 Potencial zeta em função da temperatura para a amostra padrão de silicaLudox. Resultado para a concentração padrão $10 \%$ wt. sem descontar IVP (losango preto), $10 \%$ wt. descontando IVP (quadrado azul) e 0,5\% wt. descontando IVP (círculo vermelho) . . . . . . . . . . . . . . 47

3.5 Esquema do equipamento experimental de Espalhamento de Luz, para o espalhamento de luz dinâmico a $90^{\circ}$ e eletroforético a $15^{\circ}$. . . . . . . 48 
3.6 Esquema do experimento da célula termoelétrica para medir o coeficiente Seebeck das soluções de ferrofluido, a diferença de potencial induzida por um gradiente de temperatura $S=\Delta \mathrm{V} / \Delta T \ldots \ldots \ldots \ldots$

3.7 Esquema mostrando o princípio físico do efeito de lente gerado por um feixe Gaussiano. A fonte de luz laser utilizada é um Verdi-V10 Coherent de $532 \mathrm{~nm}$ de comprimento de onda. Um gradiente de temperatura e/ou concentração gera a (des)focalização do feixe original, como é descrito no

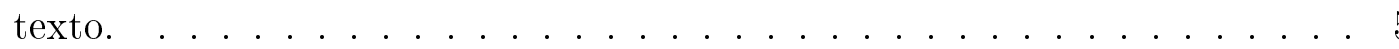

3.8 Figura esquemática do arranjo de Varredura-Z utilizado para medir os efeitos de lentes térmica e de matéria. A amostra (sample) é posicionada em torno do foco produzido pela lente L3, sendo que a duração dos pulsos de irradiação é controlado pela combinação do uso do chopper e shutter posicionados no foco da lente L1. A parte superior da figura ilustra a periodicidade dos pulsos para o experimento de lente térmica para determinar $\theta_{t h}$. O fotodetetor D1 faz a leitura de intensidade no centro do feixe. Um beam splitter BS também envia o feixe para o fotodetetor D2 que monitora a intensidade total do feixe pela focalização feita pela lente L4. . . . . . . 5

3.9 Valores para o índice de refração em uma solução de ferrofluido em várias temperaturas para algumas concentrações de partículas para obter o contraste de índice de refração $d n / d \Phi(T)$, mostrado no insert à esquerda. Os valores para $d n / d \Phi$ são obtidos a partir do ajuste linear aos dados $n \times \Phi$ para cada temperatura. . . . . . . . . . . . . . . . 61 
3.10 Desenho esquemático mostrando o experimento IRTDFRS, adaptado de [2]. Um feixe laser infravermelho é dividido em dois, sendo que um dos feixes segue para um espelho piezoelétrico e outro por uma placa de onda e uma célula Pockels, que controlam a diferença de fase entre eles. Os dois espelhos direcionam os feixes para dois prismas, usados para controlar o ângulo para a interferência dos feixes na amostra. Os feixes irradiam o mesmo spot na amostra (cell), sendo que um divisor de feixes antes da amostra direciona o feixe para uma câmera CCD, que permite visualizar o padrão de interferência. $\mathrm{O}$ feixe de leitura é direcionado diretamente através da amostra, e a intensidade espalhada pelas grades de temperatura e concentração medida por uma fotomultiplicadora. . . . . . . . . . .

4.1 Transmitância Normalizada em função do tempo $T_{N}(t)$, combinando curvas experimentais de Lente Térmica e de Lente de Matéria. No patamar indicando o tempo de saturação de Lente Térmica $t_{L T}$, o efeito térmico e Soret podem ser normalizados para análise separadamente.

4.2 Transmitância Normalizada para o experimento de Lente Térmica em função da posição z experimental para a amostra FF1, em duas temperaturas, $\mathrm{T}=20{ }^{\circ} \mathrm{C}$ - símbolos fechados - e $\mathrm{T}=60{ }^{\circ} \mathrm{C}$ - símbolos abertos. As linhas representam os melhores ajustes da equação para obter $\theta_{L T}$ e a posição

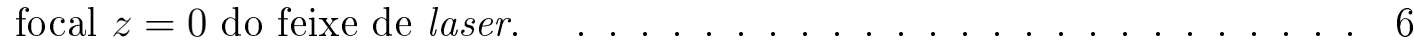

4.3 Valores de condutividade térmica obtidos pelo experimento de Lente Térmica para a amostra FF1 - símbolos fechados - e valores tabelados da mesma grandeza para a água pura. . . . . . . . . . . . . 68

4.4 Evolução temporal da Transmitância normalizada para a amostra FF2 em diferentes temperaturas: $(\bigcirc) 20{ }^{0} \mathrm{C},(\square) 35{ }^{0} \mathrm{C},(\diamond) 50{ }^{0} \mathrm{C}$, sendo que as linhas correspondem aos ajustes teóricos da equação 3.23. A diminuição do efeito de lente de matéria com o aumento de temperatura ocorre de forma semelhante para a amostra FF1, não mostrado. . . . . . . . . . . . . 69 
4.5 Coeficiente Soret em função da temperatura da amostras para as amostras FF1 (○) e FF2 (口). . . . . . . . . . . . . . . 70

4.6 Dependência com a temperatura do coeficiente de difusão de massa para a amostra FF1 (a) e FF2 (b). . . . . . . . . . . . . . 71

4.7 Valores de potencial zeta em diferentes temperaturas para a amostra FF1. 72

4.8 Esquema ilustrativo da distribuição de potencial em torno da partícula para as temperaturas mais baixa e alta investigadas considerando as interfaces de cargas (ver $[3,4])$, como descrito no texto principal. . . . . . . . . 73

4.9 Evolução temporal da diferença de potencial entre os eletrodos e amplitude do coeficiente Seebeck $S(T) \ldots \ldots \ldots \ldots \ldots$. . . . . . . 75

4.10 Melhor ajuste teórico da equação de Iacopini para $S_{T}(T)$ das amostras FF1

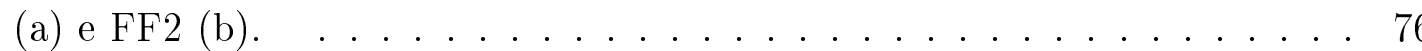

4.11 Comparação entre os resultados experimentais e o cálculo teórico (linha contínua) usando a equação 4.12 para os dados da amostra FF1. . . . . . 77

4.12 Melhor ajuste teórico da equação 4.12 sobre os dados experimentais para a amostra FF2.

4.13 Dependência com a temperatura dos termos que mais contribuem para o coeficiente Soret das nanopartículas (termoelétrico e dupla camada) em solução ácida e a soma total. (a) Amostra FF1 e (b) Amostra FF2. . . . . 78

4.14 Comparação teórica com o coeficiente Soret da amostra FF1 usando o modelo de dupla camada elétrica completo com mais um termo independente.

5.1 (a) Sinal medido no experimento IRTDFRS para soluções aquosas de TMAOH em duas diferentes concentrações: $8 \mathrm{mMol} / \mathrm{L}$ (quadrados vermelhos) e 40 mMol/L (círculos pretos), e (b) para nanopartículas dispersas em soluções com $2 \mathrm{mMol} / \mathrm{L}$ e $20 \mathrm{mMol} / \mathrm{L}$ de TMAOH. . . . . . . . . . . . . . 84

5.2 Coeficiente Soret $S_{T}^{\text {ion }}$ em função da concentração $(\mathrm{M}=\mathrm{Mol} / \mathrm{L})$ de íons nas soluções aquosas de (a) TMAOH e (b) TBAOH nas temperaturas de 293 K (azul) e 333 K (vermelho). As linhas contínuas em (a) são guias para os olhos. 
5.3 (a) Coeficiente de difusão $D_{i o n}$ e (b) coeficiente de difusão $D_{T}^{i o n}$ em função da concentração de íons nas soluções aquosas de TMAOH (símbolos fechados) e TBAOH (símbolos abertos) nas temperaturas de $293 \mathrm{~K}$ (azul) e 333

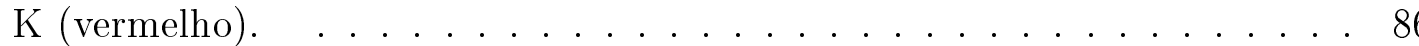

5.4 Coeficiente Soret $S_{T}^{\text {ion }}$ em função da temperatura para soluções aquosas de TMAOH (círculos azuis) e TBAOH (quadrados vermelhos), para concentrações iônicas de 0.024 e $0.02 \mathrm{~mol} / \mathrm{L}$, respectivamente. . . . . . . . . . . 87

5.5 (a) Constante de difusão $D_{i o n}$ e (b) Constante de difusão térmica $D_{T}^{i o n} \mathrm{em}$ função da temperatura para os sais investigado neste trabalho: TMAOH (círculo azul), TBAOH (quadrado vermelho), $\mathrm{NaOH}$ (triângulo rosa), $\mathrm{HNO}_{3}$ (triângulo preto), $\mathrm{NaCl}$ (estrela púrpura) e $\mathrm{KCl}$ (triângulo oliva). A linha contínua representa os valores calculados com a equação teórica $D_{T}=$ $\beta D_{t h}$, como descrito no texto principal. $\ldots \ldots \ldots . \ldots 8$

5.6 Esquema ilustrativo do deslocamento de um íon em um gradiente de temperatura. Em uma dada temperatura $T$ a energia de hidratação é dada por $\triangle G^{\text {hid }}(T)$, enquanto que a uma distância $\delta z$ e temperatura $T+\delta T$ a energia é $\triangle G^{\text {hid }}(T+\delta T)$. Sendo $\triangle G^{\text {hid }}$ associado ao trabalho $W^{\text {hid }}$ para retirar e recolocar a camada de hidratação em torno do íon, o deslocamento pode ser imaginado por um processo sem gasto de energia $W=0$. A força $F^{\text {hid }}$ move o íon para o quente (ou frio) se $\triangle G^{\text {hid }}(T)>\triangle G^{\text {hid }}(T+\delta T)$ (ou $\left.\triangle G^{h i d}(T)<\triangle G^{h i d}(T+\delta T)\right) \ldots \ldots \ldots \ldots \ldots$. . . . . . . . . 91 
5.7 Ilustração da organização das moléculas de água em torno de diferentes íons. À esquerda, os íons utilizados neste trabalho para dispersão de nanopartículas, $\mathrm{TBA}^{+}$e $\mathrm{TMA}^{+}$, e à direita os íons monoatômicos utilizados em trabalhos anteriores para investigar o efeito Soret. Devido ao efeito hidrofóbico nos íons orgânicos, as moléculas de água próximas aos íons não demonstram a interação eletrostática íon - dipolo da água, como pode ser visualizado para os íons monoatômicos. As pequenas barras pretas paralelas a ligações O-H da água ilustram a existência de uma interface entre os íons orgânicos. . . . . . . . . . . . . . . . . 93

5.8 Distribuição de diâmetro hidrodinâmico $d=2 R_{h}$ para as partículas da amostra FF3 obtido por DLS. . . . . . . . . . . . . 95

5.9 Coeficiente Soret em função da temperatura para as nanopartículas dispersas em soluções de (a) TMAOH e (b) TBAOH, nas seguintes concentrações de hidróxidos: $0 \mathrm{mMol} / \mathrm{L}$ (quadrado preto), 0,1 mMol/L (círculo vermelho), 0,5 mMol/L (triângulo azul claro), $1 \mathrm{mMol} / \mathrm{L}$ (losango oliva) e $2 \mathrm{mMol} / \mathrm{L}$ (triângulo azul escuro). As linhas contínuas são os melhores ajustes realizados com a equação 1.1, sendo as cores das linhas correspondentes às cores dos resultados experimentais. . . . . . . . . . . . . . 96

5.10 Coeficiente de difusão térmica $D_{T}$ em função da temperatura para as nanopartículas dispersas em soluções de (a) TMAOH e (b) TBAOH, nas seguintes concentrações de hidróxidos: $0 \mathrm{mMol} / \mathrm{L}$ (quadrado preto), 0,1 $\mathrm{mMol} / \mathrm{L}$ (círculo vermelho), 0,5 mMol/L (triângulo azul claro), $1 \mathrm{mMol} / \mathrm{L}$ (losango oliva) e $2 \mathrm{mMol} / \mathrm{L}$ (triângulo azul escuro). Os quadrados preenchidos mostram valores de $D_{T}$ para as soluções iônicas. . . . . . . . . . . 97 
5.11 Condutividade elétrica das soluções de nanopartículas (símbolos fechados) contendo hidróxidos nas soluções indicadas, comparado com os valores esperados pela soma dos valores para solução de nanopartículas + soluções de hidróxidos medidos separadamente (símbolos abertos), em função das concentrações de (a) TMAOH e (b) TBAOH. Os símbolos quadrados são resultados para $\mathrm{T}=20{ }^{\circ} \mathrm{C}$ e losangos para $\mathrm{T}=50{ }^{\circ} \mathrm{C} \ldots \ldots \ldots$

5.12 Linhas contínuas mostram resultados dos cálculos realizados com equação 2.27 e as linhas tracejadas os cálculos da equação 2.26, mostrando a influência da dependência com a temperatura da energia na dupla camada elétrica para (a) solução inicial $c^{N a O H} \leq 0,01 \mathrm{mMol} / \mathrm{L}$ e (b) $1 \mathrm{mMol} / \mathrm{L}$ de TMAOH (cor preta) e TBAOH (cor verde). . . . . . . . . . . . 100

5.13 Carga efetiva $Q_{e}$ das nanopartículas em função da temperatura, calculada pela equação 2.16 sem adição de hidróxidos (azul) e adição de $1 \mathrm{mMol} / \mathrm{L}$ de

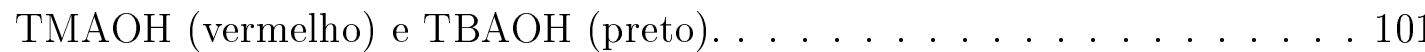

5.14 Linhas contínuas mostram resultados dos cálculos realizados com equação 2.29 mostrando a influência do efeito Seebeck para (a) solução inicial $c^{\mathrm{NaOH}} \leq 0,01 \mathrm{mMol} / \mathrm{L} \mathrm{e} \mathrm{(b)} 1 \mathrm{mMol} / \mathrm{L}$ de TMAOH (linha preta) e TBAOH (linha oliva). . . . . . . . . . . . . . . . . 102

5.15 Descrição mais provável do efeito Soret como a combinação das influências da dupla camada elétrica e do gradiente de concentração iônico. (a) Linha contínua é a soma dos valores com as equações 2.27 e 2.23 para a solução inicial $c^{\mathrm{NaOH}} \approx 0,01 \mathrm{mMol} / \mathrm{L}$. Em (b) (partículas com TMAOH) e (c) (partículas com TBAOH) as linhas pretas são os valores obtidos pela equação 2.23 e linhas oliva representam a soma das equações 2.27 e 2.23. Além dos dados para $1 \mathrm{mMol} / \mathrm{L}$ (losango oliva) e para $2 \mathrm{mMol} / \mathrm{L}$, são adicionados dados para $20 \mathrm{mMol} / \mathrm{L}$ de hidróxidos adicionados às nanopartículas. . . . . 103 
6.1 Curvas experimentais para $\triangle V(t)$ obtidos para os experimentos na célula termoelétrica para sais diluídos em água, sendo a separação dos eletrodos $l=11 \mathrm{~mm}$ e $\Delta T=10 \mathrm{~K}$ e temperatura média da célula $\mathrm{T}=298 \mathrm{~K}$. (a) $\mathrm{HCl}$ (azul), $\mathrm{HNO} 3$ (vermelho) e $\mathrm{LiCl}$ (preto) e (b) $\mathrm{NaOH}$ (azul), TMAOH (vermelho) e TBAOH (verde). . . . . . . . . . . . . . 106

6.2 Coeficiente Seebeck $S$ em função do tempo para nanopartículas da amostra FF4, dispersas em TMAOH. (a) Temperatura média da célula T $=298 \mathrm{~K}$; o inset na figura mostra que o potencial $V_{T}$ surge durante a estabilização de $\triangle T$, e que o tempo para o máximo do efeito Soret iônico é menor em relação aos resultados obtidos nas soluções iônicas sem nanopartículas. (b) Resultado para a temperatura média da célula $\mathrm{T}=328 \mathrm{~K}$, mostrando que a mudança de $\Delta V$ é mais rápida para ambos os efeitos em comparação com (a), devido ao aumento de temperatura. . . . . . . . . . . . 112

6.3 Coeficiente Seebeck em função do tempo para nanopartículas da amostra FF5, dispersas com TBAOH, mostrando o efeito da temperatura média na célula $\mathrm{T}=298 \mathrm{~K}$ (linha tracejada) e $\mathrm{T}=323 \mathrm{~K}$ (linha contínua). . . . . . 113 


\section{Lista de Tabelas}

3.1 Dados sobre as amostras usadas nesse trabalho: Nome da amostra, íons dispersantes, diâmetro médio e fator de dispersão da equação lognormal e o pH e concentração volumétrica de cada amostra-mãe. Para os experimentos que determinam $S_{T}$, as amostras foram diluídas para concentrações $\Phi \sim$ 0,1\%. As amostras FF1 e FF2 são análises de TEM e FF3, FF4 e FF5 de

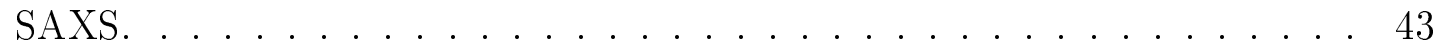

5.1 Valores de potencial- $\zeta$ de nanopartículas (em unidades de $\mathrm{mV}$ ) obtidos pelo experimento de espalhamento de luz eletroforético f . . . . . . . . 98

6.1 Tabela com valores obtidos para as duas diferentes contribuições do coeficiente Seebeck na célula termoelétrica, para os diferentes sais e a concentração utilizada. Os valores de $S$ são dados em $\mathrm{mV} / \mathrm{K}$. O sinal de $\Delta Q_{i}^{*}$ concorda com o de $S_{\triangle Q}^{e x p}$, a não ser para TBAOH. . . . . . . . . . 110 


\section{Capítulo 1}

\section{Introdução}

As nanopartículas magnéticas de óxidos de ferro dispersas em um líquido formam uma solução estável chamada ferrofluido, um tipo específico de suspensão coloidal $[5,6,7]$. Esses sistemas vêm sendo muito investigados nas últimas décadas devido a suas propriedades físicas e químicas $[8,9,10,11,12,13]$. A superfície dessas nanopartículas permite troca de cargas com o meio líquido quando dispersas em soluções eletrolíticas aquosas (líquido polar), ou adesão de moléculas surfactantes que possibilita a dispersão também em líquidos não polares $[12,14]$. Essa propriedade superficial permite a escolha de inúmeros líquidos ou soluções iônicas como dispersantes para as nanopartículas, formando diferentes suspensões coloidais. Devido a essas propriedades de superfície, há grande interesse biotecnológico no uso das partículas para carregar moléculas específicas a células e tecidos de organismos vivos $[15,16]$.

Devido ao interesse em explorar as propriedades físicas dos ferrofluidos, vários trabalhos já investigaram seu comportamento termodifusivo [17, 18, 19, 20, 21, 22, 23], que é o acúmulo de partículas induzido por um gradiente de temperatura para a parte fria ou quente da solução. Existem duas linhas distintas de pesquisa, considerando ou não a influência de campo magnético na termodifusão das nanopartículas de óxidos de ferro. Na ausência de campo magnético externo é possível usar as propriedades comuns a todas as partículas coloidais para descrever a estabilidade e a difusão dessas partículas. Os experimentos costumam investigar a influência da concentração de partículas e de íons/moléculas estabilizantes sobre o efeito termodifusivo [18, 21]. Descrições teóricas 
também foram desenvolvidas levando em consideração o tipo de recobrimento da nanopartícula [24, 25, 26], e comparados com resultados em ferrofluidos de solução ácida $[27,28]$. Na presença do campo magnético a força magnética origina a formação de estruturas, sendo que essa característica é refletida nas diferentes dependências dos coeficientes termodifusivo e difusivo das nanopartículas. Tais coeficientes adquirem diferentes valores com relação à direção do campo magnético e quando este é paralelo ou perpendicular ao gradiente de temperatura $[29,30]$.

O efeito do recobrimento superficial das partículas tem sido muito investigado em trabalhos experimentais. Foi observado que nanopartículas eletrostaticamente carregadas dispersas em solução eletrolítica ou estabilizadas por surfactantes podem acumular no lado frio ou quente dependendo do sinal da carga superficial [19, 22]. Apesar de observar comportamentos gerais, poucos resultados experimentais quantitativos foram comparados com modelos microscópicos até há poucos anos. Com o desenvolvimento dos vários modelos teóricos para o coeficiente termodifusivo de nanopartículas em geral (descritos no próximo capítulo), os experimentos com ferrofluidos passaram a ser realizados para buscar a descrição mais fundamental, o principal mecanismo físico responsável pelo comportamento termodifusivo [18] que possibilite o uso do efeito no controle da difusão das nanopartículas em gradientes de temperatura. Em um trabalho anterior usando nanopartículas de ferrite de cobalto com carga superficial positiva, dispersas em ácido nítrico, foi observado que o coeficiente Soret das nanopartículas aumenta com o aumento do tamanho das partículas [31, 32], e resultados experimentais com diferentes concentrações de sal mostraram a influência da dupla camada elétrica no comportamento termodifusivo.

No presente trabalho o interesse é investigar os efeitos físicos responsáveis pela migração de nanopartículas em um gradiente de temperatura estabelecido em amostras de ferrofluidos. O efeito de mover partículas e moléculas em um gradiente de temperatura é chamado de efeito Soret, fenômeno que vem sendo observado em todos os tipos de gases [33, 34], misturas líquidas [35, 36, 37, 38], moléculas e polímeros [39, 40, 41] e em dispersões coloidais [42, 43, 44, 45, 46] desde sua descoberta por C. Ludwig e C. Soret nos anos 1850 a 1880 em soluções iônicas $[47,48,49]$. Em colóides o efeito Soret pode também ser 
denominado de termoforese, sendo que o efeito consiste de um fluxo de partículas para o lado frio ou quente do gradiente de temperatura. Em misturas líquidas e gases ocorre processos de interdifusão dos dois componentes.

A descrição do efeito termodifusivo de nanopartículas de ferrofluidos que adquirem carga superficial em solução iônica de água $[50,51]$ é o interesse desse trabalho. Para dispersar as nanopartículas metálicas em água, são utilizados alguns ácidos e bases que promovem a protonação ou desprotonação dos sítios de carga superficial da nanopartícula [50]. Na superfície da nanopartícula haverá uma densidade de carga total dada pela combinação dos prótons ou hidróxidos nos sítios de carga e de contra-íons condensados na superfície devido à alta carga superficial. Uma camada difusa de íons é gerada a partir da superfície da partícula, a qual se move pela água com uma carga efetiva caracterizada pelo potencial eletrocinético ou potencial-zeta $[52,53]$. A extensão da camada difusa é caracterizada pela distância de Debye $\kappa^{-1}=\left(\epsilon k_{B} T / 2 e^{2} c_{0}\right)^{1 / 2}$, onde $\epsilon$ é a permissividade dielétrica, $k_{B}$ a constante de Boltzmann, $T$ a temperatura, e a carga elétrica do íon e $c_{0}$ a concentração molar de íons adicionados à solução. Ao estabelecer um gradiente de temperatura em uma solução contendo nanopartículas de óxido de ferro, íons e nanopartículas irão migrar para o lado frio ou quente. A origem desse movimento temodifusivo é descrita em algumas teorias, como a mudança da energia armazenada na camada difusa [54] ou o surgimento de um campo termoelétrico devido à diferente resposta de ânions e cátions [55], originando movimento das nanopartículas carregadas. A diferente resposta dos íons está associada ao e calor de transporte de cada íon [56, 57].

O fluxo de nanopartículas pelo movimento gerado em um gradiente de temperatura $\nabla T$ é definido por $\mathbf{j}_{T}=-\Phi D_{T} \tilde{\nabla} T$, sendo $\Phi$ a concentração volumétrica de partículas e $D_{T}$ o coeficiente de difusão térmica das nanopartículas. O acúmulo de nanopartículas no lado frio ou quente faz com que a lei de Fick origine um contrafluxo que força as partículas de volta à distribuição uniforme por toda a amostra dado por $\mathbf{j}_{c}=-D \tilde{\nabla} \Phi$, sendo $D$ a constante de difusão e $\nabla \Phi$ o gradiente de concentração de partículas. Após tempo suficiente da ação do gradiente de temperatura as duas contribuições adquirem igual intensidade e um estado estacionário, ou um perfil de distribuição de partículas 
estacionário se estabelece pela amostra. Nessa situação, o coeficiente Soret é definido como $S_{T}=D_{T} / D$, sendo que a migração das partículas para o lado frio define $D_{T}>0$ e para o lado quente $D_{T}<0$. Por consequência a mesma definição de sinal é utilizada para $S_{T}$. As questões fundamentais sobre a termodifusão de nanopartículas estão sobre o sinal e amplitude dos coeficientes $D_{T}$ e $S_{T}$, para descrever o efeito termodifusivo em amostras de interesse [58]. Algumas teorias calculam expressões para o coeficiente $D_{T}$, sendo que as grandezas físicas nas expressões teóricas podem ser determinadas experimentalmente ou são conhecidas para a água quando as concentrações de íons e partículas são muito baixas.

\subsection{Objetivos da tese}

O coeficiente Soret das nanopartículas de ferrofluidos, chamado de $S_{T}$ em todo o texto, é investigado experimentalmente neste trabalho utilizando diferentes ácidos e bases como íons dispersantes. Algumas teorias existentes para o coeficiente Soret são utilizadas para investigar os principais mecanismos físicos responsáveis pelo efeito Soret destas nanopartículas. Grandezas físicas envolvidas nas expressões teóricas também são determinadas por diferentes experimentos. Por exemplo, a dependência com a temperatura da energia eletrostática na camada difusa de íons (ou dupla camada elétrica) em torno da partícula se reflete nos valores do potencial eletrocinético ou potencial zeta, $\zeta$, grandeza acessada experimentalmente para estimar a contribuição da camada difusa no valor obtido experimentalmente para $S_{T}[59]$.

Os íons em solução respondem ao gradiente de temperatura possuindo efeito Soret intrínseco, que será investigado de duas formas. A primeira é a resposta termoelétrica, caracterizada pela determinação do coeficiente Seebeck dos íons [55], $S=-\triangle V / \triangle T$, sendo $\triangle V$ a diferença de potencial medida devido à presença da diferença de temperatura $\triangle T$ [60]. Outra forma é a determinação do gradiente de concentração iônico, ou seja, a medida do coeficiente Soret dos íons dispersantes, $S_{T}^{i o n}$. Será demonstrado que os resultados obtidos para $S_{T}$ podem ser descritos como contribuições de dupla camada e efeito Seebeck $\left(S_{T} \propto S\right)$ ou dupla camada e efeito Soret dos íons dispersantes $\left(S_{T} \propto S_{T}^{i o n}\right)$, 
descrevendo resultados para $S_{T}$ de forma inexistente na literatura. É proposta uma relação para $S$ e $S_{T}^{i o n}$ baseada nas equações que governam a resposta iônica ao gradiente de temperatura, demonstrando o porquê de as duas abordagens descreverem os resultados para $S_{T}$.

Descrever e caracterizar os fenômenos físicos que contribuem para o coeficiente $S_{T}$ é o principal objetivo deste trabalho. A seguir são discutidos a influência da temperatura e dos íons dispersantes sobre o valor de $S_{T}$ para fundamentar a investigação experimental realizada neste trabalho, que consiste na determinação experimental de $S_{T}$ em função da temperatura em soluções de nanopartículas contendo diferentes íons dispersantes.

\subsubsection{Efeito da temperatura}

As equações resultantes dos modelos teóricos para o efeito Soret apresentam forte dependência com a temperatura de equilíbrio da amostra, controlada previamente à presença do gradiente de temperatura. Resultados experimentais para o coeficiente Soret de nanopartículas eletrostaticamente estabilizadas e dispersas em água costumam mostrar uma característica comum no intervalo de temperatura $5^{\circ} \mathrm{C}<T<60^{\circ} \mathrm{C}[1,59,61,62,63,64,65]$. Os valores do coeficiente Soret, em um intervalo de temperatura definido, costumam assumir valores menores para temperaturas mais baixas e maiores para temperaturas mais altas, ou seja, as partículas migram mais para o quente quando a temperatura é baixa e mais para o frio quando a temperatura é alta, como mostrado na Figura 1.1. Em muitos sistemas é observado que as partículas podem sofrer uma mudança no sinal (de negativo para positivo) do coeficiente Soret em determinada temperatura. Uma equação fenomenológica que descreve muito bem esses resultados foi proposta por Iacopini et al [1]:

$$
S_{T}=S_{T}^{\infty}\left(1-\exp \left(\frac{T^{*}-T}{T_{0}}\right)\right)
$$

onde $T^{*}$ é a temperatura onde ocorre mudança do sinal de $S_{T}, T_{0}$ não possui um significado físico claro e $S_{T}^{\infty}$ é a máxima amplitude de $S_{T}$ para temperatura onde seu valor estabiliza (que pode ocorrer em valores de $T$ não acessíveis experimentalmente). Um fato 


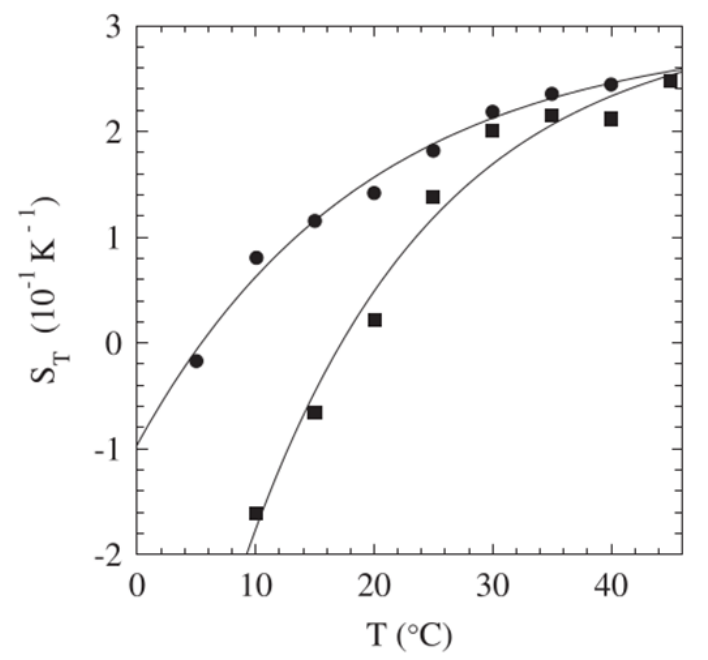

Figura 1.1: Comportamento usual obtido para o coeficiente Soret em função da temperatura. Círculos representam resultados experimentais para nanopartículas de látex de poliestireno e quadrados são resultados para DNA plasmidial, ambos dispersos em água. As linhas contínuas são melhores ajustes para a equação 1.1. Figura adaptada de [1].

interessante é nunca ter sido observada a mudança inversa, quando os valores de $S_{T}$ seriam positivos a baixas temperaturas e negativos em temperaturas mais altas. Esse fato será compreendido ao fim deste trabalho.

Apesar de descrever muito bem os resultados, a equação 1.1 não se baseia em nenhuma das teorias que descrevem fundamentalmente o efeito Soret. Um dos objetivos deste trabalho é verificar a dependência experimental $S_{T}(T)$ das nanopartículas de ferrofluido e compará-la com equações originárias de modelos fundamentais para descrever os resultados experimentais. Dessa forma esperamos compreender quais são os principais mecanismos responsáveis pelo efeito Soret em nanopartículas de ferrofluido.

\subsubsection{Efeitos específicos dos íons}

A hipótese de que a dependência $S_{T}(T)$ pode ser explicada a partir dos outros parâmetros físicos envolvidos nos processos de difusão será investigada em alguns tipos de ferrofluidos. Os tipos de íons responsáveis por estabilizar as nanopartículas em solução serão alterados, mantendo o mesmo tipo de nanopartícula. É esperado que a mudança no tipo de íon altere o coeficiente Seebeck $S$, sendo que cada íon tem o seu próprio calor de transporte $Q^{*}$. A 
influência de diferentes íons sobre $S_{T}$ de nanopartículas eletrostaticamente carregadas é observada em trabalhos anteriores [64, 66, 67].

O tipo de íon pode alterar a carga efetiva da partícula, refletindo na mudança do potencial zeta. As nanopartículas de ferrofluidos permanecem estáveis quando dispersas em soluções básicas ou ácidas devido à (des)protonação dos sítios de carga. Contudo não é possível utilizar qualquer concentração para todos os tipos de ácidos e bases. Isso ocorre devido a efeitos de interações específicas, como a complexação entre íons como $\left(\mathrm{Cl}^{-}, \mathrm{B} r^{-}, F^{-}\right)-\mathrm{Fe}^{+}$, no exemplo de soluções ácidas. Esses efeitos podem gerar a blindagem quase completa entre as partículas, levando a pouca repulsão eletrostática e a agregação. A estabilização é obtida apenas se uma quantidade muito pequena de ácidos e bases de contra-íons monoatômicos é utilizada. Se contra-íons poliatômicos são utilizados, como por exemplo ácido nítrico $\left(\mathrm{NO}_{3}^{-}\right)$e hidróxidos de tetrametilamônio e tetrabutilamônio $\left(\mathrm{TMA}^{+} \mathrm{e} \mathrm{TBA}^{+}\right)$, é possível aumentar a concentração de íons sem desestabilizar as partículas em solução. Essas soluções serão investigadas neste trabalho para determinar quais características dos íons são responsáveis pelo efeito Soret das nanopartículas.

\subsection{Organização da tese}

No Capítulo 2 será realizada uma breve descrição dos princípios teóricos que fundamentam este trabalho. O equilíbrio coloidal das partículas em soluções aquosas de ácidos e bases é detalhado. A geração de carga superficial e a repulsão entre dupla camada elétrica de duas partículas são fundamentais para explicar a estabilidade de partículas dispersas. O potencial eletrocinético e a energia eletrostática armazenada na dupla camada elétrica serão definidos, sendo essas grandezas usadas para quantificar o coeficiente $S_{T}$. Após descrever os princípios físicos do equilíbrio coloidal, as equações fenomenológicas para transporte de calor, massa e carga são descritas para processos termodinâmicos fora do equilíbrio. Tais equações são simplificadas para a determinação experimental dos coeficientes de transporte, como a difusividade térmica, o coeficiente Soret e o coeficiente Seebeck. Os modelos microscópicos para o coeficiente Soret em nanopartículas de dupla camada elétrica são baseados no efeito que o gradiente de temperatura exerce sobre o 
equilíbrio coloidal de partículas, íons e moléculas. Os principais modelos teóricos serão descritos para serem comparados com os resultados experimentais obtidos nos capítulos seguintes.

Os métodos experimentais utilizados nesse trabalho serão descritos no Capítulo 3. A amplitude (valor numérico) do coeficiente $S_{T}$ será obtida em dois experimentos diferentes. Em um experimento de lente de matéria [68, 69], um feixe de laser focalizado e perfil de intensidade Gaussiano atravessa uma fina camada do líquido contendo nanopartículas e gera aquecimento na amostra pela absorção de parte da luz, o que altera a focalização do feixe devido ao gradiente de concentração induzido. O gradiente de concentração estacionário é associado à saturação da alteração de focalização do laser.

Um segundo experimento utiliza um perfil periódico de intensidade criado pela interferência de dois feixes de um laser de luz polarizada, previamente dividido em dois, gera um perfil periódico de temperatura e por consequência de partículas [70]. A periodicidade micrométrica de temperatura e concentração causa a difração de um segundo feixe laser, sendo que através da intensidade de luz difratada são obtidos valores experimentais para $S_{T}$. O potencial eletrocinético das partículas é determinado por experimentos de atenuação eletroacústica ou espalhamento de luz, dependendo de características específicas de cada amostra. O efeito Soret intrínseco $S_{T}^{i o n}$ de cada um dos ácidos e bases, que são adicionados às soluções de nanopartículas, é também obtido pelo experimento com difração através do perfil de concentração iônico periódico. Para determinar a resposta termoelétrica o experimento realizado em uma célula termoelétrica mede a diferença de potencial $\Delta V$ entre dois eletrodos a diferentes temperaturas, separados por um espaçador isolante e contendo amostra no espaço entre eles. Esse experimento define o coeficiente Seebeck $S=\Delta V / \Delta T$. Para cada um dos experimentos, será feita uma breve descrição das teorias existentes utilizadas para obter as grandezas físicas.

Os resultados experimentais para $S_{T}$ das nanopartículas de ferrofluidos em soluções ácidas são apresentados e descritos no Capítulo 4. Partículas em meio ácido demonstram que a migração das nanopartículas para o lado quente do gradiente de temperatura é preferida e está relacionada com o surgimento de um campo termoelétrico gerado pelos 
íons. Usando resultados experimentais para o potencial eletrocinético, coeficiente Seebeck $S$ e coeficiente de difusão $D$, é possível calcular, a partir das teorias existentes para o efeito Soret, valores de coeficiente Soret $S_{T}$ na mesma ordem de grandeza que os valores obtidos experimentalmente. Um estudo da dependência com a temperatura mostra que valores experimentais para o coeficiente Soret $S_{T}(T)$ seguem o comportamento semelhante ao calculado teoricamente. Neste caso, o efeito termoelétrico é a principal contribuição para o coeficiente $S_{T}$, responsável pela migração das partículas para o lado quente do gradiente de temperatura.

No Capítulo 5, são apresentados e analisados resultados para $S_{T}$ quando hidróxidos são adicionados nas soluções de ferrofluidos. Quando as partículas são dispersas em soluções de hidróxidos de contra-íon monoatômico, como o hidróxido de sódio $(\mathrm{NaOH})$, as partículas migram para o lado quente do gradiente de temperatura em baixas temperaturas, semelhante ao caso das partículas em solução ácida, mas passam a se acumular no lado frio a partir de uma dada temperatura. Porém, nesse caso a maior contribuição surge da camada difusa de íons em torno da partícula, quantificado experimentalmente apenas pelo potencial eletrocinético em função da temperatura. Ao aumentar a concentração de hidróxidos com contra-íons orgânicos como tetrametilamônio (TMAOH) e tetrabutilamônio (TBAOH) em solução de ferrofluido contendo inicialmente uma concentração muito baixa de $\mathrm{NaOH}$ (devido ao processo de síntese das partículas), as partículas mudam a direção de migração e se acumulam no lado frio em todas as temperaturas investigadas, a partir de uma concentração crítica de hidróxido orgânico. Neste estudo, o coeficiente $S_{T}^{i o n}$ também é determinado experimentalmente e se demonstra que devido aos altos valores deste parâmetro para os hidróxidos orgânicos comparados com valores de ácidos e outros sais, o coeficiente $S_{T}$ apresenta valores positivos para todos os valores de temperatura experimentalmente investigados.

Dessa forma, a questão fundamental sobre os efeitos termodifusivos em nanopartículas de ferrofluidos recai sobre a origem do efeito Soret iônico. Para investigar a origem de tal efeito são realizados conjuntos de experimentos em função da temperatura da amostra para obter os valores de $S_{T}^{i o n}$ e do coeficiente de difusão dos íons $D^{i o n}$ em soluções de 
água e íons. Os resultados obtidos para $D_{T}^{i o n}(T)$ de hidróxidos orgânicos se assemelham aos resultados calculados a partir de uma expressão teórica existente na literatura que considera o efeito de expansão térmica da solução. O alto desvio relativo dos valores experimentais para outros sais em relação aos valores teóricos sugere que outro mecanismo físico, além da expansão térmica, também é responsável pelo efeito Soret iônico. Uma nova descrição para o efeito Soret iônico será apresentada, baseada na dependência da energia de hidratação com a temperatura.

Com os resultados obtidos no capítulo 5 para o coeficiente Soret iônico e baseado na literatura existente para o calor de transporte iônico, o capítulo 6 apresenta uma análise para resultados experimentais em célula termoelétrica. Os resultados para a diferença de potencial elétrico $\triangle V$ medido entre dois eletrodos a diferentes temperaturas, contendo as soluções dos diferentes sais ou ferrofluidos entre eles, mostram dependência com o coeficiente $S_{T}^{i o n}$. Uma relação entre o coeficiente Seebeck $S$ e $S_{T}^{i o n}$ é proposta e fundamentada pelos resultados dos capítulos 4 e 5 . Com o uso de equações resultantes de cálculos teóricos recentes, a dinâmica das cargas em soluções de íons será descrita experimentalmente na presença de gradiente de temperatura. Será demonstrado que a resposta termoelétrica das soluções, devido à diferença do efeito Soret intrínseco (ou calor de transporte) de cada íon do sal, ocorre muito rapidamente. Já a difusão do sal, os dois íons juntos, ocorre em tempo muito longo e depende da soma do efeito Soret intrínseco de cada íon, correspondente ao tempo em que o efeito ocorre no experimento com laser. O efeito mais rápido pode resultar em potencial termoelétrico $\triangle V$ negativo ou positivo dependendo do sinal da diferença do efeito Soret intrínseco de cada íon. Já o efeito Soret mais lento, resulta em $\triangle V$ com mesmo sinal para todos os tipos de íons, o que é descrito com equações adicionais que relacionam os coeficientes Seebeck e $S_{T}^{\text {ion }}$.

As conclusões e as perspectivas sobre a contribuição e a influência deste trabalho, para aprofundar as análises de resultados experimentos e a descrição do fenômeno termodifusivo em soluções de nanopartículas dispersas por íons são descritas no capítulo 7. 


\section{Capítulo 2}

\section{Termodifusão em Dispersões Coloidais}

Uma dispersão coloidal é constituída por entes nanoscópicos (nanopartículas, polímeros, moléculas, íons) estabilizados em um meio líquido [52, 71]. Entre as inúmeras possibilidades de dispersões coloidais existentes com interesses científicos e tecnológicos, as nanopartículas de óxido de ferro dispersas em água $[6,72]$ são os sistemas físicos escolhidos para serem investigados neste trabalho. Diferentes tipos de ácidos e bases são usados na estabilização das nanopartículas, para investigar o papel da dupla camada elétrica e dos contra-íons no efeito Soret. Uma dispersão estável das nanopartículas de ferrofluido em água é obtida quando forças de repulsão entre as partículas equilibram as forças de atração. Isso é possível quando existe intensa repulsão de dupla camada elétrica entre partículas, controlada pela quantidade de íons na solução [72, 73]. Dessa forma se obtém um líquido uniforme macroscopicamente que pode ser controlado por diversos campos externos (elétrico e magnético) devido às propriedades específicas das nanopartículas (carga superficial e momento de dipolo). O gradiente de temperatura induz o efeito Soret, levando as partículas para o lado quente ou frio, mas a relação desse efeito com as grandezas físicas não é bem estabelecida como nos efeitos eletroforético [74, 75] e magnetoforético [76].

A aplicação de um gradiente de temperatura a uma dispersão coloidal irá alterar o equilíbrio local devido à dependência das interações com a temperatura. A mudança na energia da dupla camada elétrica das nanopartículas estabilizadas com carga superficial é um exemplo dessa dependência [54]. As propriedades físicas da dupla camada eletrostática 
em torno da nanopartícula dependem das características da dispersão como solvente e íons dispersantes, e de variáveis físicas como a temperatura e pressão. Além disso, os próprios íons e moléculas responsáveis pela estabilização de nanopartículas também respondem ao gradiente de temperatura [56], devido ao efeito da temperatura na interação destes com as moléculas do líquido dispersante.

A descoberta da termodifusão, ou efeito Soret, foi realizada em uma solução de água e sal por C. Ludwig [47] e Charles Soret [48, 49]. Alguns modelos teóricos foram desenvolvidos nas últimas décadas para relacionar o coeficiente Soret desse tipo de nanopartículas (eletrostaticamente carregadas) com as características de cada dispersão coloidal, descrevendo o efeito como originado da própria partícula [54, 59, 77, 78] ou como consequência da resposta da solução eletrolítica devida ao efeito Soret dos íons [55, 61, 79, 80, 81, 82]. Esses modelos serão descritos na seção 2.2.

Nesse capítulo é realizada a descrição da dupla camada elétrica em partículas carregadas para obter a energia eletrostática correspondente, grandeza que é dependente da temperatura. Demais interações entre as partículas também são brevemente descritas, para discutir o equilíbrio coloidal e a possível dependência com a temperatura do potencial total de interação. A seguir, uma breve recapitulação de equações sobre termodinâmica fora do equilíbrio é apresentada para mostrar a relação entre os coeficientes termodifusivos e os campos que surgem na amostra (gradientes de temperatura, concentração e campo termoelétrico). Alguns problemas interessantes sobre o comportamento termodifusivo de nanopartículas eletrostaticamente carregadas são descritos para esclarecer os pontos que são investigados neste trabalho.

\subsection{Dispersão de nanopartículas em meio aquoso}

\subsubsection{Carga superficial e dupla camada eletrostática}

Na dispersão de nanopartículas de óxido de ferro em soluções ácidas ou básicas ocorre a protonação ou desprotonação de sítios de cargas na superfície da partícula [50]. As equações do equilíbrio de carga na superfície da partícula considerando adsorção do próton 
e hidróxido, são

$$
\begin{gathered}
\mathrm{MOH}+\mathrm{H}_{3} \mathrm{O}^{+} \rightleftharpoons \mathrm{MOH}_{2}^{+}+\mathrm{H}_{2} \mathrm{O}_{(a q)} \\
\mathrm{MOH}+\mathrm{OH}^{-} \rightleftharpoons \mathrm{M}(\mathrm{OH})_{2}^{-},
\end{gathered}
$$

para solução ácida e básica, respectivamente, onde $M$ representa o átomo metálico na superfície da partícula (geralmente ferro). A presença de ácidos (ou bases) em solução irá favorecer a protonação (ou desprotonação) gerando carga superficial positiva (ou negativa).

Dada a dimensão da superfície da nanopartícula, a (des)ocupação de um determinado número de sítios de carga confere uma densidade de carga superficial $\sigma_{S}$ e potencial superficial $\psi_{S}$. O valor de $\sigma_{S}$ depende das constantes de equilíbrio das equações de troca de carga, além do pH da solução $[83,84,85]$. A maior parte dos óxidos de ferro possui em torno de 2 sítios $/ \mathrm{nm}^{2}$ na superfície, o que confere um valor de $\sigma_{S} \sim 0,2 \mathrm{C} / \mathrm{m}^{2}$ para nanopartículas de raio $R=5 \mathrm{~nm}$, gerando um intenso potencial superficial. O alto potencial eletrostático induz a condensação de contra-íons na superfície da partícula [85, 86]. Nesse caso a teoria clássica de Debye-Hückel para a dupla camada eletrostática não se aplica exatamente. A inserção de uma camada de íons condensados é possível e o modelo clássico pode ser adaptado, originalmente proposto por Stern e Grahame $[87,88]$. Podemos traçar uma superfície imaginária em torno da partícula que contenha essa camada de contra-íons condensados, a uma distância $R+\delta$ do centro da partícula, sendo $\delta$ a espessura da camada de Stern (1 a 2 Angstroms [89]), como esquematizado na Figura 2.1. Nessa superfície concêntrica à partícula, a carga superficial efetiva terá um valor $\sigma_{0}$ menor que $\sigma_{S}$. O modelo de protonação também pode ser adaptado para considerar os íons condensados [90]. Devido a efeitos térmicos, solvatação e repulsão iônica em torno da partícula, o valor de $\sigma_{0}$ não será nulo (o que implicaria blindagem completa pela condensação de contra-íons) e o efeito do potencial eletrostático associado a $\sigma_{0}$ sobre os íons em solução origina a camada difusa de íons, geralmente conhecida como camada de Debye [89]. Uma breve descrição do modelo da dupla camada elétrica é feita a seguir. 


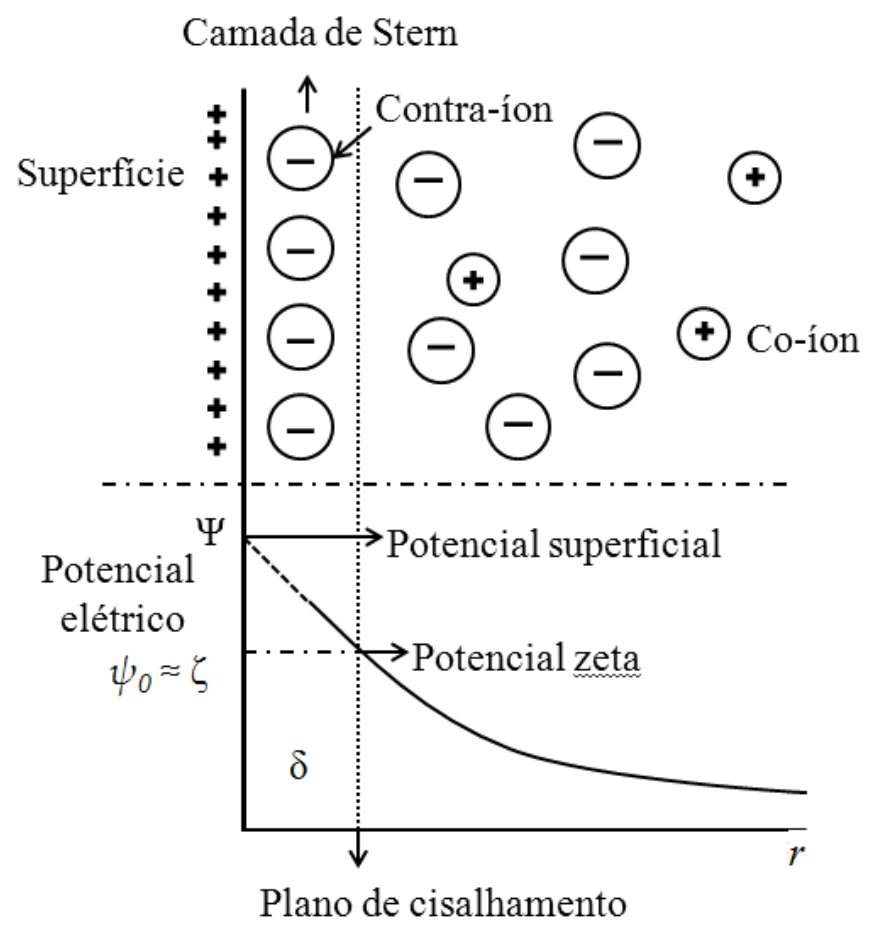

Figura 2.1: Modelo esquemático para a distribuição de íons em torno de uma partícula eletrostaticamente carregada e a distribuição do potencial eletrostático correspondente, sendo $r$ a distância à superfície da partícula.

A descrição a seguir tem por objetivo mostrar a camada difusa de íons em torno da nanopartícula, considerando que a condensação de íons e as cargas superficiais geram uma densidade de carga total $\sigma_{0}$. A força eletrostática da partícula carregada exercida sobre os íons em solução é contrária à força de difusão e no equilíbrio, quando o potencial químico $\mu$ é constante em toda a solução, obtém-se a igualdade $\nabla \mu=-e \nabla \psi$, sendo $\mu=$ $\mu_{i}^{0}+k_{B} T \ln n_{i}$ considerando a solução ideal com $\mu_{i}^{0}$ o potencial químico da solução distante da partícula e $n_{i}$ a concentração volumétrica de íons. A integração dessa equação, de um ponto distante da partícula (onde $\psi=0$ e $n_{i}=n_{0}$ ) até a superfície, resulta na distribuição de Boltzmann, que para o caso de íons monovalentes é $n_{ \pm}=n_{0} \exp \left(\mp e \psi / k_{B} T\right)$. A densidade de cargas neste caso é $\rho=-2 n_{0} e \sinh \left(e \psi / k_{B} T\right)$. A partir de $\rho$, o potencial eletrostático na camada difusa pode ser calculado pela equação de Poisson

$$
\nabla^{2} \psi=-\frac{\rho}{\epsilon}=\frac{2 n_{0} e}{\epsilon} \sinh \left(\frac{e \psi}{k_{B} T}\right)
$$

que pode ser resolvida facilmente para o caso unidimensional quando $e \psi \ll k_{B} T$, usando $\exp x \sim(1-x)$ obtém-se $\psi=\psi_{0} \exp (-\kappa x)$, sendo $\psi_{0}$ o potencial em $R+\delta, x$ a dis- 
tância em relação à superfície carregada e $\kappa^{-1}=\left(\epsilon k_{B} T / 2 e^{2} z^{2} n_{0}\right)^{1 / 2}$ é definido como o comprimento de Debye e caracteriza o decaimento do potencial eletrostático.

A solução analítica para a equação 2.3 é obtida apenas para um plano (caso unidimensional) ao multiplicar por $d \psi / d x$ e realizar uma integração desde a superfície até um ponto distante da partícula onde $\psi=0$ e $d \psi / d x=0$. A solução resultante para $d \psi / d x$ é integrada de uma posição na dupla camada até a superfície, resultando na solução completa unidimensional:

$$
\tanh \left(e \psi / 4 k_{B} T\right)=\tanh \left(e \psi_{0} / 4 k_{B} T\right) \exp [-\kappa x]
$$

e pode ser aproximado para o potencial de uma partícula se $\kappa R \gg 1$.

A densidade superficial de cargas $\sigma_{0}$ deve balancear a carga na dupla camada difusa na solução próxima à superfície, obtida a partir de $\rho$

$$
\sigma_{0}=-\int_{0}^{\infty} \rho d x
$$

resultando em uma relação entre a carga superficial $\sigma_{0}$ e o potencial superficial $\psi_{0}$,

$$
\sigma_{0}=\left(4 \epsilon k_{B} T n_{0}\left[\exp \left(-e \psi_{0} / k_{B} T\right)-1\right]\right)^{1 / 2}
$$

No caso de uma partícula esférica carregada, a equação com simetria esférica

$$
\frac{1}{r^{2}} \frac{\partial}{\partial r} r^{2} \frac{\partial \psi}{\partial r}=\frac{2 e n_{0}}{\epsilon} \sinh \left(e \psi / k_{B} T\right)
$$

com as condições $\psi(r=R)=\psi_{0}$ e $\psi(r \rightarrow \infty) \rightarrow 0$ não possui solução analítica. As soluções numéricas foram investigadas originalmente por Loeb, Overbeek e Wiersema [91].

Contudo uma solução válida para grande parte das partículas coloidais é obtida quando se considera a aproximação $e \psi \ll k_{B} T$, ou seja, $\sinh x \sim x$. A expressão para o potencial em torno da partícula, na coordenada radial $r$, é do tipo

$$
\psi(r)=\frac{\psi_{0} R}{r} \exp (\kappa(R-r))
$$

da qual é possível calcular o campo elétrico, que deve ser igual ao da lei de Coulomb próximo à superfície da partícula. O potencial superficial é então dado por $\psi_{0}=Q_{0} /$ $(4 \pi \epsilon R(1+\kappa R))$ e a energia do campo eletrostático em torno de uma nanopartícula carregada é dada por $W=Q_{0} \psi_{0} / 2$, sendo $Q_{0}$ a carga superficial efetiva da partícula (diferença 
das cargas protonadas e íons condensados na superfície). O potencial na superfície $\psi_{0}$ pode ser relacionado com a densidade de carga $\sigma_{0}$

$$
\psi_{0}=\frac{\sigma_{0} R}{\epsilon(1+\kappa R)}
$$

Quando dispersas em soluções eletrolíticas as partículas são submetidas ao potencial de repulsão eletrostático das partículas vizinhas. Para determinar a força de repulsão entre duas partículas é necessário saber a distribuição espacial do potencial eletrostático. Considerando a distribuição de potencial em torno de cada partícula dada por 2.8, é possível calcular a força de interação para o caso de potencial constante, carga constante e superposição linear [52, 92, 93]. Por exemplo, no caso de potencial constante, a expressão obtida por Russel é [52]

$$
V_{e l}=2 \pi \epsilon R\left(\frac{k_{B} T}{e}\right)^{2} \psi_{0}^{2} \ln (1+\exp (-\kappa R)) .
$$

É importante notar que as grandezas acima possuem dependência com a temperatura, como $\epsilon(T), \kappa(T)$ e possivelmente $\psi_{0}(T)$. Ao aplicar um gradiente de temperatura em uma solução coloidal, a mudança na interação entre as partículas segundo a descrição acima deve estar contida em uma teoria global para a efeito Soret de nanopartículas.

\subsubsection{Forças de van der Waals}

Forças de van der Waals de curto alcance representam interações de atração responsáveis por agregação coloidal. Geralmente são originadas por flutuações de dipolos moleculares, que interagem entre si pelo campo elétrico gerado pela oscilação. No caso de duas partículas com diferentes raios $R_{1}$ e $R_{2}$ separadas por uma distância $r$ o potencial de interação é dado por [94, 52]

$$
V_{A}(r)=-\frac{A_{12}}{6}\left[\frac{2 R_{1} R_{2}}{r^{2}-\left(R_{1}+R_{2}\right)^{2}}+\frac{2 R_{1} R_{2}}{r^{2}-\left(R_{1}-R_{2}\right)^{2}}+\ln \left\{\frac{r^{2}-\left(R_{1}+R_{2}\right)^{2}}{r^{2}-\left(R_{1}-R_{2}\right)^{2}}\right\}\right]
$$

sendo $A_{12}$ a constante de Hamaker que descreve a intensidade da interação. Para partículas metálicas como os óxidos de ferro o valor de $A_{12}$ é da ordem de $10^{-21} \mathrm{~J}$, da mesma ordem do valor de $k_{B} T$, o que pode levar à agregação das partículas na ausência de um potencial repulsivo. O resultado da equação 2.11 é obtido supondo duas esferas sem meio 
material entre elas. Quando partículas são dispersas em meio fluido (como uma solução eletrolítica) cujas moléculas interagem com as demais moléculas do sistema, o valor de $V_{A}$ deve ser muito alterado em relação ao previsto pela equação 2.11.

\subsubsection{Interação magnética}

As nanopartículas de óxido de ferro como magnetita $\left(\mathrm{Fe}_{3} \mathrm{O}_{4}\right)$ e ferritas $\left(\mathrm{MFe}_{2} \mathrm{O}_{4}, \mathrm{M}=\right.$ Co, $M n, Z n, N i)$ apresentam domínio magnético que originam interações de dipolos magnéticos. O potencial de interação magnética entre dois dipolos separados por uma distância $r$ é dado por $[72,6]$

$$
V_{\text {mag }}=\frac{\mu_{0}}{4 \pi r_{12}^{3}}\left(\vec{\mu}_{1} \cdot \vec{\mu}_{2}-3\left(\vec{\mu}_{1} \cdot \hat{\mathbf{r}}_{12}\right)\left(\vec{\mu}_{2} \cdot \hat{\mathbf{r}}_{12}\right)\right)
$$

sendo $\mu_{1} \mathrm{e} \mu_{2}$ os momentos de dipolos de duas partículas e mostra que as partículas preferem a configuração de dipolos alinhados formando cadeias de partículas. Isso é facilmente visto na aplicação de um campo magnético, e também em partículas com baixo potencial de repulsão que podem se agregar em solução mesmo na ausência de campo [95, 96].

\subsubsection{Teoria DLVO}

Para descrever teoricamente a interação total entre partículas coloidais é usual realizar a soma dos potenciais de interação $V_{\text {total }}$ em função da distância de separação $r$, que no caso dos ferrofluidos possui o termo de interação magnética somado à teoria clássica DLVO (desenvolvida por Derjaguin-Landau-Verwey-Overbeek ),

$$
V_{\text {total }}=V_{A}+V_{e l}+V_{\text {mag }}
$$

que costuma apresentar um valor de máximo próximo à partícula dependendo da espessura da camada de Debye $\kappa^{-1}$, que caracteriza o alcance da repulsão eletrostática. Ao se aproximarem devido ao movimento Browniano, a barreira de potencial deve ter intensa o suficiente para que as partículas sejam repelidas e continuem separadas em solução. Uma análise gráfica da soma dessas interações em partículas de ferrofluido é realizada nas referências [6, 72]. A influência do potencial total de interação sobre o efeito Soret de partículas submicrométricas eletrostaticamente carregadas (100 nm $<2 R<1000 \mathrm{~nm}$, não 
magnéticas) foi descrito a partir da dependência de $V_{\text {total }}$ com a temperatura por Zhao et al [97].

\subsubsection{Potencial zeta}

Na solução eletrolítica aquosa, as nanopartículas carregadas arrastam junto de si uma camada contendo contra-íons e água solvatada fortemente ligados à superfície. A uma certa distância a partir da superfície, a atração se torna mais fraca e a solução eletrolítica não se move com a nanopartícula, definindo o plano de cisalhamento (shear plane). A diferença de potencial existente entre esse plano e o seio da solução é definido como potencial- $\zeta$ (zeta). Quando um campo externo de baixa intensidade for aplicado à solução, a força aplicada à nanopartícula será dependente desse potencial. O valor do potencial zeta é semelhante ao valor do potencial próximo à superfície $\psi_{0}$, sendo que o campo externo deforma a camada difusa de íons em torno da partícula. Pode-se definir uma densidade de carga eletrocinética $\sigma_{e}$ obtida quando a equação 2.5 é integrada até o plano de cisalhamento [53], onde $\psi=\zeta$

$$
\sigma_{e}=\frac{4 e n_{0}}{\kappa} \sinh \left(\frac{e \zeta}{2 k_{B} T}\right)
$$

que apesar de ser o caso 1D, pode ser aproximado para partículas quando o raio de curvatura destas é muito maior que a espessura da dupla camada, $\kappa R \gg 1$. Usando a equação 2.8 como distribuição radial de potencial eletrostático a partir da partícula, a carga eletrocinética $Q_{e}$ é obtida realizando a integração $Q_{e}=-\int_{R}^{\infty} 4 \pi r^{2} \rho d r$, resultando em

$$
Q_{e}=4 \pi \epsilon R(1+\kappa R) \zeta
$$

Quando as aproximações $e \psi_{0} \ll k_{B} T$ e $\kappa R \gg 1$ não são respeitadas, diferentes soluções para $\psi$ são obtidas, geralmente não analíticas [91]. Uma equação para $Q_{e}(\zeta)$ que pode ser utilizada para valores arbitrários de $\kappa R$ é [53]

$$
Q_{e}=\frac{4 \pi \epsilon k_{B} T \kappa R^{2}}{e}\left(2 \sinh \left(\frac{e \zeta}{2 k_{B} T}\right)+\frac{4}{\kappa R} \tanh \left(\frac{e \zeta}{4 k_{B} T}\right)\right) .
$$

Por essa descrição baseada na teoria clássica da dupla camada, fica evidente a de- 
pendência de $Q_{e}(\zeta)$ com a temperatura, considerando $\epsilon(T)$ e $\kappa(T)$. Como a carga $Q_{e}$ geralmente não é obtida experimentalmente, a influência da temperatura sobre essa grandeza será investigada medindo $\zeta(T)$.

A forma mais utilizada para obter o potencial $\zeta$ é medir a velocidade $v_{e}$ adquirida pela partícula ao aplicar um campo elétrico. A razão $v_{e} / E$ é definida como a mobilidade eletroforética $\mu_{e}$, dependente do potencial zeta [89, 98]. Apesar de poder definir uma carga eletroforética, as equações clássicas de Smoluchowski $\mu_{e}=\epsilon \zeta / \eta$ quando $R \gg \kappa^{-1}$ e de Hückel $\mu_{e}=2 \epsilon \zeta / 3 \eta$ quando $R \ll \kappa^{-1}$ são os resultados mais simples, obtidos a partir da equação de Stokes com o termo da força elétrica [89]. Quando os limites não se aplicam, isto é $R \sim \kappa^{-1}$, a função de Henry fornece um valor entre 1 e $2 / 3$ para o fator numérico de $\mu_{e}$ [99]. O método experimental mais utilizado para obter o potencial- $\zeta$ de nanopartículas aplicando um campo externo é o experimento de Espalhamento de Luz Eletroforético [100]. Esse método é restrito a soluções que não sejam opacas e tenham baixa absorção da luz utilizada.

Outra forma bem desenvolvida para obter o potencial- $\zeta$, utilizada principalmente em altas concentrações de partículas, é aplicar uma onda de ultrassom na dispersão coloidal usando técnicas experimentais de eletroacústica [101]. Em resposta à onda de pressão, a dupla camada elétrica em torno da partícula é deformada gerando dipolos momentâneos, sendo que a intensidade desses depende da freqüência da onda aplicada. A soma dos dipolos cria uma diferença de potencial que varia com a freqüência, chamada de Potencial de Vibração Coloidal (ou CVP - Colloidal Vibration Potential), e é relacionado com o potencial zeta, como será descrito na seção experimental.

Apesar da teoria da dupla camada eletrostática clássica não diferenciar o tipo de íon, alguns resultados experimentais mostram que o valor do potencial zeta pode ser alterado com a mudança do contra-íon do hidróxido em soluções contendo nanopartículas de óxido de ferro [102], por exemplo. Isso pode ocorrer por conta de interações específicas dos íons com a superfície da partícula, mostrando que a descrição de íons como cargas pontuais na teoria para a dupla camada eletrostática é apenas uma aproximação.

O valor do potencial zeta é muito utilizado para caracterizar a estabilidade de disper- 
sões coloidais. Valores para $|\zeta|>20 \mathrm{mV}$ geralmente são obtidos para soluções estáveis e partículas com $|\zeta|<20 \mathrm{mV}$ podem ser estáveis ou não, dependendo do potencial de atração. Além de indicar estabilidade, o potencial zeta pode ser utilizado para demonstrar afinidade específica entre partículas e íons ou moléculas que são adicionadas à solução.

\subsection{Termodifusão em dispersões coloidais}

As soluções de nanopartículas investigadas nesse trabalho estarão submetidas à ação de um gradiente de temperatura nos experimentos de termodifusão. As equações gerais de fluxo de calor e partículas são apresentadas para justificar o uso de equações mais simples para comparação com experimentos. Nas subseções seguintes as principais teorias microscópicas para o efeito Soret de nanopartículas eletrostaticamente carregadas são descritas, para as quais as leis da termodinâmica são verificadas.

\subsubsection{Fluxo de calor e de partículas}

Para um sistema heterogêneo simples, como partículas dispersas em um líquido, os coeficientes de transporte de calor e de massa devem estar relacionados com a condutividade térmica e com o coeficiente Soret. Considerando o sistema de partículas dispersas em um líquido a uma concentração volumétrica $\Phi$ pode-se escrever para as densidades de fluxo de calor $\mathbf{J}_{\mathbf{q}}$ e de partículas $\mathbf{J}_{\boldsymbol{\Phi}}[103,104,105]$ :

$$
\begin{aligned}
\mathbf{J}_{\mathbf{q}} & =-\left(\frac{L_{q q}}{T^{2}}\right) \nabla T-\frac{L_{q \Phi}}{T(1-\Phi)}\left(\frac{\partial \mu}{\partial \Phi}\right) \nabla \Phi, \\
\mathbf{J}_{\Phi} & =-\left(\frac{L_{\Phi q}}{T^{2}}\right) \nabla T-\frac{L_{\Phi \Phi}}{T(1-\Phi)}\left(\frac{\partial \mu}{\partial \Phi}\right) \nabla \Phi .
\end{aligned}
$$

Dessas equações obtém-se a relação entre condutividade térmica $k_{T}$ e as constantes de difusão de massa e térmica com os coeficientes de Onsager [105]: $k_{T}=L_{q q} / T^{2}, D=$ $(\partial \mu / \partial \Phi) L_{\Phi \Phi} /(1-\Phi) T$ e $D_{T}=L_{\Phi q} /(1-\Phi) T^{2}$.

Dessa forma, ao aplicar um gradiente de temperatura a uma dispersão de nanopartículas como os ferrofluidos, a equação para a densidade de fluxo de partículas pode ser escrita como 


$$
\mathbf{J}_{\boldsymbol{\Phi}}=-D \nabla \Phi-\Phi(1-\Phi) D_{T} \nabla T
$$

a qual pode ser investigada experimentalmente quando se atinge o estado estacionário para difusão de massa, definindo o coeficiente Soret como

$$
S_{T}=-\frac{1}{\Phi(1-\Phi)} \frac{|\nabla \Phi|}{|\nabla T|}=\frac{D_{T}}{D}
$$

onde se define $S_{T}>0$ quando as partículas migram para a região fria e $S_{T}<0$ quando migram para a região quente.

\subsubsection{Origem do efeito Soret em nanopartículas carregadas}

O efeito Soret em nanopartículas carregadas e dispersas em solução eletrolítica foi descrito originalmente por Talbot et al [42], E. Ruckenstein [106] e J. L. Anderson [107] e nestes casos o efeito foi denominado termoforese. A teoria de Ruckenstein [106] foi fundamentada em que a partícula adquire velocidade de migração em um gradiente de temperatura devido ao gradiente de tensão interfacial. A definição de velocidade termoforética é dada por $v_{T}=-l / \eta(d \gamma / d z)=-l / \eta(d \gamma / d T)(d T / d z)$, onde $l$ é um comprimento característico ( $l=\kappa^{-1}$ para a partícula carregada), $\eta$ a viscosidade do líquido e $\gamma$ a tensão interfacial. Como $\gamma$ possui dimensão de energia interfacial $\left(\left[\mathrm{J} / \mathrm{m}^{2}\right]\right)$, o cálculo de $\gamma(T)$ é feito a partir da energia da dupla camada em torno da partícula

$$
\gamma=-\int_{0}^{\zeta} \sigma(\psi) d \psi
$$

onde a integral é a energia da dupla camada até o plano que define o potencial- $\zeta$. O resultado para o coeficiente de difusão térmica, ao desprezar a dependência com a temperatura do comprimento de Debye $d \kappa^{-1} / d T \sim 0$, é simplesmente $D_{T}=-\epsilon \zeta^{2} / 12 \pi \eta T$.

Outra contribuição para a velocidade da partícula a partir do efeito interfacial é obtida ao considerar a dependência de $\gamma$ na equação 2.21 com a concentração de íons $n_{i}$, definindo um coeficiente de migração dado aproximadamente por $D_{T}=l / \eta\left(d \gamma / d n_{i}\right)\left(d n_{i} / d z\right)=$ $\epsilon \zeta^{2} / 12 \pi \eta n_{i}$ [106]. Considerando uma solução eletrolítica 1:1 na qual pode haver a geração de um gradiente de concentração iônico (nesse caso devido ao gradiente de temperatura gerando o efeito Soret iônico), pode-se esperar que ocorra tal efeito. Uma equação para a velocidade da partícula $v_{d}$, em um gradiente de concentração iônico, também foi derivada 
por Prieve et al [108] a partir das equações para o fluxo de íons em solução, obtendo

$$
v_{d}=\frac{\epsilon}{\pi \eta} \frac{k_{B} T}{e}\left(\beta \zeta+\frac{4 k_{B} T}{e} \ln \left(\cosh \frac{e \zeta}{4 k_{B} T}\right)\right) \frac{d \ln n_{0}}{d x},
$$

onde $n_{0}$ é a concentração de íons no bulk da solução, o parâmetro $\beta=\left(D_{+}-D_{-}\right) /$ $\left(D_{+}+D_{-}\right)$caracteriza o primeiro termo como eletroforético no caso de diferentes constantes de difusão para cátions $D_{+}$e ânions $D_{-}$. A velocidade $v_{d}$ é denominada difusioforética. Usando a definição para o coeficiente Soret iônico $\nabla \ln n_{0}=S_{T}^{i o n} \nabla T$, uma equação para o coeficiente Soret das nanopartículas devido a um gradiente de concentração de íons é

$$
S_{T}=\frac{\epsilon}{\pi \eta D} \frac{k_{B} T}{e}\left(\beta \zeta+\frac{4 k_{B} T}{e} \ln \left(\cosh \frac{e \zeta}{4 k_{B} T}\right)\right) S_{T}^{i o n}
$$

No contexto desta pesquisa, envolvendo o efeito Soret nas soluções de ferrofluidos, o gradiente de concentração de íons na equação 2.22 é gerada pelo próprio efeito Soret dos íons. Portanto, o gradiente de concentração iônico não é controlado externamente, mas também será medido experimentalmente através do coeficiente $S_{T}^{i o n}$, e esta influência sobre o coeficiente Soret das nanopartículas pode então ser quantificada através da equação 2.23.

Além dos efeitos mencionados acima baseados na mudança de energia interfacial da partícula no gradiente de temperatura, dois modelos microscópicos mais recentes serão descritos a seguir. O primeiro deles descreve o efeito Soret a partir da dependência com a temperatura da energia eletrostática armazenada na camada eletrostática difusa em torno da nanopartícula. O segundo supõe a existência de um campo termoelétrico gerado pela diferença no coeficiente Soret de cátions e ânions, diferente da suposição feita apenas para o coeficiente de difusão para obter a velocidade devido ao efeito difusioforético.

\subsubsection{Contribuição da dupla camada eletrostática - modelo tipo capacitor}

Alguns modelos teóricos para a termodifusão de nanopartículas são baseados na energia eletrostática da dupla camada elétrica, considerando a camada difusa de íons [109, 110, 111]. Eles consideram que a dependência com a temperatura da distribuição de cargas 
terá influência sobre o efeito Soret das nanopartículas $[61,77,110]$. No modelo de Dhont [54], a força exercida sobre uma partícula é obtida a partir da variação espacial da energia eletrostática armazenada na dupla camada $\mathbf{F}=-\left(\partial W^{r} / \partial \rho_{l}\right) \nabla \rho_{l}-\left(\partial W^{r} / \partial T\right) \nabla T$, sendo $W^{r}$ a energia reversível correspondente à formação da dupla camada e $\rho_{l}$ a densidade do fluido. Não é considerada a força de repulsão entre as partículas vizinhas, sendo que o modelo é desenvolvido para uma partícula única em líquido. Usando a equação da continuidade, os coeficientes de difusão de massa e difusão térmica são relacionados com $W^{r}$ :

$$
\begin{gathered}
D=D_{0} \rho_{l} / k_{B} T\left(\partial W^{r} / \partial \rho_{l}\right), \\
D_{T}=D_{0} \rho_{l} / k_{B} T\left(\partial W^{r} / \partial T\right) .
\end{gathered}
$$

O desenvolvimento do modelo considera que todos os grupos iônicos na superfície da partícula estejam dissociados, como no modelo clássico para a dupla camada elétrica. Para as partículas de óxidos de ferro com alta densidade de carga superficial, a suposição de uma camada de contra-íons condensada como descrito na Seção 2.1.1 requer cuidado ao usar o modelo. Dessa forma, a energia $W^{r}$ é obtida a partir da distribuição do potencial eletrostático $W^{r}=Q_{0} \psi_{0} / 2$, e após as derivações das equações 2.24 e 2.25, o coeficiente Soret é dado por $[54,112]$

$$
\begin{gathered}
T S_{T}=1+\frac{1}{4}\left(\frac{4 \pi l_{B}^{2} \sigma_{0}}{e}\right)^{2} \frac{\kappa R}{(1+\kappa R)^{2}}\left(\frac{R}{l_{B}}\right)^{3}\left[1-\frac{\mathrm{d} \ln \epsilon}{\mathrm{d} \ln T}\left(1+\frac{2}{\kappa R}\right)\right]+ \\
\frac{1}{4}\left(\frac{4 \pi l_{B}^{2} \sigma_{0}}{e}\right)^{2} \frac{1}{1+\kappa R}\left(\frac{R}{l_{B}}\right)^{3} \frac{\mathrm{d} \ln Q}{\mathrm{~d} \ln T}
\end{gathered}
$$

Expressões como essa são utilizadas com freqüência para comparação com resultados experimentais que obtém a dependência do coeficiente Soret com o comprimento de Debye $\kappa^{-1}$ [112], ou a carga efetiva a partir do cálculo de grupos iônicos ligados à partícula [113]. Para nanopartículas de ferrofluidos, a equação foi utilizada para descrever a dependência do coeficiente Soret com $\kappa^{-1}$ de nanopartículas de ferrite de cobalto dispersas em meio 
ácido [31], onde a grandeza $\sigma_{0}$ foi obtida pelo melhor ajuste da equação 2.26 aos dados $S_{T}\left(\kappa^{-1}\right)$, e interpretada como carga superficial efetiva da nanopartícula. No desenvolvimento teórico da equação 2.26, não há restrição para os valores de $\kappa^{-1}$ ou $\kappa R$ [54]. Aqui, ela será novamente utilizada para analisar resultados experimentais de $S_{T}(T)$ em amostras que não respeitam a aproximação de Debye-Huckel. Para a densidade de carga $\sigma_{0}$ e carga superficial $Q$, serão utilizadas as expressões para a carga eletroforética $Q_{e}(\zeta)$ proposta por Loeb [91] para aliviar a restrição $\kappa R \gg 1$. Dessa forma, a partícula é representada com uma carga efetiva na distância de cisalhamento, a qual pode ser estimada por experimentos de Espalhamento Dinâmico de Luz. Tal representação foi verificada recentemente [114], propondo que a distância de cisalhamento é aproximadamente o valor de $\kappa^{-1}$ e o raio da partícula dado na equação 2.16 sendo o raio hidrodinâmico $R_{h}$.

Outra forma de comparar a teoria para $S_{T}$ da dupla elétrica com resultados experimentais é considerar a aproximação de Debye-Huckel $e \psi_{0} \ll k_{B} T$ e $\kappa R \gg 1$, e o plano de cisalhamento próximo à superfície da partícula, sendo o potencial zeta aproximadamente o potencial superficial $\zeta \sim \psi_{0}$. O coeficiente Soret é escrito como [59]

$$
T S_{T}=\frac{4 \pi \epsilon R \zeta^{2}(1+\kappa a)}{k_{B} T}\left(\frac{2 T}{\zeta} \frac{\partial \zeta}{\partial T}+\frac{T}{\epsilon} \frac{\partial \epsilon}{\partial T}-\frac{\kappa R\left(1+\frac{T}{\epsilon} \frac{\partial \epsilon}{\partial T}\right)}{2(1+\kappa R)}\right) .
$$

Uma teoria mais completa desenvolvida por Dhont e Briels adiciona outras duas contribuições à força sobre a partícula, além dessa descrita acima [77]. A primeira delas se origina da deformação da dupla camada devido ao gradiente de temperatura, causando uma assimetria no potencial eletrostático e por consequência uma força sobre a partícula carregada. A segunda contribuição que também não será descrita é a força de atrito entre a partícula e o solvente. Ambos termos são semelhantes aos efeitos derivados do gradiente de tensão interfacial. Portanto, considerar várias contribuições para o coeficiente Soret que tenham princípios semelhantes pode ser redundante.

\subsubsection{Campo termoelétrico}

A aplicação de um gradiente de temperatura a uma dispersão coloidal de nanopartículas estabilizadas em solução eletrolítica induz o efeito Soret dos íons que estão livres em solução. A resposta do sal em solução aquosa foi a primeira observação do efeito termodifusivo 
$[47,48,49]$, sendo observado o acúmulo de sal em um dos lados de um tubo com diferentes temperaturas em suas extremidades. O efeito Soret dos íons em solução aquosa é associado ao calor de transporte iônico [115], o qual reflete a mudança sofrida pela camada de solvatação com a mudança de temperatura [56, 116]. A interação entre íon e solvente costuma ser específica, implicando que calor de transporte e coeficiente Soret também sejam específicos para cada íon [115, 117]. Uma certa separação pode ser esperada entre os diferentes tipos de íons em uma solução, gerando um gradiente de densidade de cargas e por conseqüência um campo elétrico interno [55, 79]. Considerando as equações de fluxo para os íons (co-íons e contra-íons), obtém-se [82]

$$
\mathbf{J}_{ \pm}=-D_{ \pm}\left(\nabla n_{ \pm}+\frac{2 n_{ \pm} \alpha_{ \pm}}{T} \nabla T-n_{ \pm} \frac{z_{ \pm} e \mathbf{E}}{k_{b} T}\right)
$$

onde $\alpha_{ \pm}=Q_{ \pm}^{*} / 2 k_{B} T$ é o coeficiente Soret iônico sendo $Q_{ \pm}^{*}$ o calor de transporte de cátions e ânions e $\mathbf{E}$ é o chamado campo termoelétrico dependente da diferença $Q_{+}^{*}-Q_{-}^{*}$, com $S=E /|\nabla T|=\left(\alpha_{+}-\alpha_{-}\right) k_{B} / e$ definido como o coeficiente Seebeck da solução iônica.

O efeito termoelétrico em soluções eletrolíticas tem sido muito investigado recentemente, tanto teoricamente $[81,118,119,120]$ quanto experimentalmente $[18,121,122$, 123, 124, 125], devido ao interesse que este efeito possui sobre nano e micro partículas localizadas onde gradientes térmicos existem. Há também muito interesse em compreender todos os detalhes do efeito termoelétrico devido ao uso de gradientes de temperatura para gerar e armazenar eletricidade [60, 126, 127, 128].

A diferença de potencial originada entre as regiões fria e quente implica na existência de uma força eletrostática sobre uma partícula carregada na solução eletrolítica. Quando nanopartículas carregadas são dispersas em uma solução eletrolítica deve ser levada em consideração na equação do coeficiente Soret das nanopartículas a interação entre a partícula carregada e o campo termoelétrico. Isso foi realizado por Eslahian et al [64], que adicionaram o efeito termoelétrico em uma equação para $S_{T}$ contendo também as contribuições do gradiente de tensão interfacial descritos anteriormente. A equação obtida por eles é

$$
S_{T}=\frac{\epsilon}{\eta T D_{M}}\left(\frac{\zeta^{2}}{12}\left(1+\tau+\alpha_{s a l}\right)-\zeta S T\right)
$$


onde $\alpha_{s a l}=\left(Q_{+}^{*}+Q_{-}^{*}\right) / 2 k_{B} T$ é o coeficiente Soret intrínseco de cada sal, $\tau=-\mathrm{d} \ln \epsilon / \mathrm{d} \ln T$ e o primeiro termo 1 em parênteses se refere ao modelo de Ruckenstein. O coeficiente $\alpha_{\text {sal }}$ pode ser calculado a partir dos valores de $Q_{ \pm}^{*}$ ou determinado experimentalmente, sendo que será denominado $S_{T}^{\text {ion }}$ quando se referir aos valores experimentais. Recentemente, o efeito Seebeck tem sido utilizado para descrever a alteração da concentração de cargas iônicas em torno de nanopartículas carregadas aquecidas pela absorção de luz [129].

Ao considerar que essa descrição do efeito termoelétrico pode ser aplicada para o coeficiente Soret de nanopartículas, as questões fundamentais do fenômeno de termodifusão sempre recaem sobre a origem do efeito Soret das cargas iônicas. Algumas extensas teorias foram desenvolvidas para descrever o calor de transporte $Q_{i}^{*}$ baseado nas interações íons-solvente, solvente-solvente e íons-íons [117, 130, 131, 132, 133, 134]. Contudo, a comparação de resultados experimentais com essas teorias mais complexas não é possível.

Será realizada uma descrição completa dos efeitos contribuindo para o potencial termoelétrico no experimento em uma célula termoelétrica. Este estudo final irá verificar a correspondência entre os tempos do efeito Soret nos experimentos para determinar os coeficientes Soret de íons e nanopartículas, com os tempos de mudança do potencial termoelétrico da célula termoelétrica. Dessa forma, todas as hipóteses feitas nesse trabalho podem ser verificadas pelo uso de diferentes experimentos e as diferentes relações entre os coeficientes termodifusivos. 


\section{Capítulo 3}

\section{Materiais e Métodos}

\subsection{Síntese e Caracterização das Nanopartículas}

Parte deste trabalho é realizado em colaboração com o Grupo de Fluidos Complexos da Universidade de Brasília. Os professores que participam da colaboração são responsáveis pela síntese química e parte da caracterização de algumas amostras. A síntese desses ferrofluidos é descrita na seção a seguir. Outra amostra utilizada foi uma amostra comercial da empresa Chemicell ${ }^{\circledR}$, que é sintetizada por método semelhante às amostras do grupo de Brasília.

\subsubsection{Síntese de ferrofluidos com nanopartículas de ferrite de co- balto}

Os ferrofluidos utilizadas nesse trabalho são obtidos a partir do método de coprecipitação [7, 135, 136]. O processo consiste em alguns passos principais, ilustrados na Figura 3.1: i) formação da nanopartícula a partir dos átomos em solução, ii) tratamento químico da superfície e iii) dispersão em líquido de interesse.

i) Nanopartículas de ferrite de cobalto $\mathrm{CoFe}_{2} \mathrm{O}_{4}$ ou magnetita $\mathrm{Fe}_{3} \mathrm{O}_{4}$ são obtidas a partir da mistura dos átomos de $\mathrm{Co}^{2+} \mathrm{ou} \mathrm{Fe}^{2+}$ e $\mathrm{Fe}^{3+}$ em solução alcalina de $\mathrm{NaOH}$. A condensação química, combinação dos átomos em células unitárias do tipo espinélio 


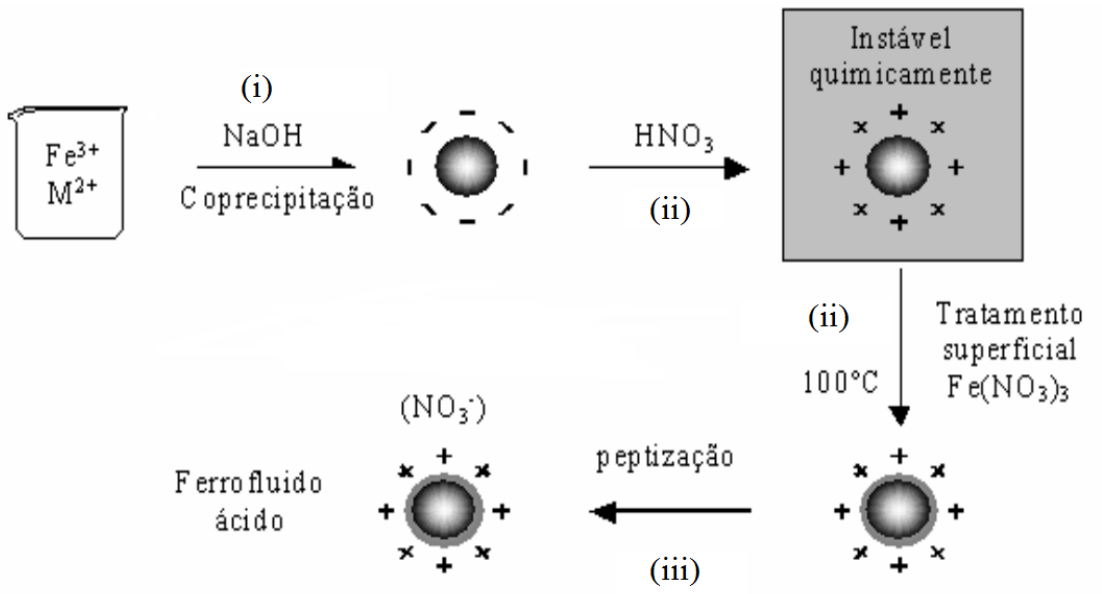

Figura 3.1: Esquema ilustrando o método de síntese de nanopartículas pelo método de coprecipitação.

(nucleação) e organização dessas em nanocristais, forma a nanopartícula. O controle das condições físico-químicas da síntese ( $\mathrm{pH}$, temperatura, concentração) permite um certo controle sobre as características finais da nanopartícula, como tamanho e morfologia. Várias reações inorgânicas ocorrem para formar o nanocristal e não são apresentadas aqui.

ii) Ao fim do primeiro processo as partículas são instáveis e em forma de precipitado. O meio está com pH de alto valor e a carga superficial está blindada por contra-íons de $\mathrm{N}^{+}$. A alta concentração de íons faz com que a dupla camada seja muito fina e a pouca repulsão entre as partículas causa agregação. A lavagem da solução com água, repetidamente por algumas vezes, retira o excesso desses íons da solução. Além disso, é feita uma lavagem com ácido nítrico $\mathrm{HNO}_{3}, 1 \mathrm{M}$ ou mais alta concentração, seguida de lavagem com água. As partículas adquirem carga positiva, mas não são estáveis devido à corrosão da ferrite pelo ácido. Para evitar isso, é realizado um tratamento superficial, colocando a solução a $100{ }^{\circ} \mathrm{C}$ com nitrato férrico $\left(\mathrm{Fe}\left(\mathrm{NO}_{3}\right)_{3}\right)$ para formar uma camada exterior de maghemita $\left(\gamma-\mathrm{Fe}_{2} \mathrm{O}_{3}\right)$, permitindo a estabilidade das partículas tanto em meio ácido quanto alcalino.

iii) Após a camada de maghemita formada em torno das partículas, elas são dispersas em solução aquosa de alta concentração de íons: pH entre 1,5 e 3,5 para meio ácido e entre 11 e 13 para meio alcalino. A concentração volumétrica final de partículas geralmente fica 
na faixa de $1 \%$ a $5 \%$ em volume. Devido ao processo aleatório de nucleação e formação de nanocristais, as nanopartículas apresentam uma dispersão de tamanhos. Algumas técnicas como Microscopia Eletrônica de Transmissão e Espalhamento de raios X a Baixo Ângulo fornecem a distribuição de tamanhos das partículas.

\subsubsection{Diluição de ferrofluidos em meios ácido e alcalino}

A seleção da concentração volumétrica de nanopartículas a ser investigada é realizada a partir do experimento de Lente de Matéria para determinação do coeficiente Soret. Nesse trabalho os valores de concentração volumétrica (\% de volume de nanopartículas na solução) utilizados foram de $0,075 \%$ ou $0,1 \%$, para investigar a influência da temperatura sobre as grandezas físicas envolvidas no efeito Soret das soluções ácidas e básicas. A diluição da solução-mãe pode ser feita de duas formas: i) A solução final estando no mesmo valor de pH da solução-mãe, adicionando a quantidade necessária de ácido ou base ou ii) Realizar a diluição simples, o que altera o pH da solução final. No caso das soluções em meio ácido é utilizada uma concentração iônica de $0,01 \mathrm{M}(\mathrm{pH}=2)$, sendo que o pH da solução-mãe estava em torno de 2,5. A escolha desse valor de pH é para possibilitar a comparação com propriedades dos íons, que costumam ter valores tabelados para concentração 0,01 M. Nas soluções alcalinas os experimentos para $\mathrm{pH}=12$ também são realizados para comparação com a literatura. Além disso, valores de $\mathrm{pH}=11$ e abaixo também serão investigados.

\subsubsection{Microscopia Eletrônica de Transmissão e Espalhamento de raios X a Baixos Ângulos}

Os ferrofluidos não apresentam um único tamanho de partículas, mas uma distribuição de tamanhos. É comum supor uma distribuição lognormal de partículas, que costuma descrever bem os resultados experimentais. Para estimar a distribuição em cada uma das amostras utilizadas foram realizados experimentos de Microscopia Eletrônica de Transmissão (MET) e de Espalhamento de raios X a Baixos Ângulos (SAXS - Small Angle X-Ray Scattering). 


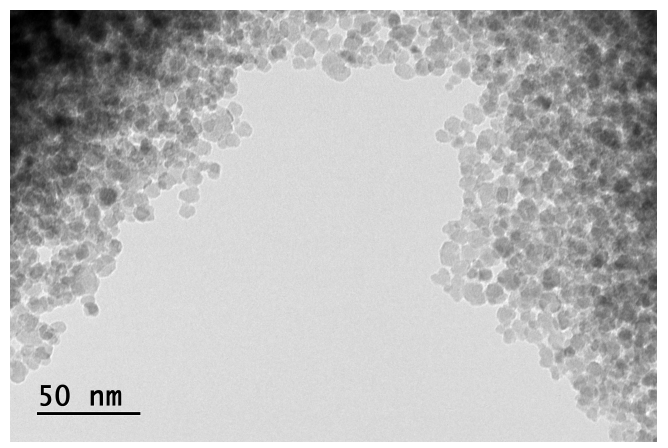

(a)

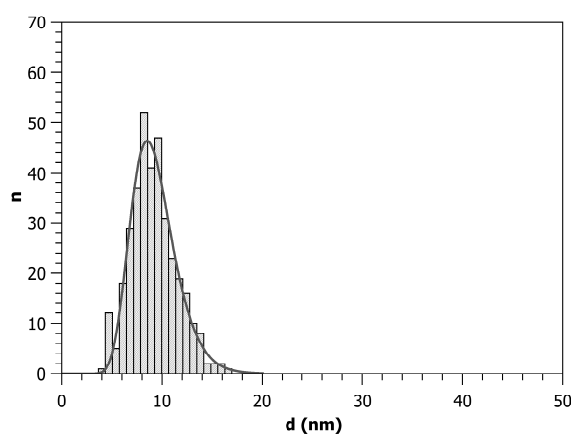

(b)

Figura 3.2: (a) Imagem de MET de partículas de ferrofluido. (b) Distribuição de tamanhos obtida da análise de uma série de imagens e ajuste da distribuição lognormal.

Os experimentos de MET foram realizados em microscópios do tipo JEOL JEM 2100, e as imagens foram analisadas usando o software ImageJ, traçando o contorno de cada partícula e medindo seu maior eixo. A Figura 3.2 mostra uma imagem de uma amostra e a respectiva distribuição de tamanho. Após obter a distribuição de partículas pelas imagens, a distribuição lognormal é usada para obter o tamanho médio $<d_{0}>$ e o fator de polidispersão $\sigma_{P}$, a partir da distribuição lognormal $P(d)=\left(1 / d \sigma_{P} \sqrt{2 \pi}\right) \exp \left(-\ln ^{2}\left(d / d_{0}\right) / \sigma_{P}\right)$. A Tabela 3.1 mostra as informações sobre as amostras utilizadas nesse trabalho. As amostras FF1 e FF2 foram utilizadas no estudo de alta concentração de íons $(\kappa R>1)$, e a distribuição para o tamanho cristalino obtida por MET teve mais precisão, sendo que o valor de $R$ é utilizado para calcular valores teóricos para $S_{T}$. As amostras FF3, FF4 e FF5 são para estudos em que o raio hidrodinâmico (obtido por Dynamic Light Scattering DLS) foi utilizado $(\kappa R<1)$ no cálculo de $S_{T}$, e a informação da distribuição de tamanhos por SAXS é apenas para verificação do tamanho cristalino aproximado.

Outra forma de investigar a distribuição de tamanhos é realizar experimentos de SAXS. A vantagem desse método sobre o TEM é a maior amostragem de partículas, já que o experimento é feito com a amostra em solução. A Figura 3.3 ilustra o básico do experimento de SAXS. Os experimentos foram realizados em um sistema Xenocs Xeuss, que possui um sistema Genix de saída de Raios X com fonte microfocus de anodo $\mathrm{Cu}$, comprimento de 


\begin{tabular}{|c|c|c|c|c|c|}
\hline Amostra & Dispersante & $\left\langle d_{0}\right\rangle(\mathrm{nm})$ & $\sigma_{P}$ & $\mathrm{pH}$ (amostra-mãe) & $\Phi$ (\% vol.) \\
\hline \hline FF1 & $\mathrm{HNO}_{3}$ & 13,6 & 0,2 & 3,2 & 1,0 \\
\hline FF2 & $\mathrm{HNO}_{3}$ & 3,1 & 0,25 & 3 & 1,0 \\
\hline FF3 & NaOH & 8,2 & 0,6 & 9 & 0,5 \\
\hline FF4 & TMAOH & 9,5 & 0,54 & 13,5 & 5,2 \\
\hline FF5 & TBAOH & 8,1 & 0,63 & 13,5 & 3,3 \\
\hline
\end{tabular}

Tabela 3.1: Dados sobre as amostras usadas nesse trabalho: Nome da amostra, íons dispersantes, diâmetro médio e fator de dispersão da equação lognormal e o pH e concentração volumétrica de cada amostra-mãe. Para os experimentos que determinam $S_{T}$, as amostras foram diluídas para concentrações $\Phi \sim 0,1 \%$. As amostras FF1 e FF2 são análises de TEM e FF3, FF4 e FF5 de SAXS.

(a)

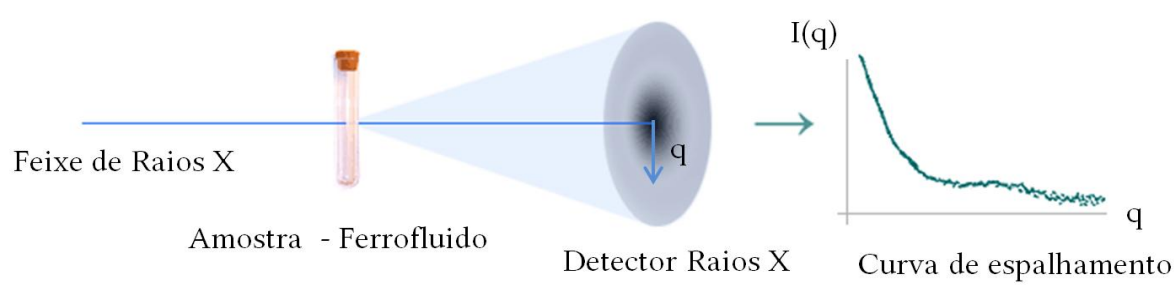

(b)
Figura 3.3: (a) Figura esquemática do experimento de SAXS. (b) Resultado característico da intensidade espalhada em função de $q$.

onda $\lambda=1,5411 \AA$, um sistema de colimação de duas fendas que entrega à amostra um feixe quadrado de seção transversal de $0,8 \mathrm{~mm}$ x $0,8 \mathrm{~mm}$, e um detector 2D Pilatus 300K $20 \mathrm{~Hz}$ da Dectris.

As curvas de espalhamento obtidas (Intensidade de espalhamento em função do módulo do vetor de onda $q=4 \pi \sin \theta / \lambda$, onde $2 \theta$ é o ângulo de espalhamento) dependem do fator de estrutura $S(q)$ e do fator de forma $F(q), I(q)=S(q) F(q)$, sendo que $F$ depende da forma e da distribuição de tamanhos das partículas. A forma das partículas é considerada esférica, apesar de ser uma aproximação como visto nas imagens de TEM. As curvas I (q) são analisadas pelo método GIFT (Generalized Inverse Fourier Transform), método desenvolvido por O. Glatter [137, 138] para obter a distribuição de tamanhos. 


\subsection{Potencial Zeta - Atenuação Eletroacústica}

Apesar de as soluções com nanopartículas de ferrofluidos utilizadas para investigar o efeito Soret terem baixa concentração volumétrica $(\Phi<0,20 \%)$, elas ainda apresentam alta turbidez, o que dificultou o uso de experimentos que usam espalhamento de luz para determinar o potencial zeta em algumas soluções. Outro fator é a quantidade de íons em solução, sendo o experimento de espalhamento de luz é possível apenas para o estudo com a amostra FF3 que possui baixa concentração de íons. Dessa forma, o experimento utilizado para obter o potencial zeta nas amostras com alta concentração de íons é baseado no efeito eletroacústico, utilizando o espectrômetro acústico (equipamento modelo DT1200, Dispersion Technology Inc.). As principais equações utilizadas para obter o potencial zeta são descritas a seguir. Após, será descrito o procedimento experimental para obter o potencial zeta no equipamento DT1200 [101].

Ao aplicar a onda de som no fluido contendo nanopartículas, uma diferença de pressão $\Delta p$ gera o movimento das partículas (quando a densidade é diferente em relação ao líquido) deformando a dupla camada elétrica e gerando o potencial de vibração coloidal CVP, o qual está relacionado à Intensidade de Vibração Coloidal CVI. Ambas grandezas, $\Delta p$ e CVI, são medidas pelo equipamento. A razão CVI $/ \Delta p\left(\omega, \Delta \rho / \rho_{l}, \zeta, \eta, \Phi, R\right)$ é dependente das seguintes grandezas [98, 139]: freqüência da onda ultrassônica $\omega$, diferença $\Delta \rho=\rho_{p}-\rho_{l}$ entre a densidade da partícula $\rho_{p}$ e do líquido $\rho_{l}$. Os parâmetros medidos pelo experimento eletroacústico estão relacionados à mobilidade eletroforética

$$
\frac{\mathrm{CVI}}{\Delta p} \propto \Phi \frac{\Delta \rho}{\rho} \mu_{e l}
$$

onde a mobilidade $\mu_{e l}$ é relacionada com o potencial- $\zeta$ [140]. Para nanopartículas na aproximação $R \gg \kappa^{-1}$, a relação entre a mobilidade e potencial- $\zeta$ é dada pela equação

$$
\mu_{e l}=\left(\frac{2 \epsilon \zeta}{\eta}\right)\left(1+f\left(\alpha_{s}\right)\right) G\left(\alpha_{s}\right)
$$

As funções $f\left(\alpha_{s}\right)$ e $G\left(\alpha_{s}\right)$ são funções complexas [101], dependentes da fase do campo elétrico gerado pelos dipolos momentâneos das partículas. $f\left(\alpha_{s}\right)$ é uma medida do campo elétrico tangencial à partícula e $G\left(\alpha_{s}\right)$ é relacionado à inércia da partícula e fortemente dependente do seu tamanho. Porém, a análise da função mostra que ela segue para limite 
assintótico $(G(R, \Phi)=1)$ quando as partículas são menores que $100 \mathrm{~nm}[98,139]$. Todas essas funções são determinadas pelo software de aquisição do equipamento.

O desenvolvimento da teoria eletroacústica leva a uma expressão relacionando as grandezas das partículas e parâmetros do equipamento [139]:

$$
\frac{3 \epsilon \zeta(1-\Phi) \Phi}{2 \eta(1+0,5 \Phi)} \frac{\left(\rho_{p}-\rho_{l}\right)}{\rho_{l}} G(R, \Phi)=\frac{v_{s} C_{c a l}}{f}\left(1-i \frac{\alpha_{s} v_{s}}{2 \omega}\right) \sqrt{S_{\text {exp }}} \frac{Z_{s}+Z_{\text {rod }}}{2 Z_{s}} \exp \left(\frac{\alpha_{s} L}{2}\right)
$$

onde $v_{s}$ é a velocidade do som no fluido, $f$ a freqüência, $C_{c a l}$ uma constate de calibração do equipamento, relacionada ao sinal experimental $S_{\text {exp }}=I_{\text {out }} / I_{\text {in }}, I_{\text {out }}$ é a intensidade da onda medida após a onda atravessar a amostra e $I_{i n}$ a intensidade enviada à amostra, $Z_{s}$ é a impedância acústica da solução e $Z_{\text {rod }}$ a impedância do sensor. $C_{c a l}$ e $Z_{\text {rod }}$ são grandezas gravadas ao realizar experimentos de referência em amostra com potencial zeta conhecido, como explicado adiante.

Esse método é sugerido quando se deseja usar dispersões com qualquer concentração de partículas, e partículas de qualquer tamanho e forma (para $R \lesssim 100 \mathrm{~nm}$ ). Assim é possível o uso da técnica para verificar efeitos de concentração [141] e do tipo de íon [102] da solução eletrolítica sobre o potencial zeta de nanopartículas de óxidos de ferro que costumam apresentar tamanho em torno de $10 \mathrm{~nm}$.

\subsubsection{Procedimento Experimental no espectrômetro acústico}

Para determinação do potencial zeta escolhemos realizar o procedimento mais simples possível: a seleção da onda eletroacústica com apenas uma freqüência, sem analisar o tamanho de partículas. Isso porque o método eletroacústico é impreciso para determinar o tamanho de partículas em torno de $10 \mathrm{~nm}$. O procedimento descrito a seguir é baseado nas referências [101, 139].

O equipamento consiste de duas partes principais: eletrônica e sensor. O sensor consiste de um elemento piezoelétrico que transforma o sinal elétrico em onda ultrassônica para a solução. O potencial de vibração coloidal é detectado por uma antena eletroacústica, que transforma o potencial em onda acústica novamente para medir a amplitude CVI e a diferença de fase em relação à onda aplicada. O software de controle da interface 
eletrônica é responsável por todo o processo, fornecendo o valor final do potencial zeta.

Antes de realizar o experimento nas soluções com nanopartículas de ferrofluidos, é necessário realizar a calibração do sensor em uma solução com potencial zeta conhecido. Para este equipamento são utilizadas partículas de silica-Ludox $10 \%$ de concentração em massa (\% wt.) em $0,01 \mathrm{M}$ de $\mathrm{KCl}$ que possui potencial zeta bem conhecido em torno de $-38 \mathrm{mV}$ à temperatura ambiente $T \sim 295 \mathrm{~K}$. Ao realizar a calibração, o equipamento grava sua impedância própria $Z_{\text {rod }}$ e a constante $C_{c a l}$. Dessa forma, o equipamento está pronto para o experimento com o ferrofluido.

Os ferrofluidos investigados possuem concentração de íons relativamente alta $c \sim$ 0,01 M e baixa concentração de partículas $\Phi<0,2 \%$. A alta concentração dos íons livres gera um potencial de vibração iônica (IVP - Ionic Vibration Potential) que se soma ao CVP e pode ser muito maior que este, devido a baixa concentração de partículas. É possível descontar o IVP realizando essa medida em uma solução de mesmo pH que o ferrofluido, com a mesma solução iônica usada nas partículas de ferrofluidos. O programa de aquisição da interface eletrônica do DT1200 grava o potencial IVP medido e é possível selecionar esse valor para descontar do CVP medido para a solução de ferrofluido.

Para realizar os experimentos em função da temperatura, o valor de IVP é gravado para cada nova temperatura e descontado para o experimento com o ferrofluido na respectiva temperatura. Para investigar se há uma possível influência da temperatura nos valores de impedância na equação 3.3, que pode implicar em erros no cálculo do potencial zeta, investigamos a dependência do potencial zeta com a temperatura da amostra padrão. Se o resultado obtido é semelhante aos valores existentes na literatura, poderemos concluir que o método é bastante confiável para obter $\zeta(T)$. A Figura 3.4 mostra que a forte dependência com a temperatura diminui quando IVP é descontado. As medidas com a solução de 0,5\% em massa, sem descontar IVP, que apresentou valores entre $-300 \mathrm{mV}$ e -700 mV, valores irreais devido ao maior sinal IVP em relação ao CVP. Dessa forma, o procedimento é confiável para obter o potencial- $\zeta$ em função da temperatura [101]. 


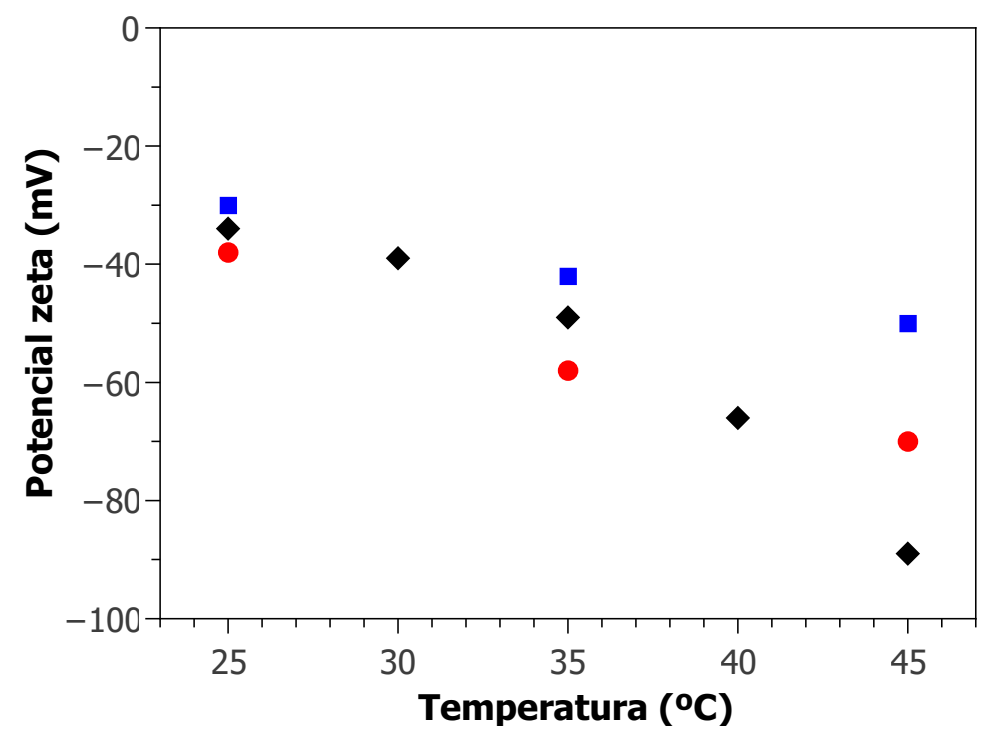

Figura 3.4: Potencial zeta em função da temperatura para a amostra padrão de silicaLudox. Resultado para a concentração padrão $10 \%$ wt. sem descontar IVP (losango preto), $10 \%$ wt. descontando IVP (quadrado azul) e 0,5\% wt. descontando IVP (círculo vermelho).

\subsection{Potencial zeta e espalhamento dinâmico de luz}

No estudo com a amostra FF3, devido a baixas concentrações iônicas, o potencial zeta foi determinado através do espalhamento de luz eletroforético. A figura 3.5 ilustra o funcionamento do experimento, realizado em um equipamento Brookhaven ZetaSizer 90 Plus. Dois eletrodos com separação definida são inseridos na amostra para aplicação de um campo elétrico. Um feixe de luz laser de comprimento de onda $\lambda=632,8 \mathrm{~nm}$ atravessa a amostra entre os eletrodos. O espalhamento de luz gerado pelas partículas com velocidade transversal, na direção do campo elétrico, é defasada em relação ao feixe original, sendo a diferença de fase usada para determinar a velocidade das partículas. Esse espalhamento é medido por um fotodetetor a $15^{\circ}$ com relação ao eixo de propagação do feixe. A razão $v / E=\mu_{e l}$ define a mobilidade eletroforética, proporcional ao potencial- $\zeta$. O controle de temperatura é feito internamente pelo equipamento, com precisão $\Delta T=0,5 \mathrm{~K}$.

O espalhamento de luz dinâmico DLS (Dynamic Light Scattering) é medido pela autocorrelação da intensidade de luz espalhada a $90^{\circ}$, e fornece o tamanho hidrodinâmico das nanopartículas. O decaimento da função de autocorrelação está relacionado com o raio hidrodinâmico ou com a distribuição de tamanhos hidrodinâmicos [10]. Este expe- 


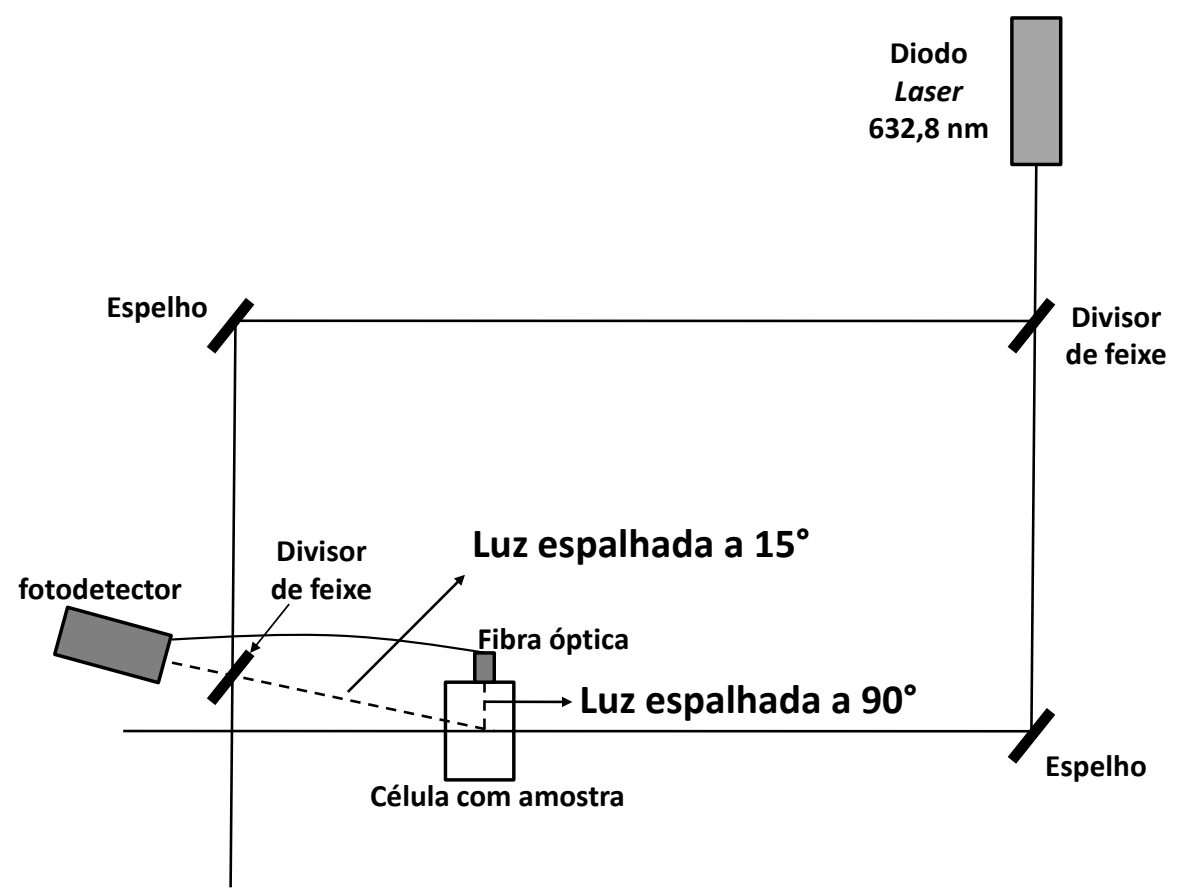

Figura 3.5: Esquema do equipamento experimental de Espalhamento de Luz, para o espalhamento de luz dinâmico a $90^{\circ}$ e eletroforético a $15^{\circ}$.

rimento é realizado separadamente do experimento de luz eletroforético. Os resultados para o tamanho hidrodinâmico obtido deste experimento serão utilizados no estudo com a amostra FF3, quando $\kappa^{-1}>R$.

\subsection{Célula Termoelétrica - Medida do Coeficiente Se- ebeck}

Para verificar a existência do efeito termoelétrico (Seção 2.2.4) das soluções iônicas e das nanopartículas de ferrofluidos, foi montado um experimento para medir a diferença de potencial eletrostático através da solução, quando um gradiente de temperatura é aplicado. Isso pode ser feito na condição de circuito aberto, onde a solução é inserida entre os dois eletrodos a diferentes temperaturas.

Uma célula termoelétrica é constituída de dois eletrodos metálicos em contato com uma solução eletrolítica [57]. Os eletrodos não são necessariamente idênticos, possuindo 
diferenças microscópicas, e são colocados a diferentes temperaturas para induzir o efeito termodifusivo de íons e partículas na solução. A diferença de potencial entre os dois eletrodos é medida conectando-os a dois cabos metálicos ligados a um multímetro de alta impedância. A Figura 3.6 ilustra o aparato do experimento. A diferença de potencial medida $\Delta \mathrm{V}$ irá depender de três contribuições:

i) A diferença de potencial devido ao efeito termoelétrico dos cabos em suas junções com os eletrodos, que se origina devido ao efeito Seebeck no metal e costuma apresentar valores máximos de dezenas de $\mu V / K$. Esse efeito será desprezado na amplitude final devido à maior amplitude do coeficiente Seebeck em soluções iônicas e ferrofluidos. Essa amplitude pode ser obtida colocando ambos eletrodos em contato e ao estabelecer uma diferença de temperatura, uma pequena diferença de potencial será observada no multímetro devido ao efeito Seebeck metálico total $S_{m e t}$ em todo o aparato experimental.

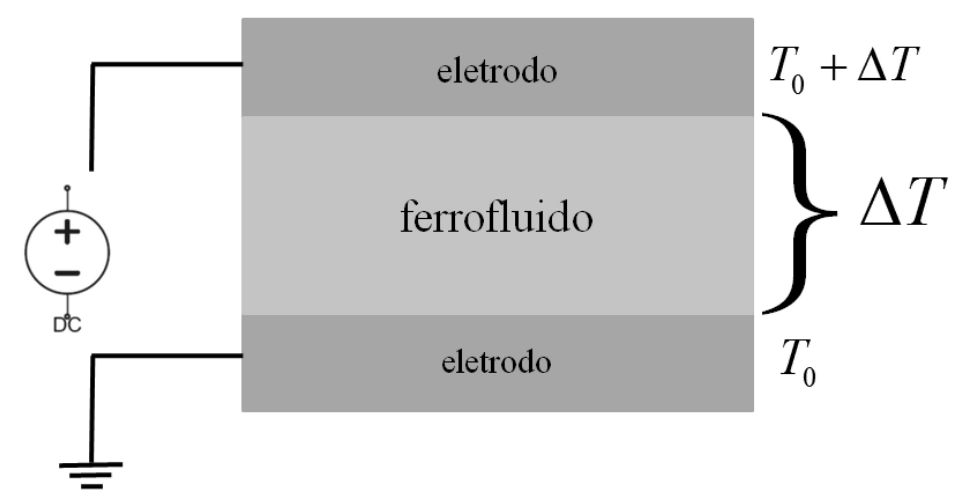

Figura 3.6: Esquema do experimento da célula termoelétrica para medir o coeficiente Seebeck das soluções de ferrofluido, a diferença de potencial induzida por um gradiente de temperatura $S=\Delta \mathrm{V} / \Delta T$.

ii) A diferença de potencial absoluto de cada um dos dois eletrodos em relação à solução investigada. As pequenas diferenças microscópicas entre os dois eletrodos geram efeitos de interface (como adsorção de íons/partículas e oxidação-redução) de forma não simétrica. Um campo elétrico interno $E_{0}$ surge devido a essa assimetria, gerando uma diferença de potencial $\Delta \mathrm{V}_{0}=\left\|V_{\text {inf }}-V_{\text {sup }}\right\|=E_{0} l$, sendo $V_{\text {inf }} \mathrm{e} V_{\text {sup }}$ o potencial absoluto de cada eletrodo em relação a um eletrodo de referência. Ao estabelecer a diferença de temperatura entre os eletrodos, o potencial absoluto de cada eletrodo irá se alterar devido à ação 
térmica sobre as interfaces. A diferença de potencial entre os eletrodos irá mudar para um novo valor $\Delta \mathrm{V}_{0}^{\prime}=E_{0}^{\prime} l$ no qual deve se estabilizar quando o gradiente de temperatura atingir um valor constante. Essa contribuição é considerada em vários trabalhos ao longo dos últimos 100 anos [57, 142].

iii) A mudança de potencial devida ao campo termoelétrico gerado pela diferença no coeficiente Soret das cargas iônicas em solução. De acordo com Agar [57], o calor de transporte $Q_{i}^{*}$, a entropia de Eastman $S^{*}$ e o coeficiente Soret $S_{T}^{\text {ion }}$ para cada íon componente da solução estão relacionados através da equação

$$
T\left(S_{+}^{*}+S_{-}^{*}\right)=\left(Q_{+}^{*}+Q_{-}^{*}\right)=2 R T^{2}\left(1+\left(\partial \ln \gamma_{ \pm} / \partial \ln c^{i}\right)\right) S_{T}^{i o n}
$$

onde $\gamma_{ \pm}=\left(\gamma_{+} \gamma_{-}\right)^{1 / 2}$ é o coeficiente de atividade médio da solução e $S_{T}^{\text {ion }}$ o coeficiente Soret. A formação do gradiente de concentração de íons pelo gradiente de temperatura gera a evolução na diferença de potencial entre os eletrodos [60, 143, 144],

$$
\Delta \mathrm{V}(t)-\Delta \mathrm{V}(0)=\Delta \mathrm{V}(\infty)-\Delta \mathrm{V}(0)\left(1-\frac{8}{\pi^{2}} \sum_{n \text { impar }} \frac{\exp \left(-n^{2} t / t_{c}\right)}{n^{2}}\right)
$$

onde $t_{c}=l^{2} /\left(\pi^{2} D\right)$ é o tempo característico de difusão e $D$ a constante de difusão. Considerando constantes de difusão típicas para íons da ordem de $10^{-9} \mathrm{~m}^{2} / \mathrm{s}$ e separação entre os eletrodos $l \sim 10^{-2} \mathrm{~m}, t_{c}$ assume valores da ordem $10^{4} \mathrm{~s}$, o que implica que o gradiente de temperatura se estabilize em centenas de segundos.

A resolução do conjunto de equações da seção 2.2.4 para o campo termoelétrico, a partir da redistribuição de íons em uma solução eletrolítica causada por um gradiente de temperatura linear, foi obtida por Majee e Würger [82]. O campo termoelétrico E decai a um valor constante na distância $\kappa^{-1}$, onde ocorre separação dos íons devido aos diferentes coeficientes Soret de cátions e ânions. Essa análise se mostrou boa para explicar o efeito Soret de partículas carregadas em soluções de baixa concentração [1, 64, 145]. Considerando um gradiente de temperatura induzido por feixe laser de perfil de intensidade Gaussiano, o perfil de concentração iônico e do campo elétrico são mais complicados, porém é possível a separação dos íons no gradiente de temperatura [81]. Esse último será discutido melhor na seção onde o experimento de lente de matéria para determinar $S_{T}$ a partir de um feixe Gaussiano é descrito. Contudo, apesar de existirem muitos trabalhos 
sobre o efeito termoelétrico de íons em solução líquida, ainda não está claro tanto teórica quanto experimentalmente as escalas de tempo em que ocorrem os efeitos de separação das cargas aniônicas e catiônicas, e do efeito Soret do sal sem ocorrer separação de cargas, mas acúmulo do sal em um dos lados do gradiente de temperatura.

\subsubsection{Procedimento Experimental para medir o coeficiente See- beck}

A termalização de cada um dos dois eletrodos mostrados na Figura 3.6 é feita de maneira diferente. O eletrodo inferior possui um sistema interno de circulação de água ligado a um banho térmico colocado previamente a temperatura desejada para o reservatório frio. Esse eletrodo é eletricamente aterrado para evitar acúmulo de carga estática. Já o eletrodo superior é aquecido por um resistor ligado a uma fonte de corrente contínua (Modelo Minipa MPM-3503). O resistor realiza boa troca de calor com o eletrodo, sendo eletricamente isolado por uma fina camada coaxial de cerâmica e recoberto por uma camada externa metálica.

O fechamento da célula é feito colocando um anel espaçador de Teflon de $8 \mathrm{~mm}$ de altura com O-rings abaixo e acima entre os eletrodos e o espaçador. Isso confere uma separação $l=11,0 \pm 0,5 \mathrm{~mm}$ entre os eletrodos e um raio interno de $\sim 1 \mathrm{~cm}$. Esta configuração implica em tempos da ordem de $10^{4} \mathrm{~s}$ para os experimentos e foi utilizada para o estudo do efeito termoelétrico com os diferentes sais, com o objetivo de identificar respostas rápidas e lentas. Os experimentos para medir $S$ em função da temperatura média da amostra foram realizados com separação entre os eletrodos de $l=2,0 \pm 0,5$ mm para diminuir o tempo de experimento e obter a resposta termoelétrica total sem a necessidade de separação de diferentes efeitos. Para preencher a célula com amostra, duas agulhas em lados opostos da célula são colocadas pelo O-ring superior, uma para inserir as soluções com uma seringa e outra para deixar vazar o ar interior da célula. Após a célula ser preenchida, um programa de aquisição grava a leitura da diferença de potencial medida pelo multímetro digital em função do tempo. Os multímetros utilizados para medir $\triangle V$ são dos modelos Agilent U2141A e Minipa MDM 8156-A. Como descrito em 
ii) da seção anterior, a diferença de potencial não é nula quando ambos eletrodos estão em contato com a solução isotérmica. O equilíbrio para um valor de $\Delta V_{0}$ constante pode levar algum tempo, antes de ser estabelecida a diferença de temperatura. Ao estabilizar $\Delta V_{0}$, a corrente no resistor do eletrodo superior é ligada para estabelecer o gradiente de temperatura. O gradiente de temperatura leva um tempo da ordem de 500 segundos para estabilizar em toda a amostra, que é o tempo característico de difusão de calor $\tau_{t h}=l^{2} / \pi^{2} D_{t h}$, onde $D_{t h}$ é a difusividade térmica da solução.

Para obter a amplitude de $S$ em função da temperatura, o banho térmico para o eletrodo inferior é colocado a uma nova temperatura bem como o valor de corrente elétrica aplicada à resistência do eletrodo superior. A diferença de temperatura entre os eletrodos é mantida aproximadamente constante $\Delta \mathrm{T} \sim 10^{\circ} \mathrm{C}$, de forma que os resultados apresentados nos próximos capítulos serão $S$ em função da temperatura média na célula.

\subsubsection{Modelagem da célula termoelétrica.}

Como o estabelecimento do gradiente de temperatura implica na mudança da diferença de potencial inicial $\Delta \mathrm{V}_{0} \rightarrow \Delta \mathrm{V}_{0}^{\prime}$, o transporte de íons e partículas na solução será devido aos efeitos de migração (campo elétrico), difusão (gradiente de concentração) e termodifusão (gradiente de temperatura). Como uma aproximação frequente para ser possível a análise dos resultados, consideramos que a condutividade térmica e o gradiente térmico sejam constantes durante todo o processo.

Para descrever os experimentos na célula termoelétrica deve-se considerar que antes de estabelecer a diferença de temperatura, os constituintes estavam em um estado de equilíbrio resultando em $\Delta \mathrm{V}_{0}$. Ao se estabelecer $\Delta T$, a evolução de $\Delta \mathrm{V}_{0} \rightarrow \Delta \mathrm{V}_{0}^{\prime}$ implica em uma redistribuição iônica devido à migração, além do efeito termoforético. Após um tempo muito longo $t \rightarrow \infty$, quando o sistema atinge um estado estacionário com a diferença de temperatura estabelecida, a equação para a densidade de fluxo de íons será

$$
\mathbf{J}_{ \pm}=0=-D_{ \pm}\left(\nabla n_{ \pm}+\frac{2 n_{ \pm} Q_{ \pm}^{*}}{k_{B} T^{2}} \nabla T \mp \frac{n_{ \pm} e}{k_{B} T}\left(\mathbf{E}-\mathbf{E}^{\prime}\right)\right)
$$

onde $E^{\prime}=\Delta V_{0}^{\prime} / l$ e para partículas

$$
\mathbf{J}=0=-D \nabla \Phi+\Phi\left(\mu_{e}\left(\mathbf{E}-\mathbf{E}^{\prime}\right)-\mu_{T} \nabla T\right) .
$$


Considerando em primeira aproximação a concentração de partículas muito baixa que é utilizada nesse trabalho, uma expressão para $\mathbf{E}-\mathbf{E}^{\prime}$ considerando apenas efeitos iônicos é:

$$
\mathbf{E}-\mathbf{E}^{\prime}=\frac{2\left(n_{+} D_{+} Q_{+}^{*}-n_{-} D_{-} Q_{-}^{*}\right)}{e\left(n_{+} D_{+}-n_{-} D_{-}\right)} \frac{\nabla T}{T}+\frac{k_{B} T}{e} \frac{\left(D_{+} \nabla n_{+}-D_{-} \nabla n_{-}\right)}{\left(n_{+} D_{+}-n_{-} D_{-}\right)}
$$

e deve ser resolvida com o auxílio da equação de Poisson $\nabla \cdot\left(\mathbf{E}-\mathbf{E}^{\prime}\right)=\rho / \epsilon, \rho=$ $e\left(n_{+}-n_{-}\right)$para as quantidade desconhecidas $\mathbf{E}-\mathbf{E}^{\prime}$ e $\nabla n_{ \pm}$, sendo $\rho$ a densidade de cargas. Dessa forma é possível chegar a uma expressão para $\mathbf{E} / \nabla T=\triangle \mathrm{V} / \triangle T$, que fornece o coeficiente Seebeck $S$ necessário para descrever o efeito termodifusivo nas nanopartículas do ferrofluido. Como as equações são não lineares, as soluções se tornam complicadas para resolver analiticamente, e apenas recentemente problemas semelhantes estão sendo resolvidos numericamente [146, 147, 148].

\subsection{Coeficiente Soret - Lente de Matéria}

O coeficiente Soret das nanopartículas é obtido através do experimento de lente de matéria, um fenômeno generalizado da lente térmica. O efeito de lente térmica acontece quando um feixe laser aquece um meio absorvedor e gera uma distribuição de temperatura não homogênea [149]. A expansão do meio gera um perfil de densidade que produz perfil de índice de refração e modifica a divergência do feixe transmitido. Esse efeito foi descoberto durante o desenvolvimento de fontes laser e passou a ser utilizado principalmente como um método espectroscópico para determinar o coeficiente de absorção em amostras com coeficientes de extinção muito baixos [150].

Na maioria dos casos, quando um feixe laser Gaussiano com raio de dezenas de micrometros é absorvido por uma amostra líquida, o gradiente de temperatura se estabelece em tempos característicos da ordem de milisegundos. Se o tempo de irradiação contínua é muito maior, a temperatura continua a aumentar a uma taxa muito menor no spot de irradiação até atingir um valor estável, quando o calor continuamente gerado é conduzido para as partes não iluminadas da amostra. Os constituintes da dispersão coloidal podem então se mover no gradiente de temperatura devido ao efeito Soret. Como discutido no 
capítulo anterior, o coeficiente Soret é definido no estado estacionário de fluxo de matéria, onde o fluxo termoforético iguala o fluxo devido à lei de Fick. Isso pode ser facilmente obtido pelo experimento de lente de matéria, quando o índice de refração é sensível à mudança de concentração da partícula, sendo que o tempo decorrido para obter a estabilização do gradiente de concentração depende das características específicas de cada amostra.

Nesta seção serão descritos os fenômenos de lente térmica e de lente de matéria, mostrando que o coeficiente Soret pode ser obtido a partir da lente de matéria. As respectivas distâncias focais para as duas lentes e suas dependências com a mudança de intensidade no centro do feixe laser medida experimentalmente serão calculadas.

\subsubsection{Difusão de calor e de massa em duas dimensões.}

A Figura 3.7 mostra o esquema básico para um experimento de lente térmica: um laser com perfil de intensidade Gaussiano, uma lente para realizar a focalização do feixe, o porta amostra e o fotodetector para medir a mudança de intensidade no centro do feixe.

O desenvolvimento do modelo de lente térmica considera que o calor gerado pela absorção da luz é conduzido radialmente para partes não irradiadas da amostra e não na direção de propagação do feixe, definida como eixo z. O aumento de temperatura na amostra é encontrado resolvendo a equação de calor [151]

$$
\frac{\partial \triangle T(r, t)}{\partial t}=D_{t h} \nabla^{2} \triangle T(r, t)+\frac{q(r)}{\rho c_{p}},
$$

sendo $D_{t h}=k_{T} / \rho c_{p}$ a difusividade térmica, $\rho$ a densidade e $c_{p}$ o calor específico do meio e $k_{T}$ a condutividade térmica. O termo $q(r)$, sendo que $r$ é a distância do centro do feixe a qualquer ponto no plano perpendicular ao eixo z, representa o calor gerado pelo feixe laser

$$
q(r)=\frac{2 \alpha P}{\pi w^{2}} \exp \left(-\frac{2 r^{2}}{w^{2}}\right),
$$

dependente do coeficiente de absorção linear $\alpha$, da potência do feixe $P$ e do raio do feixe w. A solução para o perfil de temperatura calculado para esse problema é [149] 


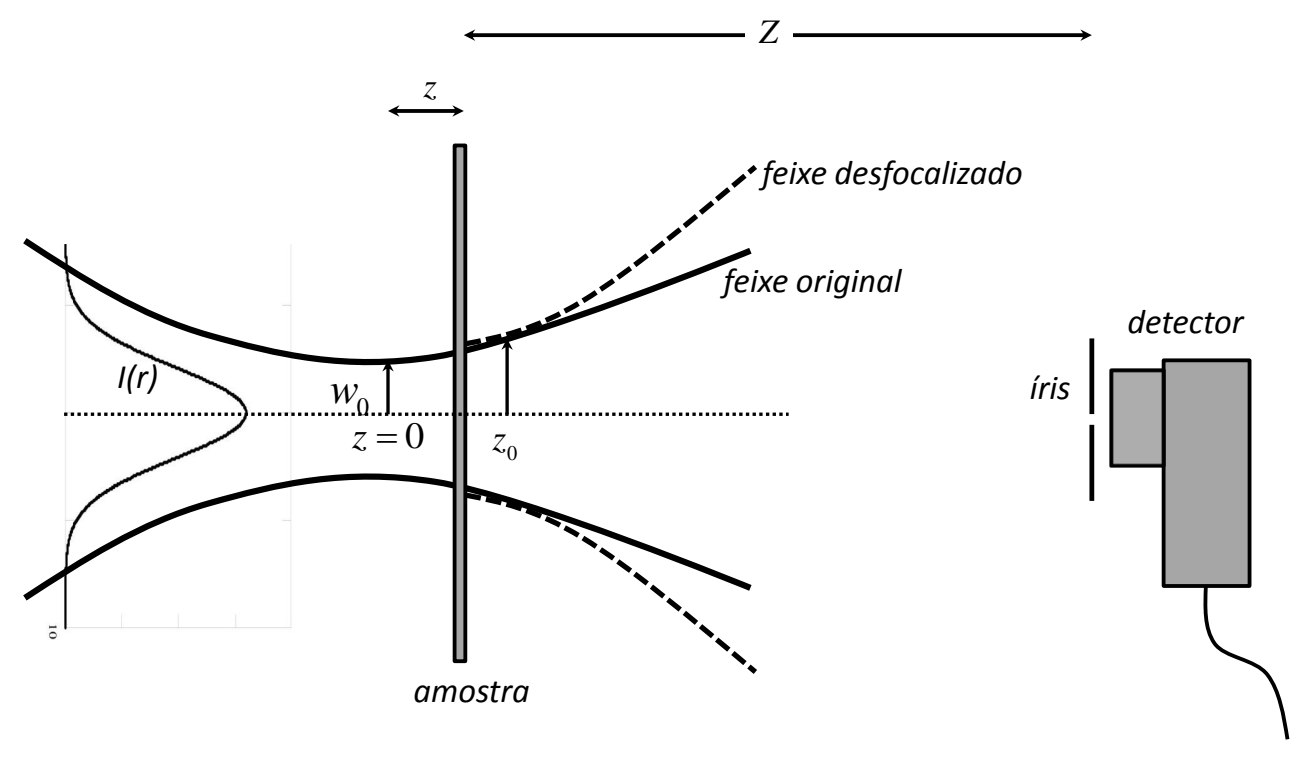

Figura 3.7: Esquema mostrando o princípio físico do efeito de lente gerado por um feixe Gaussiano. A fonte de luz laser utilizada é um Verdi-V10 Coherent de $532 \mathrm{~nm}$ de comprimento de onda. Um gradiente de temperatura e/ou concentração gera a (des)focalização do feixe original, como é descrito no texto. 


$$
\triangle T(r, t)=\frac{0.06 \alpha P}{\pi k_{T}}\left[E i\left(-\frac{2 r^{2}}{w^{2}}\right)-E i\left(-\frac{2 r^{2}}{8 D_{t h} t+w^{2}}\right)\right],
$$

sendo $\operatorname{Ei}(x)$ a função exponencial integral. Como a intensidade é medida no centro do feixe, a equação acima pode ser aproximada para $r \rightarrow 0$ [149, 152],

$$
\Delta T(r, t)=\frac{0.06 \alpha P}{\pi k_{T}}\left[\ln \left(1+\frac{2 t}{t_{t h}}\right)-\frac{2 r^{2}}{w^{2}} \frac{2 t}{2 t+t_{t h}}\right],
$$

sendo $t_{t h}=w^{2} / 4 D_{t h}$ o tempo característico de difusão de calor. A distribuição de temperatura gera um perfil no índice de refração

$$
n(r, t)=n_{0}+\left(\frac{d n}{d T}\right) \triangle T(r, t),
$$

sendo $d n / d T$ o coeficiente termo óptico e que a distância focal é dependente do gradiente de índice de refração [153, 154, 155]:

$$
\frac{1}{f_{L T}}=-l \frac{d n}{d T} \frac{d^{2} \triangle T(r, t)}{d r^{2}}
$$

resultando

$$
\frac{1}{f_{L T}}=\theta_{L T} \frac{1}{z_{0}\left(1+\gamma^{2}\right)} \frac{2 t}{2 t+t_{t h}}
$$

sendo $z_{0}=\pi w_{0}^{2} / \lambda$ o parâmetro de Rayleigh, $\gamma=z / z_{0}$ a posição relativa da amostra em relação ao foco do feixe e a amplitude da lente térmica definida por

$$
\theta_{L T}=\frac{0.24 \alpha P l}{k_{T} \lambda} \frac{d n}{d T}
$$

O efeito da lente térmica sobre o feixe Gaussiano é de desfocalização (para $d n / d T<0$ ) ou de focalização (para $d n / d T>0$ ). Nos dois casos o raio do feixe onde se posiciona o fotodetector muda e também a intensidade do centro do feixe $I_{c f}$ que passa pela íris e é medida. Usando as expressões acima e a formulação matricial da óptica geométrica [20, 156], obtém-se a seguinte relação para a evolução temporal da transmitância $T_{N}$

$$
T_{N}=\frac{I_{c f}(t)}{I_{c f}(0)}=\left[1-2 \gamma\left(\frac{\theta_{L T}}{1+\gamma^{2}} \frac{2 t}{2 t+t_{t h}}\right)+\left(\frac{2 t \theta_{L T}}{\left(2 t+t_{t h}\right)\left(1+\gamma^{2}\right)^{1 / 2}}\right)^{2}\right]^{-1} .
$$

Considerando a equação 2.19 para o fluxo de partículas e a equação de continuidade $\partial c(r, t) / \partial t=-\nabla \cdot \mathbf{J}$, a seguinte equação deve ser resolvida para obter a distribuição de partículas devido ao efeito Soret 


$$
\frac{\partial \triangle \Phi(r, t)}{\partial t}=D_{M} \nabla^{2} \triangle \Phi(r, t)+D_{T} \Phi \nabla^{2} T(r, t)
$$

com as condições $\partial T(r, t) / \partial t=0, \nabla^{2}(\triangle T(r, t))=-q / k_{T}$ e o tempo característico de difusão de massa muito maior que o tempo de difusão de calor $t_{c} \gg t_{t h}$, a distribuição de concentração de partículas é [68, 145]

$$
\Delta \Phi(r, t)=\frac{0.06 \Phi S_{T} \alpha P}{\pi k_{T}}\left[\ln \left(1+\frac{2 t}{t_{c}}\right)-\frac{2 r^{2}}{w^{2}} \frac{2 t}{2 t+t_{c}}\right]
$$

sendo

$$
t_{c}=w^{2} / 4 D_{M}
$$

$D_{M}$ a constante de difusão de massa da partícula. Da mesma forma que no caso da lente térmica, pode-se definir a distância focal para a lente de matéria

$$
\frac{1}{f_{\text {Soret }}}=-l \frac{d n}{d \Phi} \frac{d^{2} \Phi(r, t)}{d r^{2}}=\theta_{\text {Soret }} \frac{1}{z_{0}\left(1+\gamma^{2}\right)} \frac{2 t}{2 t+t_{c}}
$$

onde a amplitude de lente de matéria é dada por

$$
\theta_{\text {Soret }}=-\frac{0.24 \alpha P l \Phi S_{T}}{k_{T} \lambda} \frac{d n}{d \Phi}=-\theta_{L T} \Phi S_{T} \frac{d n}{d \Phi}\left(\frac{d n}{d T}\right)^{-1} .
$$

O efeito sobre a mudança de intensidade medida pelo fotodetector é semelhante ao efeito da lente térmica [20]

$$
T_{N}=\frac{I_{c f}(t)}{I_{c f}\left(t \rightarrow t_{T L}\right)}=\left[1-2 \gamma\left(\frac{\theta_{\text {Soret }}}{1+\gamma^{2}} \frac{2 t}{2 t+t_{c}}\right)+\left(\frac{2 t \theta_{\text {Soret }}}{\left(2 t+t_{c}\right)\left(1+\gamma^{2}\right)^{1 / 2}}\right)^{2}\right]^{-1},
$$

onde $t \rightarrow t_{T L}$ significa um tempo no qual a lente térmica não contribui mais para a mudança de $I_{c f}(t)$ e um tempo ainda muito pequeno para ter contribuição significativa devido ao efeito Soret. Para $w \sim 60 \mu \mathrm{m}, t_{t h} \sim 2 \mathrm{~ms}$ e $t_{c} \sim 5 \mathrm{~s}$, mostrando que $t_{T L}$ pode ser definido no intervalo $200 \mathrm{~ms}<t^{\prime}<500 \mathrm{~ms}$ [32]. A equação 3.23 será utilizada para obter as grandezas $S_{T}$ e $D_{M}$, como é normalmente realizado para os experimentos ópticos de termodifusão [157]. 


\subsubsection{Montagem Experimental - Varredura-Z}

A Figura 3.8 mostra o esquema de Varredura-Z. O feixe de luz laser com comprimento de onda de $532 \mathrm{~nm}$ é alinhado na montagem experimental da seguinte forma: primeiro, focalizado pela lente L1 para que um shutter e um chopper mecânicos posicionados próximos ao foco de L1 realizem o controle do tempo de irradiação da amostra; a lente L2 faz a colimação do feixe, que é então focalizado novamente pela lente L3; após L3, um trilho é posicionado no qual o porta amostra é colocado sobre um deslocador controlado pelo computador. O deslocamento é realizado na direção de propagação da luz, com precisão de $10 \mu m$ e um programa de aquisição no computador controla cada deslocamento. Após o laser passar pela amostra, um divisor de feixe direciona parte do feixe para o fotodetector D1, o qual mede a mudança de intensidade através de uma pequena íris devido aos efeitos de lente térmica e de matéria. A outra parte do feixe é direcionada para o fotodetector D2, sendo totalmente focalizada na placa fotodetectora e analisando uma possível variação na absorção de luz pela amostra.

O esquema na parte superior da Figura 3.8 mostra o perfil de intensidade de irradiação: no experimento de lente térmica para determinar $\theta_{t h}$, o perfil periódico com pulsos de 30 ms do chopper é combinado com aberturas periódicas do shutter, de 100 ms de abertura e 2 segundos de fechamento para evitar efeito Soret acumulativo [158]. O experimento também pode ser feito mesmo sem a presença do chopper, colocando o tempo de abertura de shutter em 30 ms com intervalos de alguns segundos entre cada pulso. O experimento para determinar a amplitude da lente de matéria $\theta_{\text {Soret }}$ é realizado enviando pulsos com duração de até 100 segundos (dependendo da constante de difusão $D_{M}$ ) controlados apenas pelo shutter.

\subsubsection{Procedimento experimental para determinar o coeficiente Soret.}

Dada a grande quantidade de parâmetros dos quais depende a amplitude de lente de matéria, a melhor forma de obter o coeficiente Soret é realizar dois experimentos nas diferentes 


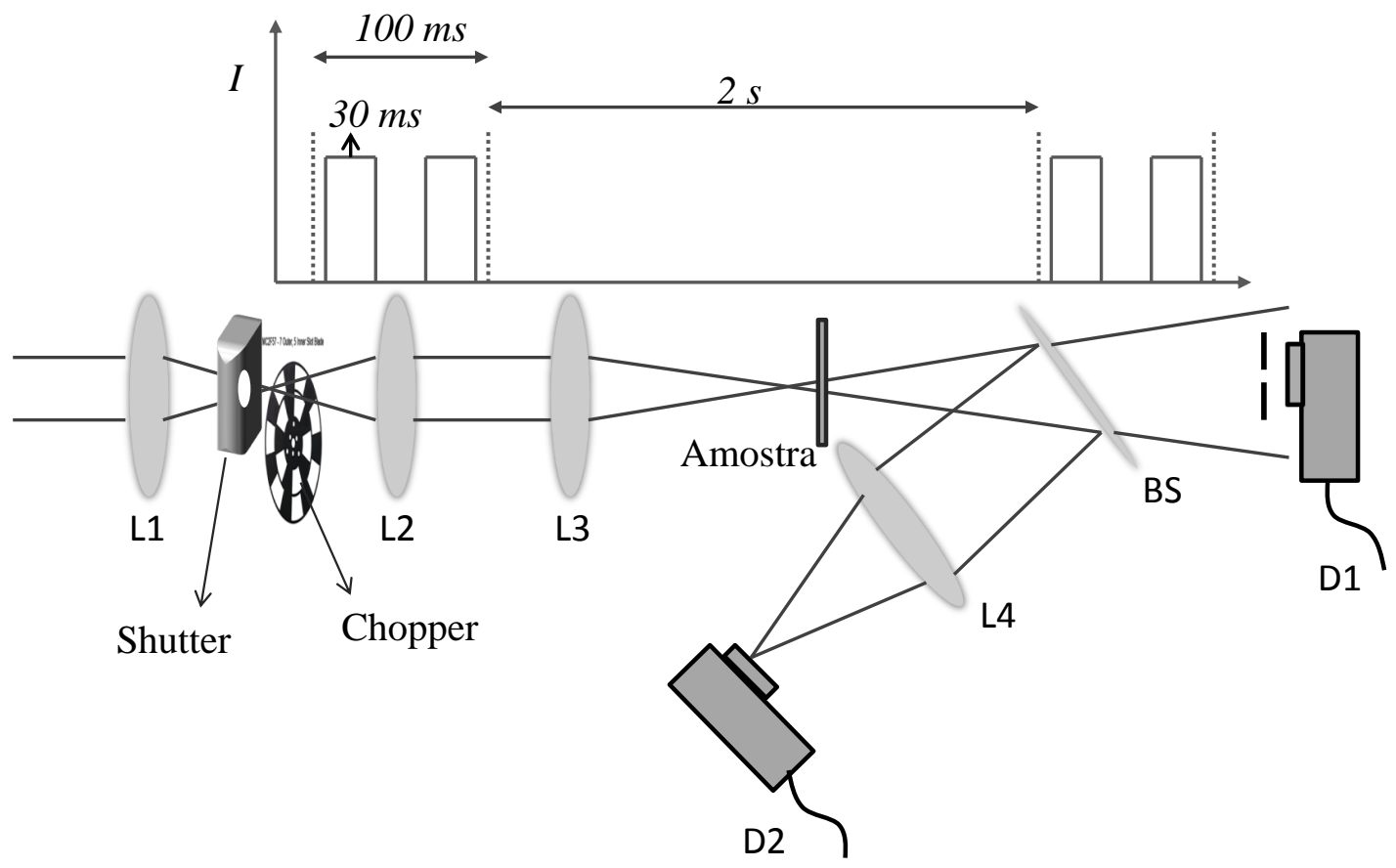

Figura 3.8: Figura esquemática do arranjo de Varredura-Z utilizado para medir os efeitos de lentes térmica e de matéria. A amostra (sample) é posicionada em torno do foco produzido pela lente L3, sendo que a duração dos pulsos de irradiação é controlado pela combinação do uso do chopper e shutter posicionados no foco da lente L1. A parte superior da figura ilustra a periodicidade dos pulsos para o experimento de lente térmica para determinar $\theta_{t h}$. O fotodetetor D1 faz a leitura de intensidade no centro do feixe. Um beam splitter BS também envia o feixe para o fotodetetor D2 que monitora a intensidade total do feixe pela focalização feita pela lente L4. 
escalas de tempo. Para obter a amplitude lente térmica $\theta_{t h}$ é realizado um experimento onde o tempo de irradiação da amostra é da ordem de dezenas de milisegundos ( $30 \mathrm{~ms})$, e a transmitância obtida pela equação 3.17. A obtenção da amplitude de lente de matéria $\theta_{\text {Soret }}$ pode ser feita com experimentos com tempo de irradiação da ordem de vários segundos, com pulsos entre 50 e 100 segundos e análise da transmitância pela equação 3.23. Conhecendo a concentração de partículas em volume $\Phi$ e os contrastes ópticos $d n / d \Phi$ e $d n / d T$, obtém-se o coeficiente Soret $S_{T}$. Dessa forma, temos a propagação da incerteza apenas na determinação de $\theta_{t h}$ ao invés de medir e ter as propagações de incertezas das grandezas $\alpha, P, l$ e $k_{T}$.

\subsubsection{Determinação dos coeficientes ópticos $d n / d \Phi$ e $d n / d T$.}

Um refratômetro ATAGO500i de alta precisão $\left(2 \times 10^{-5} \mathrm{nD}\right)$ é utilizado para determinar os coeficientes de contrastes do índice de refração com a concentração $d n / d \Phi$ e com a temperatura $d n / d T$. O equipamento possui controle de temperatura com precisão de 0,01 K. A Figura 3.9 mostra os valores medidos do índice de refração em função da temperatura para alguns valores de concentração de partículas, permitindo obter valores para $d n / d \Phi(T)$ e $d n / d T(T)$.

\subsection{Coeficiente Soret - Experimento IRTDFRS}

Outro experimento para determinar o coeficiente Soret é a técnica IRTDFRS - InfraRed Thermal Diffusion Forced Rayleigh Scattering - Espalhamento Rayleigh Forçado para Termodifusão no Infravermelho. Este experimento foi desenvolvido a partir do início dos anos 1990 para medir o coeficiente Soret de misturas líquidas binárias e de íons, moléculas e nanopartículas dispersas em líquidos, sendo que os detalhes sobre a técnica podem ser encontrados em vários trabalhos na literatura [35, 70, 159, 160, 161, 162]. O fato de usar laser infravermelho induz absorção de luz pela água, fazendo com que o experimento seja utilizado para determinar o coeficiente Soret de íons e moléculas que não possuem 


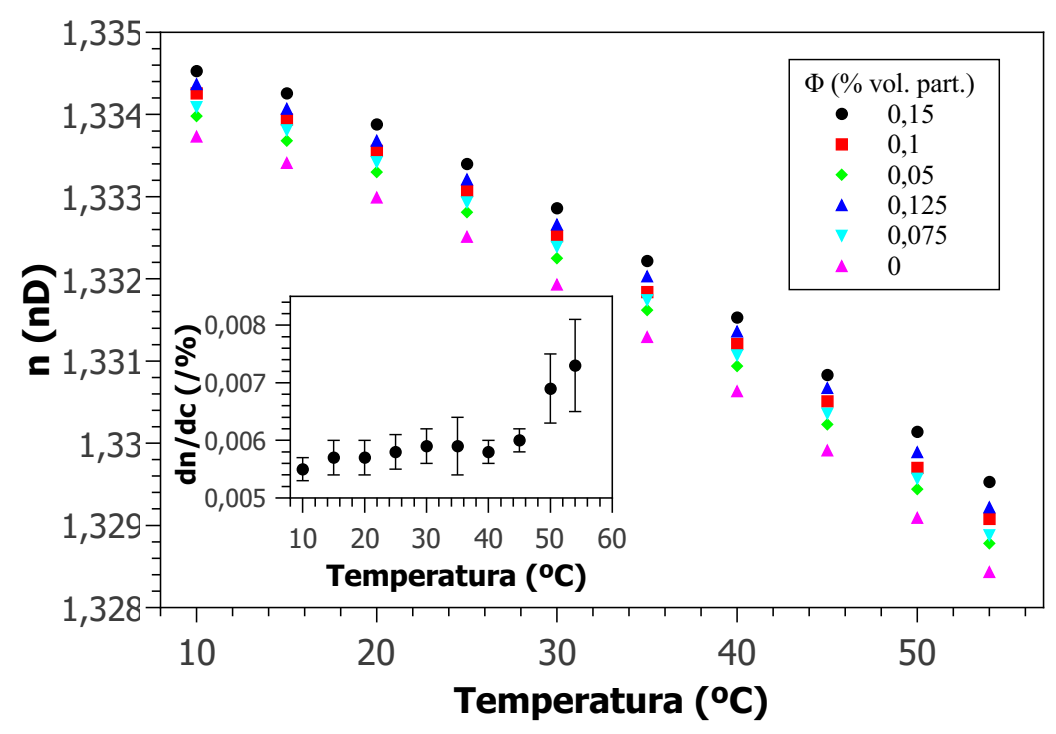

Figura 3.9: Valores para o índice de refração em uma solução de ferrofluido em várias temperaturas para algumas concentrações de partículas para obter o contraste de índice de refração $d n / d \Phi(T)$, mostrado no insert à esquerda. Os valores para $d n / d \Phi$ são obtidos a partir do ajuste linear aos dados $n \times \Phi$ para cada temperatura.

absorção de luz [63, 163].

Os principais detalhes da técnica são descritos aqui, com uso da figura 3.10. Um laser infravermelho de comprimento de onda $\lambda_{w}=980 \mathrm{~nm}$ com e potência $P \approx 0,5 \mathrm{~W}$ é dividido em dois feixes de mesma potência que são direcionados por dois espelhos para o mesmo ponto da amostra. Um filtro espacial utilizado antes da divisão expande o feixe para diâmetro de aproximadamente $7 \mathrm{~mm}$. A estabilização da fase entre os feixes divididos é realizada por um espelho montado sobre cerâmica piezoelétrica e o controle para mudar a fase de $180^{\circ}$ é realizado por placa de onda de $\lambda / 2$ e célula Pockels (Pockels cell). Dois prismas próximos entre si direcionam os feixes para o mesmo ponto de irradiação na amostra, causando a interferência entre eles e definindo o ângulo $\theta$ do vetor de onda da grade de interferência $q=4 \pi \sin (\theta / 2) / \lambda$. A distância entre máximos ou mínimos consecutivos é dada por $d=2 \pi / q$. Sendo o ângulo $\theta \lesssim 5^{\circ}$ difícil de medir exatamente, a grade de interferência é observada diretamente por uma câmera CCD pelo uso de um espelho M1 antes da amostra. Os valores utilizados para $d=2 \pi / q$ nos experimentos para este trabalho são de $20 \mu \mathrm{m}$ a $25 \mu \mathrm{m}$. As células de amostra (fabricadas pela Hellma) possuem janelas de quartzo e espessura de amostra de $0,2 \mathrm{~mm}$. A célula contendo amostra é inserida em um recipiente de latão, com aberturas apenas para passagem dos feixes laser, 
e circulação interna de água para controle de temperatura. A temperatura é controlada por banho térmico (Lauda) com precisão de $0,02{ }^{\circ} \mathrm{C}$.

A interferência dos dois feixes gera um perfil de intensidade senoidal periódico, sendo que o perfil de temperatura adquire dependência espacial semelhante ao perfil de intensidade. Se a amostra é irradiada por tempo suficiente, as partículas migram para os pontos de máximo ou mínimo de temperatura, dependendo do sinal do coeficiente Soret. Para repetir o experimento várias vezes, a fase entre os dois feixes é alterada de $180^{\circ}$. A polarização vertical do feixe infravermelho gera as franjas da grade de interferência na direção vertical, e por consequência também as de temperatura e de concentração de partículas. As grades de temperatura e de partículas implicam em perfil periódico do índice de refração, causando a difração de um laser de prova (read out beam). O laser de prova utilizado possui $\lambda_{r}=632,8 \mathrm{~nm}$ e não é absorvido pela amostra. A intensidade difratada é medida por uma fotomultiplicadora conectada a uma fibra óptica monomodo (mono mode fiber), posicionada após a amostra a um pequeno ângulo em relação ao eixo de propagação do feixe infravermelho. A intensidade do sinal medido é proporcional às amplitudes das grades de temperatura e concentração. Os detalhes para obtenção do coeficiente Soret são descritos a seguir.

\subsubsection{Obtenção do Coeficiente Soret}

A análise descrita aqui considera uma solução ternária, onde dois tipos de partículas com constantes de difusão muito diferentes estão dispersas em um líquido, como no caso das nanopartículas de ferrofluido estabilizadas por diferentes ácidos e bases em água. Detalhes sobre essa análise são encontrados no trabalho de Kita et al [164]. A amplitude total do sinal heterodino espalhado $\zeta^{\text {het }}(t)$ é dada por [2]

$$
\zeta^{h e t}(t)=1-e^{-t / \tau_{t h}}-A^{i o n}\left(1-e^{-t / \tau^{i o n}}\right)-A^{N P}\left(1-e^{-t / \tau^{N P}}\right)
$$

onde $\tau_{t h}=1 / q^{2} D_{t h}$ é o tempo de difusão de calor relacionado com a difusividade térmica $D_{t h}, \tau^{i o n}=1 / q^{2} D_{i o n}$ a constante de tempo relacionada com a difusão dos íons dispersantes 


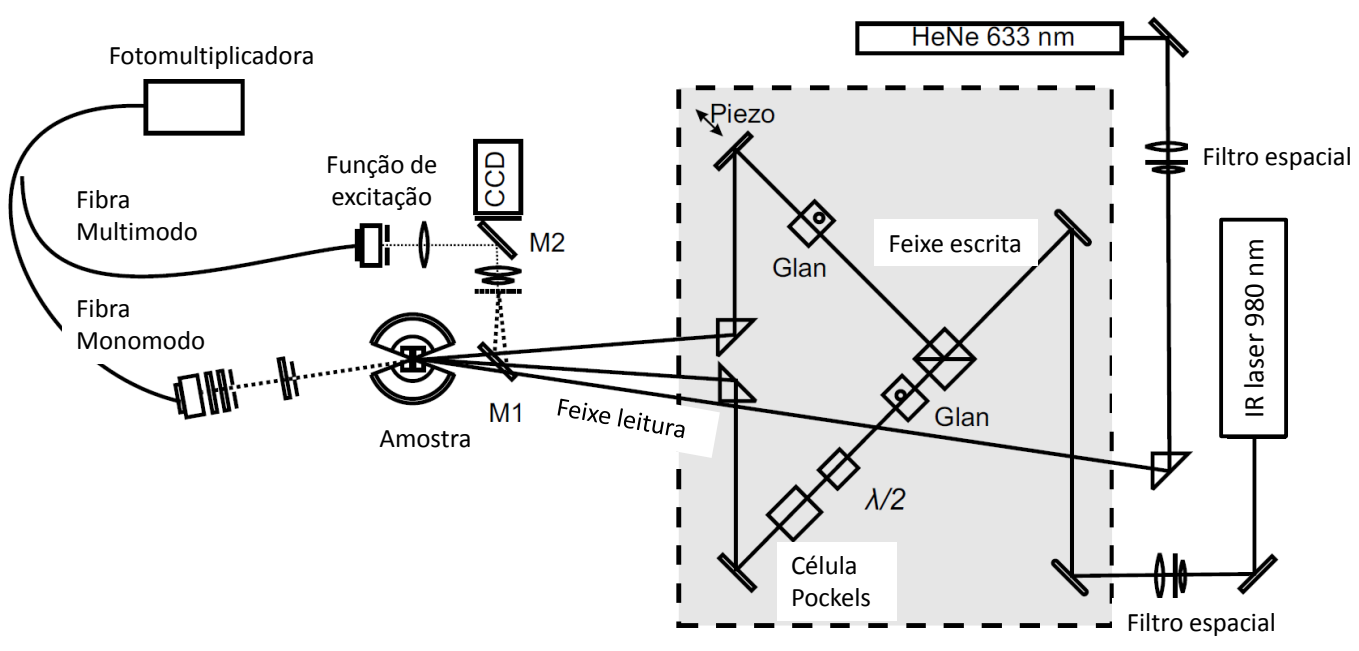

Figura 3.10: Desenho esquemático mostrando o experimento IRTDFRS, adaptado de [2]. Um feixe laser infravermelho é dividido em dois, sendo que um dos feixes segue para um espelho piezoelétrico e outro por uma placa de onda e uma célula Pockels, que controlam a diferença de fase entre eles. Os dois espelhos direcionam os feixes para dois prismas, usados para controlar o ângulo para a interferência dos feixes na amostra. Os feixes irradiam o mesmo spot na amostra (cell), sendo que um divisor de feixes antes da amostra direciona o feixe para uma câmera $\mathrm{CCD}$, que permite visualizar o padrão de interferência. O feixe de leitura é direcionado diretamente através da amostra, e a intensidade espalhada pelas grades de temperatura e concentração medida por uma fotomultiplicadora. 
$D_{i o n}$ e $\tau^{N P}=1 / q^{2} D$ relacionada à difusão das partículas $D$. As amplitudes $A^{i o n}$ e $A^{N P}$ de cada uma das grades de concentração dada por

$$
\begin{aligned}
& A^{i o n}=\frac{(\partial n / \partial w)_{P, T, \Phi}}{(\partial n / \partial T)_{P, w, \Phi}} w(1-w) S_{T}^{i o n}, \\
& A^{N P}=\frac{(\partial n / \partial \Phi)_{P, T, w}}{(\partial n / \partial T)_{P, \Phi, w}} \Phi(1-\Phi) S_{T},
\end{aligned}
$$

sendo $S_{T}^{i o n}$ o coeficiente Soret do sal e $S_{T}$ o coeficiente Soret das nanopartículas. Ao determinar $S_{T}^{i o n}$ experimentalmente sem a presença de nanopartículas em solução, o último termo da equação 3.24 não é considerado. Para a análise de resultados experimentais para as nanopartículas dispersas em íons, a constante de tempo de difusão dos íons $\tau^{i o n}$ é parâmetro conhecido e permite a determinação das outras através do melhor ajuste da equação 3.24 aos resultados experimentais. Contudo, nos experimentos para determinar $S_{T}$ as concentrações de íons onde os resultados mais importantes são obtidos são baixas, e $A^{i o n}$ não contribui significativamente para o sinal $\zeta^{\text {het }}(t)$ medido nas amostras contendo nanopartículas. Dessa forma, experimentos para os diferentes sais são feitos até o limite de baixa concentração, para posterior comparação com os resultados obtidos com as nanopartículas. 


\section{Capítulo 4}

\section{$S_{T}(T)$ para ferrofluidos de solução ácida}

Esse capítulo apresenta os resultados publicados por nós nos artigos [69, 158] sobre os efeitos termodifusivos em amostras de colóides magnéticos de meio ácido (neste caso ácido nítrico). O efeito Soret em sistemas semelhantes foi investigado por vários autores em trabalhos anteriores $[19,21,31]$. O comportamento termofílico $\left(S_{T}<0\right)$ é um resultado experimental frequentemente encontrado para partículas em meio ácido, mas o fenômeno físico microscópico responsável por acumular partículas no lado quente não estava claro. Na Seção 2.2 alguns modelos teóricos recentes foram brevemente descritos, e serão comparados com os resultados experimentais apresentados nesse capítulo. As grandezas físicas que surgem nos cálculos teóricos são obtidas experimentalmente para tornar possível essa comparação. Comparações dessa forma foram realizadas recentemente em ferrofluidos de meio ácido [28], onde os resultados foram comparados com a descrição teórica de Morozov [24]. O mesmo tipo de análise foi feita para o efeito Soret em partículas de poliestireno em várias soluções eletrolíticas [64]. Na referência [28] o modelo teórico usado é baseado na mudança da dupla camada elétrica em torno das partículas, enquanto que em [64] a teoria usada é baseada no efeito termoelétrico gerado pela diferença no calor de transporte de cada íon. Nesta última, os resultados $S_{T}(T)$ foram bem descritos nos dois casos (campo termoelétrico com sentidos quente-frio e frio-quente). Em um trabalho mais antigo [59], os resultados obtidos para $S_{T}(T)$ das nanopartículas de poliestireno não foram satisfatoriamente descritos pelas teorias então presentes $[24,78,106,107,110]$. Os resultados que serão apresentados neste capítulo poderão indicar os mecanismos físicos mais importantes 
no efeito Soret das partículas de ferrofluidos quando dispersas em soluções ácidas.

A dependência com a temperatura do coeficiente Soret $S_{T}(T)$ das nanopartículas foi obtida experimentalmente e comparada com as teorias para o efeito termoelétrico e de dupla camada. Foi considerada a dependência com a temperatura das grandezas físicas envolvidas: $D(T), \zeta(T), S(T), \eta(T), \epsilon(T)$, sendo que as três primeiras foram determinadas experimentalmente e, para as duas últimas, foram utilizados os valores da água. Essa abordagem é válida, pois a solução possui baixa concentração de nanopartículas e a concentração de ácido nítrico $(\leq 0,01 \mathrm{Mol} / \mathrm{L})$ não altera significativamente os valores de $\eta$ e $\epsilon[165,166]$.

O capítulo é dividido em duas partes. Na primeira, serão apresentados os resultados obtidos nos experimentos de lente térmica e lente de matéria em diferentes temperaturas, dos quais se obtém a condutividade térmica $k_{T}(T)$ e as amplitudes dos coeficientes Soret $S_{T}(T)$ de difusão de massa $D(T)$. Também serão apresentados os resultados para $\zeta(T)$, e $S(T)$. Na segunda parte esses resultados serão utilizados para a comparação teórica com os valores experimentais obtidos de $S_{T}(T)$.

\subsection{Resultados}

\subsubsection{Lente Térmica e Lente de Matéria}

Nos experimentos de Lente Térmica e Lente de Matéria é medida a transmitância em função do tempo no centro do feixe Gaussiano. A diferença entre os dois experimentos é a escala de tempo, sendo que no de Lente Térmica a amostra é irradiada por um tempo de 30 a 40 ms e no experimento de Lente de Matéria a irradiação é por pulsos de 50 a 100 segundos de duração. A separação temporal dos dois efeitos de lente pode ser vista no patamar de valores constante para $T_{N}(t) \approx 1$, como mostra a Figura 4.1 para posição $\mathrm{Z}=-7 \mathrm{~mm}$ em relação à posição focal e com raio do feixe $w \approx 80 \mu \mathrm{m}$.

Os dados do experimento de Lente Térmica são normalizados de acordo com $T_{N}(z)=$ $I\left(z, t_{L T}\right) / I(z, t \rightarrow 0)$, fornecendo curvas características do experimento de Varredura-Z 


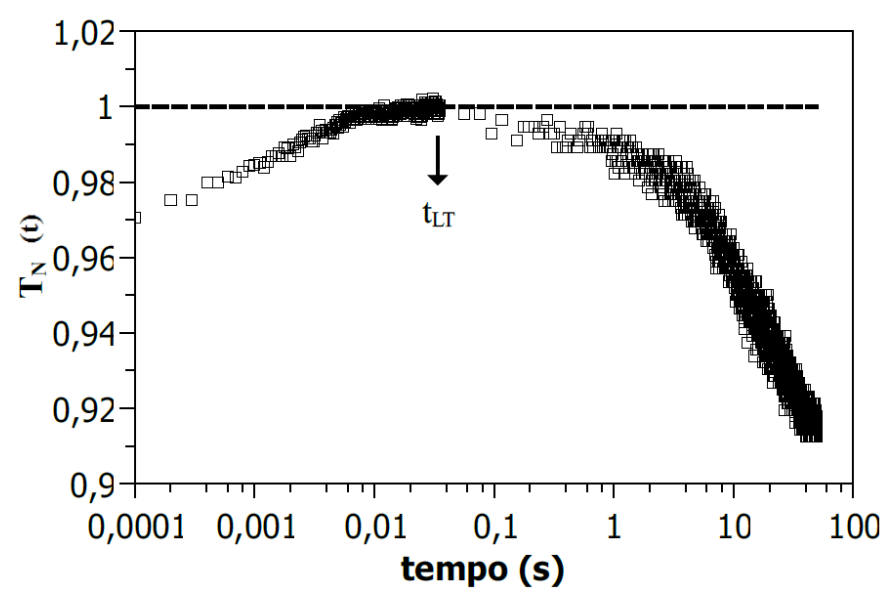

Figura 4.1: Transmitância Normalizada em função do tempo $T_{N}(t)$, combinando curvas experimentais de Lente Térmica e de Lente de Matéria. No patamar indicando o tempo de saturação de Lente Térmica $t_{L T}$, o efeito térmico e Soret podem ser normalizados para análise separadamente.

como mostrado na Figura 4.2. As linhas dos gráficos mostram os melhores ajustes da equação 3.17 para obter a amplitude $\theta_{L T}$, sendo a condutividade térmica da amostra o parâmetro de ajuste.

Os valores obtidos para a condutividade térmica em função da temperatura da amostra FF1 são apresentados na Figura 4.3 e comparados com os valores tabelados para a condutividade térmica da água pura. Apenas nas mais altas temperaturas os valores experimentais de $k_{T}$ são maiores que os valores para a água. Para as baixas concentrações volumétricas de partículas $(\Phi=0,075 \%)$ e de ácido $\left(c^{\mathrm{HNO}_{3}}=0,01 \mathrm{Mol} / \mathrm{L}\right)$ utilizadas nestes experimentos, não é previsto aumento significativo da condutividade térmica pelos principais modelos existentes para transporte de calor em dispersões coloidais [167, 168].

Para a análise dos resultados experimentais da Lente de Matéria, a intensidade medida é normalizada da forma $T_{N}(z, t)=I(z, t) / I\left(z, t_{L T}\right)$, sendo que o experimento pode ser realizado em uma única posição $z$ em função do tempo e analisado pela equação 3.23 para fornecer valores de $\theta_{\text {Soret }}$ e $t_{\text {Soret }}$ e permitir o cálculo de $S_{T}$ e $D$. A Figura 4.4 mostra a evolução temporal da lente de matéria obtida com a amostra FF2 em diferentes temperaturas, para concentração de partículas $\Phi=0,075$ \%vol.. Os pontos experimentais 


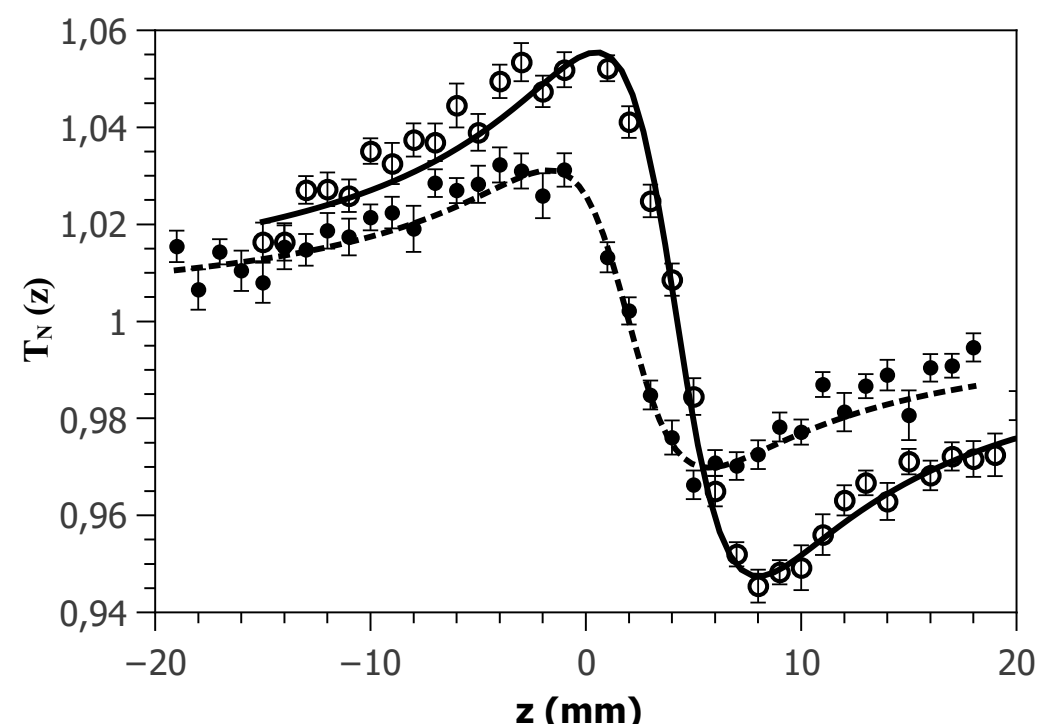

Figura 4.2: Transmitância Normalizada para o experimento de Lente Térmica em função da posição z experimental para a amostra FF1, em duas temperaturas, $\mathrm{T}=20{ }^{\circ} \mathrm{C}$ símbolos fechados - e $\mathrm{T}=60{ }^{\circ} \mathrm{C}$ - símbolos abertos. As linhas representam os melhores ajustes da equação para obter $\theta_{L T}$ e a posição focal $z=0$ do feixe de laser.

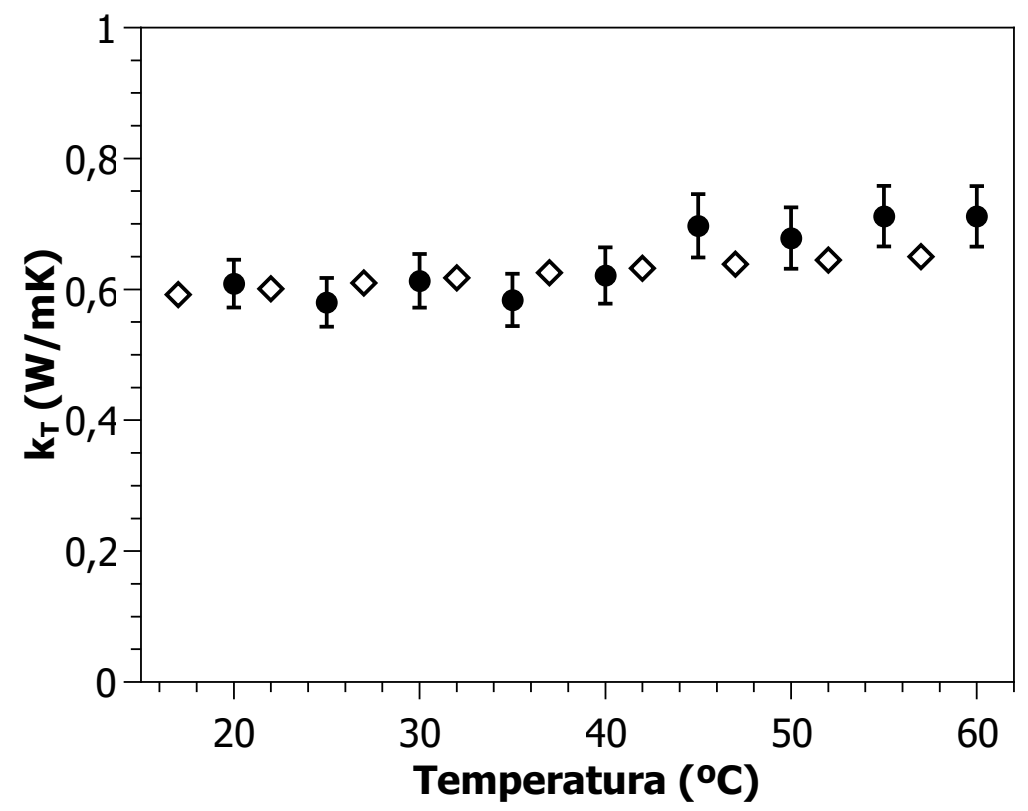

Figura 4.3: Valores de condutividade térmica obtidos pelo experimento de Lente Térmica para a amostra FF1 - símbolos fechados - e valores tabelados da mesma grandeza para a água pura. 


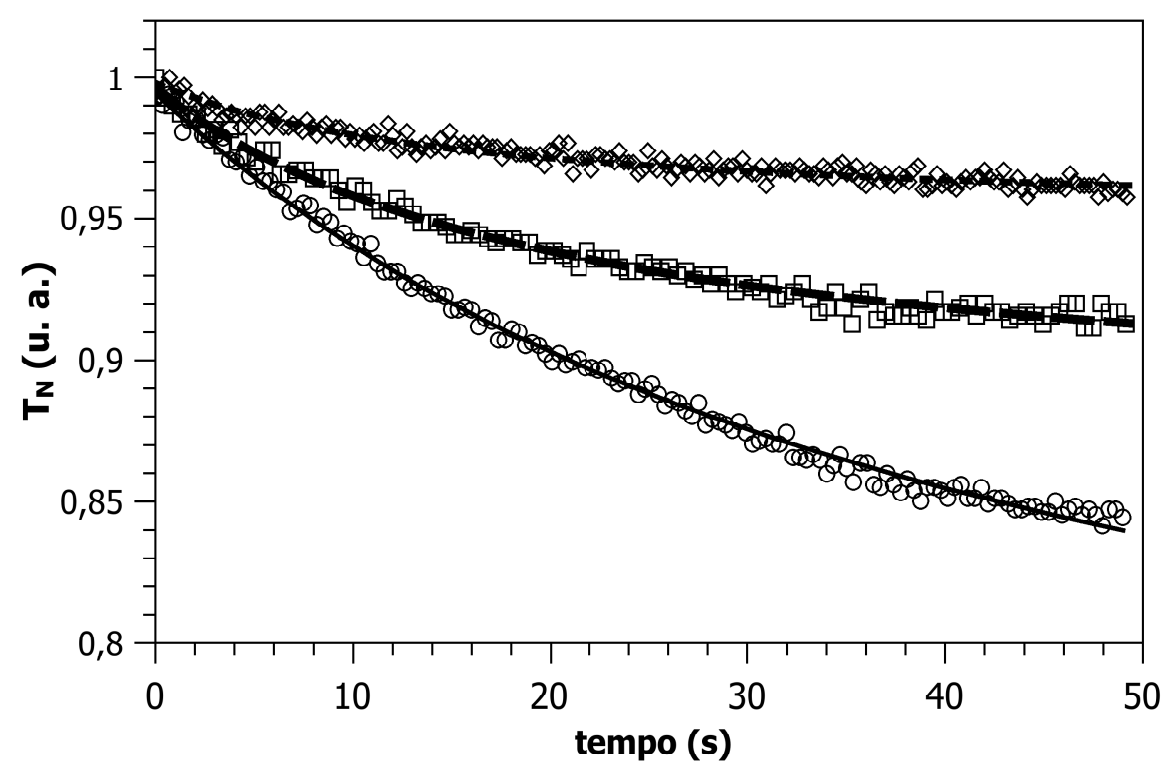

(a)

Figura 4.4: Evolução temporal da Transmitância normalizada para a amostra FF2 em diferentes temperaturas: $(\bigcirc) 20{ }^{\circ} \mathrm{C},(\square) 35{ }^{0} \mathrm{C},(\diamond) 50{ }^{\circ} \mathrm{C}$, sendo que as linhas correspondem aos ajustes teóricos da equação 3.23. A diminuição do efeito de lente de matéria com o aumento de temperatura ocorre de forma semelhante para a amostra FF1, não mostrado.

$T_{N}(t)$ são a média de pelo menos 10 medidas independentes para cada temperatura. Essa concentração de partículas é escolhida como a mínima possível que resulta boa razão sinal/ruído do sinal de evolução temporal da lente de matéria em todos os valores de temperatura em que o experimento é realizado. As linhas sobre os pontos experimentais são os melhores ajustes teóricos realizados usando a equação 3.23, das quais se obtém a amplitude de lente $\theta_{\text {Soret }}$ e o tempo característico de difusão $t_{\text {Soret }}$.

O cálculo dos valores $S_{T}(T)$ é feito a partir de $\theta_{\text {Soret }}=\Phi \theta_{L T} S_{T} d n / d \Phi(d n / d T)^{-1}$, sendo que a amplitude de $\theta_{L T}$ é obtida no experimento de lente térmica. O experimento de Varredura-Z de lente térmica determina exatamente a posição focal experimental do feixe, para uso do valor exato de $z$ na equação 3.23. As curvas experimentais da Figura 4.4 foram obtidas com as amostras posicionadas antes do foco do laser $(z<0)$, do lado esquerdo do foco no esquema da Figura 3.7. A diminuição da transmitância com o tempo significa que o raio do feixe na posição do fotodetector está aumentando com o tempo, ou 


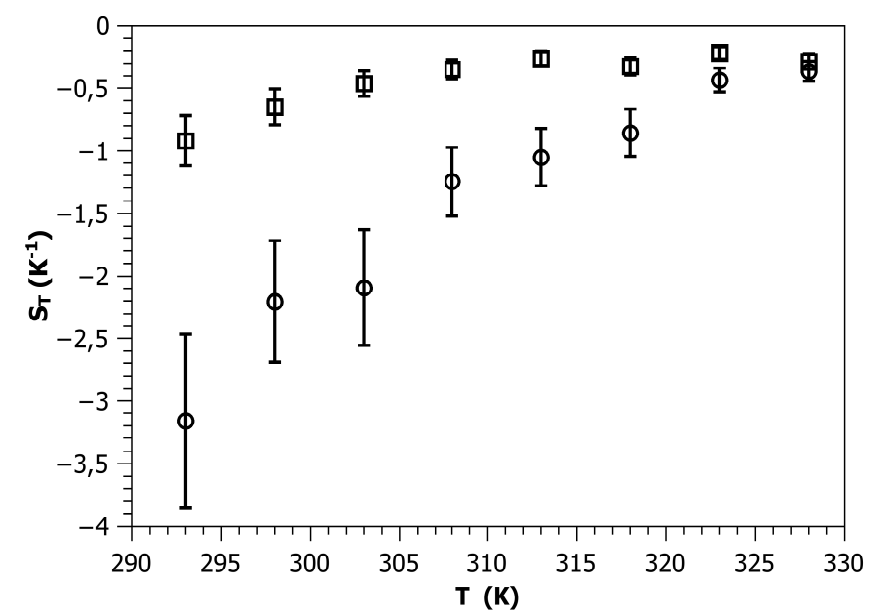

Figura 4.5: Coeficiente Soret em função da temperatura da amostras para as amostras FF1 (○) e FF2 (口).

seja, o feixe está sendo focalizado pela lente de partículas para mais próximo da amostra em relação ao foco original. Sendo $d n / d \Phi>0$ para esses ferrofluidos, as partículas estão migrando para o centro do feixe Gaussiano, a região mais quente da amostra, o que significa $S_{T}<0$ pela definição.

A Figura 4.5 mostra os valores obtidos para $S_{T}(T)$ nas amostras FF1 e FF2. Em trabalhos anteriores, já havia sido observado o comportamento termofílico das nanopartículas de ferrofluidos quando dispersas em meio ácido [17, 19, 22, 31], enquanto que neste trabalho o interesse é analisar os valores de $S_{T}(T)$ e investigar quais os principais mecanismos físicos responsáveis pelo efeito Soret. Dessa forma, o efeito da temperatura mais acentuado na amostra FF1 em relação à amostra FF2 na Figura 4.5 deverá ser compreendido. Principalmente, a não ocorrência da mudança de sinal de $S_{T}$ em alguma temperatura nesse intervalo deve estar relacionada com os efeitos físicos responsáveis pela movimentação das nanopartículas para o lado quente.

A partir dos ajustes nos experimentos de lente de matéria também foram obtidos os valores para a constante de difusão de massa para o intervalo de temperatura investigado, mostrados na Figura 4.6. As linhas sólidas nos gráficos são curvas de ajuste linear, dependência que é a indicada pelos pontos experimentais. O aumento de $D$ com a temperatura é esperado devido à diminuição da viscosidade, que diminui cerca de $50 \%$ no intervalo de 


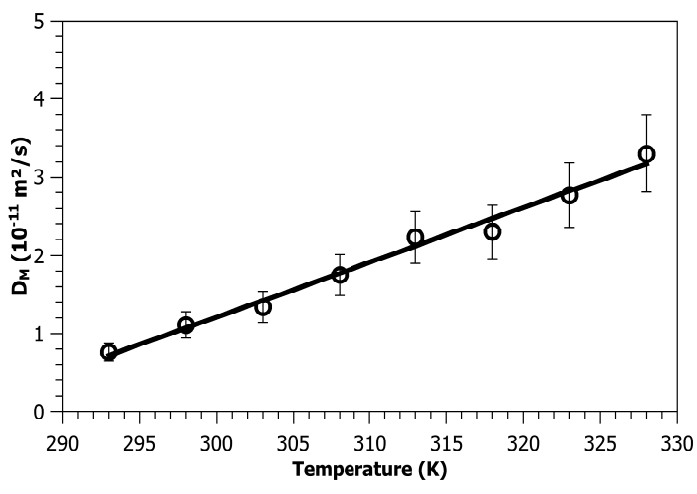

(a)

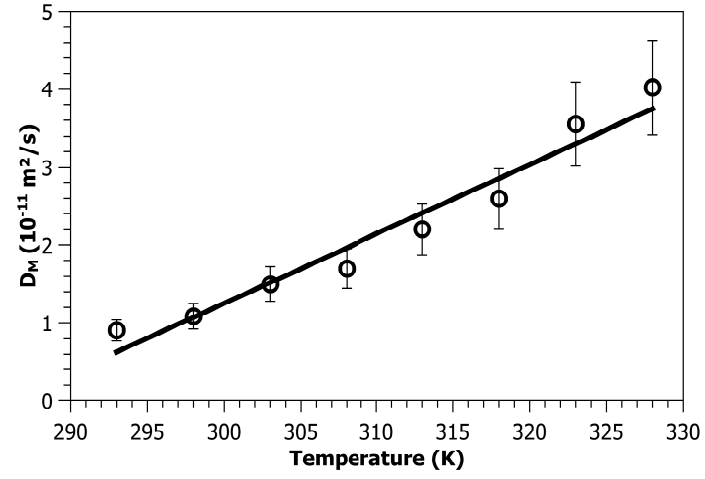

(b)

Figura 4.6: Dependência com a temperatura do coeficiente de difusão de massa para a amostra FF1 (a) e FF2 (b).

temperatura estudado (considerando $\eta_{\text {ferrofluido }} \sim \eta_{\text {água }}$ ). Os valores de $D$ são da mesma ordem de grandeza de resultados encontrados na literatura para ferrofluidos em meio ácido $[10,22,169]$.

\subsubsection{Potencial zeta}

O potencial- $\zeta$ das nanopartículas dispersas em meio ácido foi investigado usando o experimento eletroacústico. O procedimento utilizado é o descrito na seção 3.2.1, onde uma solução de referência com o mesmo pH do ferrofluido foi usada para descontar a contribuição devida à vibração iônica. Contudo, a amostra FF2 não forneceu valores estáveis, com valores oscilando entre $-50 \mathrm{mV}$ e $90 \mathrm{mV}$ em diferentes medidas independentes. Isso porque os valores para o potencial de vibração total (CVP + IVP) medidos na amostra FF2 são semelhantes aos valores para o potencial de vibração iônico (IVP) medido na solução de ácido, resultando em alta flutuação do valor calculado do potencial- $\zeta$. Para a amostra FF1 a variância nos valores obtidos para cada temperatura foi muito menor, sendo o valor médio e o desvio padrão da média de 10 medidas independentes mostrados na Figura 4.7.

O aumento do potencial com a temperatura pode ser explicado a partir das diferentes 


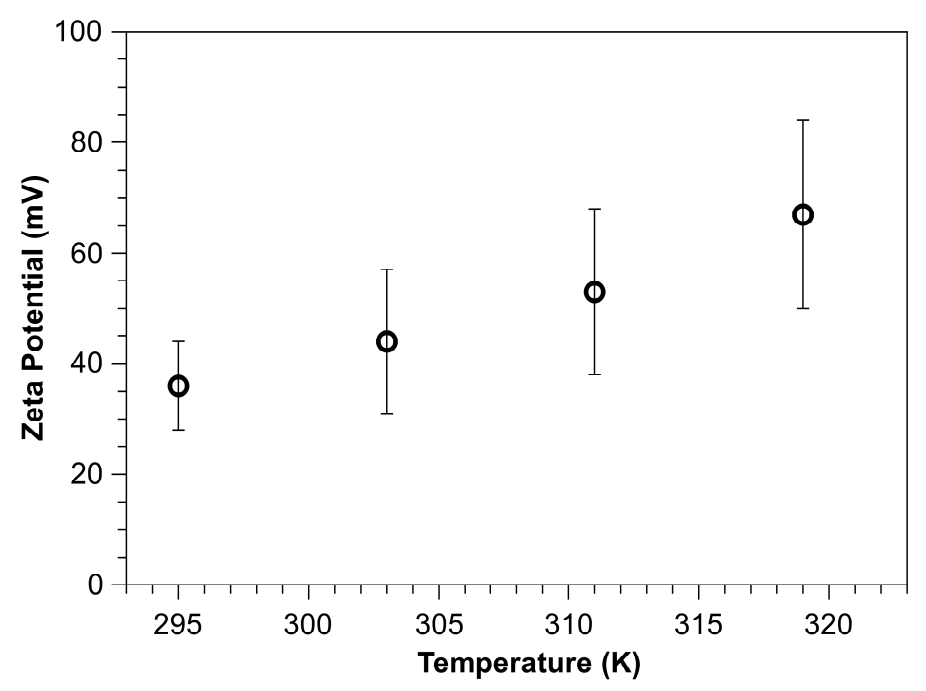

Figura 4.7: Valores de potencial zeta em diferentes temperaturas para a amostra FF1.

constantes de dissociação das cargas na dupla camada elétrica e na superfície da partícula. A Figura 4.8 mostra a distribuição de potencial eletrostático proposta para os casos em que a temperatura da amostra é a mais baixa $\zeta_{c}\left(T_{c}\right)$ e a mais alta $\zeta_{h}\left(T_{h}\right)$ no intervalo de temperatura investigado. A explicação proposta para esse efeito térmico do aumento do potencial é baseado nas constantes de troca entre cada interface de carga (baseado nas referências $[3,4,89])$ :

i) A primeira interface é a superfície da partícula, que possui uma fina camada externa de maghemita (ver Seção 3.1.1), que dispersa em meio ácido adquire carga positiva devido à preferência pela protonação dos sítios $\mathrm{FeOH}$

$$
\mathrm{FeOH}+\mathrm{H}^{+} \rightleftharpoons \mathrm{FeOH} \mathrm{H}_{2}^{+}
$$

em relação à desprotonação dada por

$$
\mathrm{FeOH} \rightleftharpoons \mathrm{FeO}^{-}+\mathrm{H}^{+}
$$

com constantes de troca de cargas dadas respectivamente por

$$
K_{p}=\exp \left(\frac{F \psi_{0}}{R T}\right) \frac{\Gamma\left(F e O H_{2}^{+}\right)}{a\left(H^{+}\right) \Gamma(F e O H)}
$$




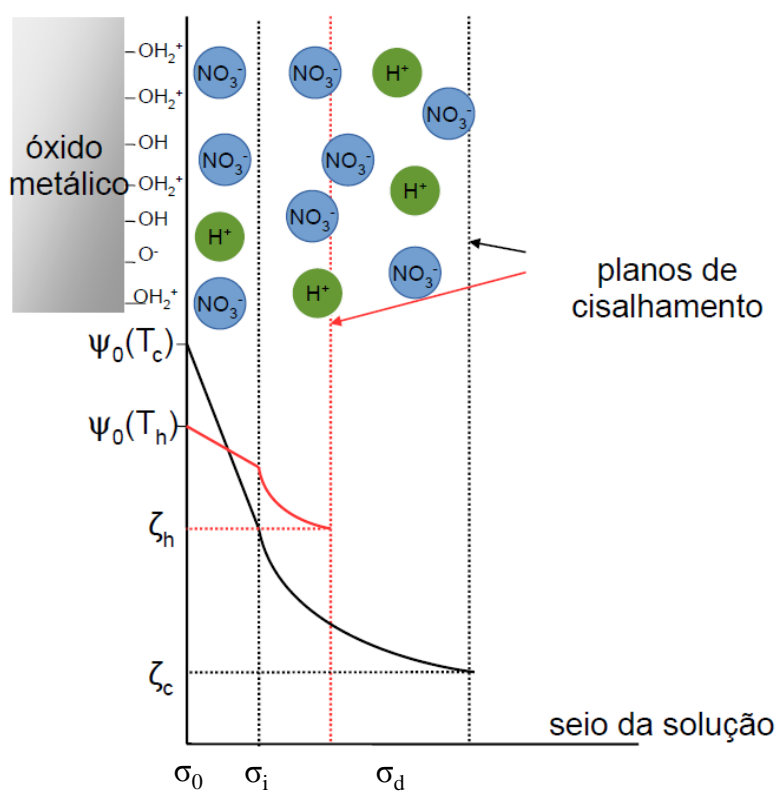

Figura 4.8: Esquema ilustrativo da distribuição de potencial em torno da partícula para as temperaturas mais baixa e alta investigadas considerando as interfaces de cargas (ver $[3,4])$, como descrito no texto principal.

$$
K_{d}=\exp \left(-\frac{F \psi_{0}}{R T}\right) \frac{\Gamma\left(F e O^{-}\right) a\left(H^{+}\right)}{\Gamma(F e O H)}
$$

sendo $\Gamma(x)$ a densidade superficial do grupo $x, a$ o coeficiente de atividade, $F$ a constante de Faraday e $R$ a constante de gás ideal. A quantidade total dos sítios $\mathrm{FeOH}_{2}^{+}$irá definir a carga superficial das partículas.

ii) A segunda interface formada é entre as cargas superficiais e os íons que se condensam próximos à superfície, onde está o plano de carga $\sigma_{0}$. As equações de troca de cargas nessa interface podem ser escritas como $[3,4]$

$$
\begin{gathered}
\mathrm{FeOH}_{2}^{+}+\mathrm{NO}_{3}^{-} \rightleftharpoons \mathrm{FeOH}_{2}^{+} \bullet \mathrm{NO}_{3}^{-}, \\
\mathrm{FeO}^{-}+\mathrm{H}^{+} \rightarrow \mathrm{FeO}^{-} \bullet \mathrm{H}^{+},
\end{gathered}
$$

e a constante de equilíbrio de cargas como 


$$
\begin{gathered}
K_{a}=\exp \left(-\frac{F \psi_{\beta}}{R T}\right) \frac{\Gamma\left(F e O H_{2}^{+} \bullet N O_{3}^{-}\right)}{a\left(N O_{3}^{-}\right) \Gamma^{*}\left(F e O H_{2}^{+}\right)}, \\
K_{c}=\exp \left(\frac{F \psi_{\beta}}{R T}\right) \frac{\Gamma\left(F e O^{-} \bullet H^{+}\right)}{a\left(H^{+}\right) \Gamma^{*}\left(F e O^{-}\right)} .
\end{gathered}
$$

Com essas equações para o equilíbrio de cargas, as densidades de carga em cada inteface podem ser definidas:

$$
\begin{gathered}
\sigma_{0}=F\left[\Gamma\left(\mathrm{FeOH}_{2}^{+}\right)+\Gamma\left(\mathrm{FeOH}_{2}^{+} \bullet \mathrm{NO}_{3}^{-}\right)-\Gamma\left(\mathrm{FeO}^{-}\right)-\Gamma\left(\mathrm{FeO}^{-} \bullet \mathrm{H}^{+}\right)\right], \\
\sigma_{i}=F\left[\Gamma\left(\mathrm{FeO} \mathrm{O}^{-} \bullet \mathrm{H}^{+}\right)-\Gamma\left(\mathrm{FeOH} \mathrm{H}_{2}^{+} \bullet N \mathrm{O}_{3}^{-}\right)\right], \\
\sigma_{d}=-\left(\sigma^{0}-\sigma^{i}\right)=F\left[\Gamma\left(\mathrm{FeOH}_{2}^{+}\right)-\Gamma\left(\mathrm{FeO}^{-}\right)\right] .
\end{gathered}
$$

Sendo que a densidade de carga $\sigma_{d}$ é relacionada com o potencial superficial pela equação 2.9 (alterando $\left(\sigma_{0}, \psi_{0}\right)$ por $\left(\sigma_{d}, \psi_{d}\right)$ ), a mudança com a temperatura das constantes de dissociação irá refletir na mudança do potencial zeta. Sendo $\psi_{\beta}<\psi_{0}$, as constantes $K_{a}$ e $K_{c}$ devem possuir valores menores que $K_{p}$ e $K_{d}$ e também sofrem maior influência do aumento da temperatura, explicando a menor blindagem das partículas pelos contra-íons o aumento do potencial zeta com a temperatura.

Apesar de não existirem trabalhos relacionando a descrição de trocas de carga descrita acima com a constate de difusão de nanopartículas, a menor blindagem das nanopartículas representado na Figura 4.8 parece ser a causa do aumento de $D_{M} \operatorname{com} T$ na Figura 4.6, além daquele esperado pela mudança de viscosidade $\eta(T)$.

\subsubsection{Campo termoelétrico - efeito Seebeck}

Nessa seção são descritos os resultados obtidos na medida de $\triangle \mathrm{V}(t)$ no experimento da célula termoelétrica. A Figura 4.9a mostra a evolução temporal da diferença de potencial 


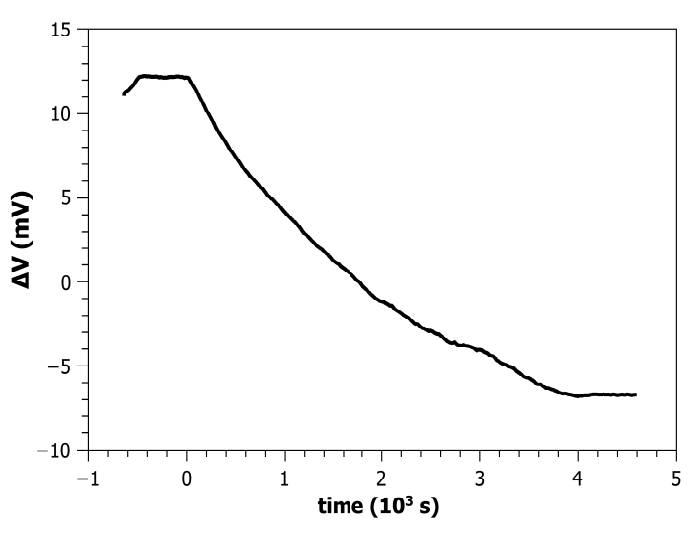

(a)

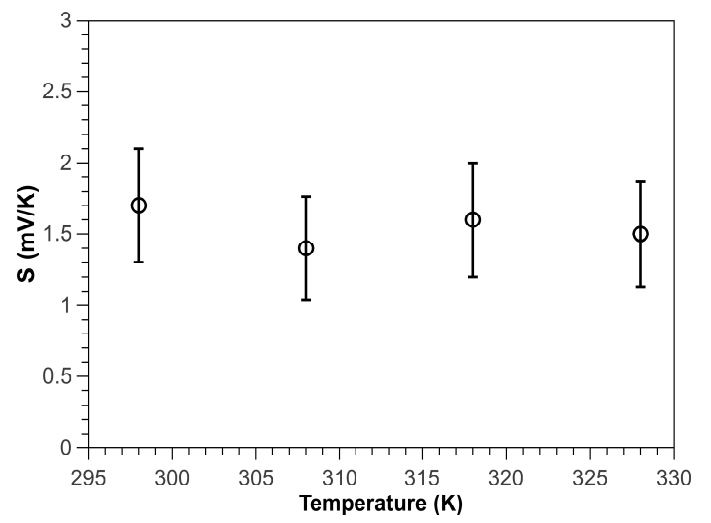

(b)

Figura 4.9: Evolução temporal da diferença de potencial entre os eletrodos e amplitude do coeficiente Seebeck $S(T)$.

para a amostra FF1 na concentração de partículas $\Phi=0,075 \%$, sendo que experimentos na amostra FF2 mostraram resultados semelhantes. $\mathrm{O}$ valor de $\triangle \mathrm{V} \sim 13 \mathrm{mV}$ é correspondente a $\triangle V_{0}$ descrito na seção 3.4. A evolução temporal até o fim da curva de $\triangle \mathrm{V}(t)$ é considerado como a amplitude do coeficiente Seebeck $S=\triangle \mathrm{V}(\mathrm{t} \rightarrow \infty) / \triangle T$, sendo que $\triangle \mathrm{V}(t)$ é descrito fenomenologicamente pela equação 3.5 e $\triangle T=10 \mathrm{~K}$. Essa também é a forma que os dados de $\triangle \mathrm{V}(t)$ foram descritos em [60]. Os valores de $S$ em função de $T$ são mostrados na Figura 4.9b. Os valores obtidos experimentalmente para $S$ são maiores que os previstos para o estado estacionário de fluxo de íons dentro da solução $S=k_{B} / e\left(Q_{+}^{*}-Q_{-}^{*}\right)$ [55], usando valores de $Q_{i}^{*}$ definidos por Agar [115].

\subsection{Análise teórica de $S_{T}(T)$}

A primeira análise de $S_{T}(T)$ da Figura 4.5 a ser feita é comparar os valores com a equação empírica 1.1. Esta equação é proposta para o comportamento $S_{T}(T)$ de partículas eletrostaticamente carregadas em solução eletrolítica e não está relacionada com os fenômenos que dão origem ao efeito Soret. A Figura 4.10 mostra o ajuste da equação 1.1 para os dados das amostras FF1 e FF2, porém nenhuma informação sobre os fenômenos físicos é obtida. Apenas é verificado que também para esse sistema a equação proposta descreve 


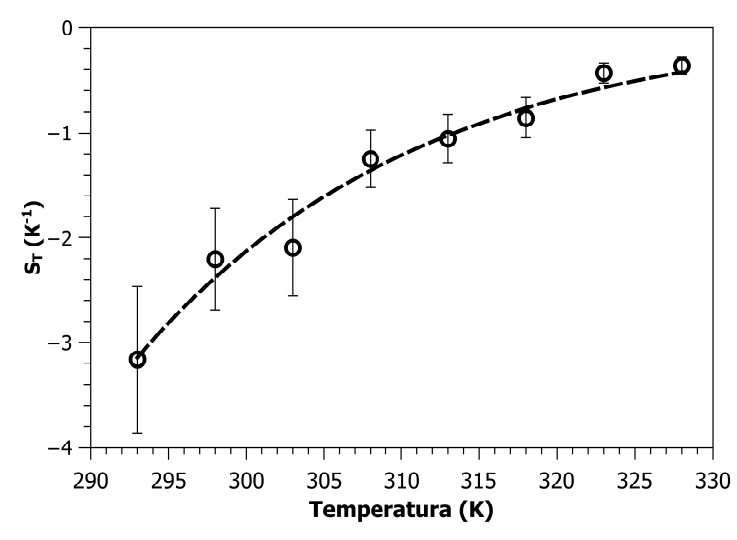

(a)

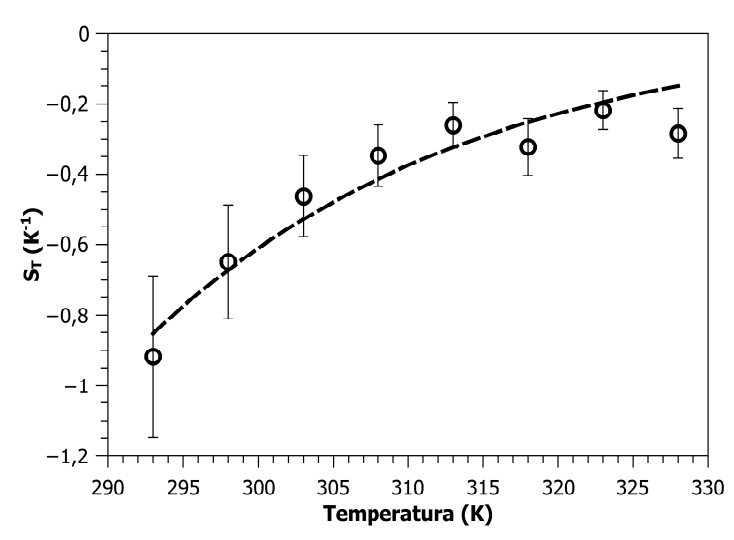

(b)

Figura 4.10: Melhor ajuste teórico da equação de Iacopini para $S_{T}(T)$ das amostras FF1 (a) e FF2 (b).

empiricamente os resultados experimentais.

É proposta a descrição dos resultados experimentais de $S_{T}(T)$ a partir das teorias que consideram as contribuições da dupla camada e do efeito Seebeck, usando as equações 2.27 e 2.29. Um primeiro cálculo mostrou que as contribuições dominantes para a amostra FF1 (que teve todas as grandezas obtidas experimentalmente) foram o termo contendo $\partial \zeta / \partial T$ na equação 2.27 e o termo contendo o coeficiente Seebeck $S$ na equação 2.29 . A equação composta pelos termos dominantes é

$$
S_{T}(T)=\frac{\epsilon}{\eta T D}(-\zeta S T)+\frac{4 \pi \epsilon R(1+\kappa R) \zeta^{2}}{k_{B} T^{2}} \frac{2 T}{\zeta} \frac{\partial \zeta}{\partial T}
$$

e foi proposta para descrever os resultados obtidos para $S_{T}(T)$, com as grandezas $D(T)$, $\zeta(T)$ e $S(T)$ medidas experimentalmente e $\eta(T)$ e $\epsilon(T)$ os valores para a água. A Figura 4.11 mostra a curva teórica calculada usando a equação 4.12, sem nenhum parâmetro de ajuste desconhecido adicional. É possível observar que o comportamento qualitativo da curva é muito semelhante ao experimental.

Para a amostra FF2 os valores experimentais de potencial zeta não puderam ser medidos. A comparação teórica foi feita utilizando a equação 4.12 para obter os valores $\zeta(T)$ que melhor ajustam a curva teórica com os resultados experimentais. A Figura 4.12 mostra o ajuste teórico aos resultados experimentais. Os valores resultantes do melhor ajuste 


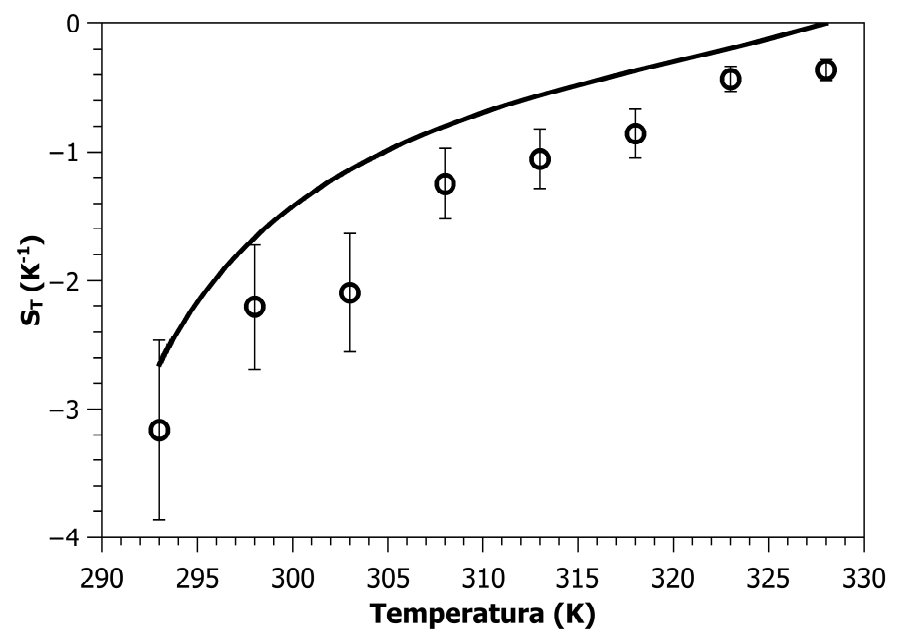

Figura 4.11: Comparação entre os resultados experimentais e o cálculo teórico (linha contínua) usando a equação 4.12 para os dados da amostra FF1.

possuem uma dependência linear $\zeta(T)$ que fornece $\zeta(293 K)=3 \mathrm{mV}$ e $\zeta(323 K)=6 \mathrm{mV}$. Esses valores e aqueles obtidos na Figura 4.7 estão de acordo com resultados anteriores, presentes na literatura, onde a carga superficial das partículas diminui com o tamanho da partícula [84].

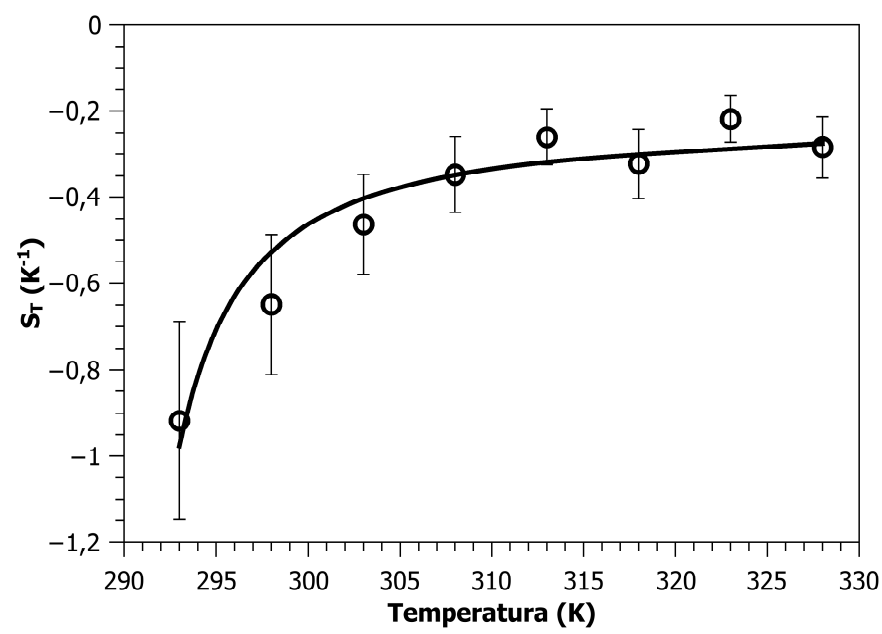

Figura 4.12: Melhor ajuste teórico da equação 4.12 sobre os dados experimentais para a amostra FF2.

Alguns detalhes interessantes também valem nota e discussão. O primeiro é o comportamento com a temperatura dos dois termos da equação 4.12, como mostrado na Figura 4.13. As duas contribuições (dupla camada e termoelétrico) são maiores para a amostra FF1 em relação à amostra FF2; além disso, em ambas as amostras o efeito termoelétrico 


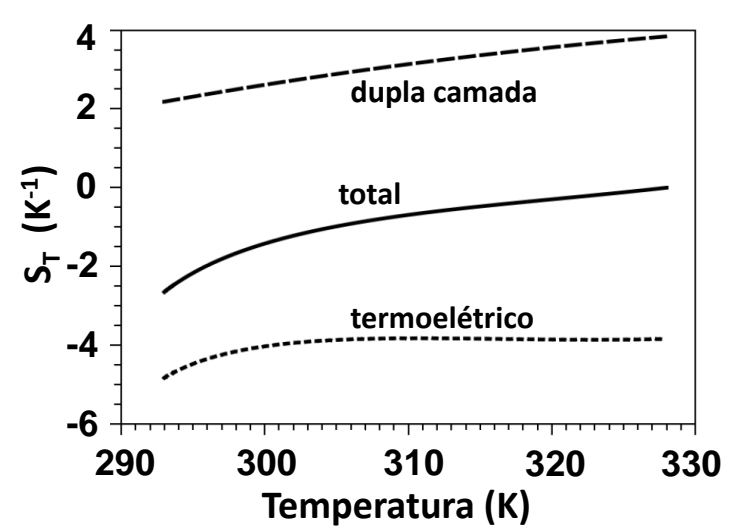

(a)

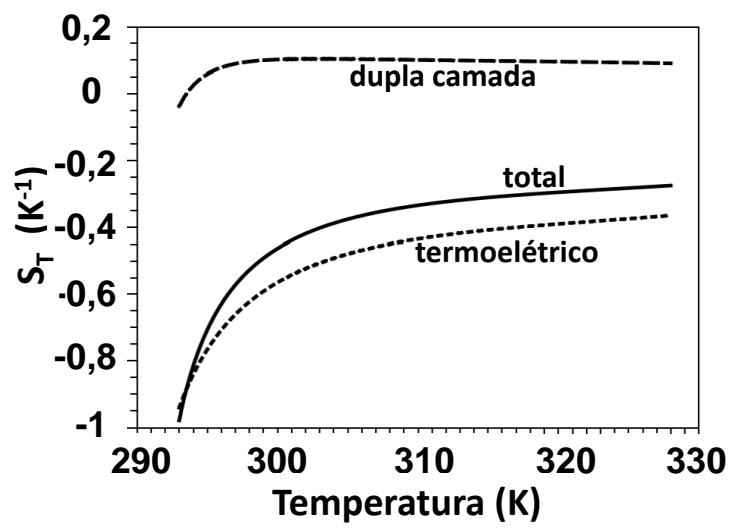

(b)

Figura 4.13: Dependência com a temperatura dos termos que mais contribuem para o coeficiente Soret das nanopartículas (termoelétrico e dupla camada) em solução ácida e a soma total. (a) Amostra FF1 e (b) Amostra FF2.

é dominante. Contudo a abordagem realizada neste trabalho foi uma dentre as possíveis. Isso porque apenas o termo contendo a variação de potencial do modelo de dupla camada foi adicionado à equação teórica final, para não repetir a contribuição de $d \epsilon(T) / d T$ contida em ambos modelos. Outra forma possível da comparação com as teorias é considerar todos os termos do modelo baseado na dupla camada e somar apenas a contribuição do termo contendo o coeficiente Seebeck. Isso porque os valores obtidos para $S$ e $D$ fazem com que o termo $\propto \zeta S$ seja maior que os termos na equação 2.29 desenvolvida por Würger e colaboradores.

A Figura 4.14 mostra uma comparação com a teoria para os dados da amostra FF1, onde o modelo de dupla camada (equação 2.27) foi utilizado com a adição de um termo constante. A constante $A$ representa contribuições físicas não presentes naquele modelo. A linha contínua mostra o ajuste teórico mostrando que o modelo de dupla camada com a adição de uma constante descreve bem as mudanças de valores com a temperatura. O valor obtido pelo ajuste $A=-8,83 \mathrm{~K}^{-1}$ mostra que é da ordem de grandeza daquela obtida para a contribuição do efeito Seebeck. Outra interpretação para a constante $A$ feita pelos autores do modelo [112] é que esta pode ser uma contribuição devido à camada de hidratação e, possivelmente, do material que constitui o núcleo cristalino da partícula. 


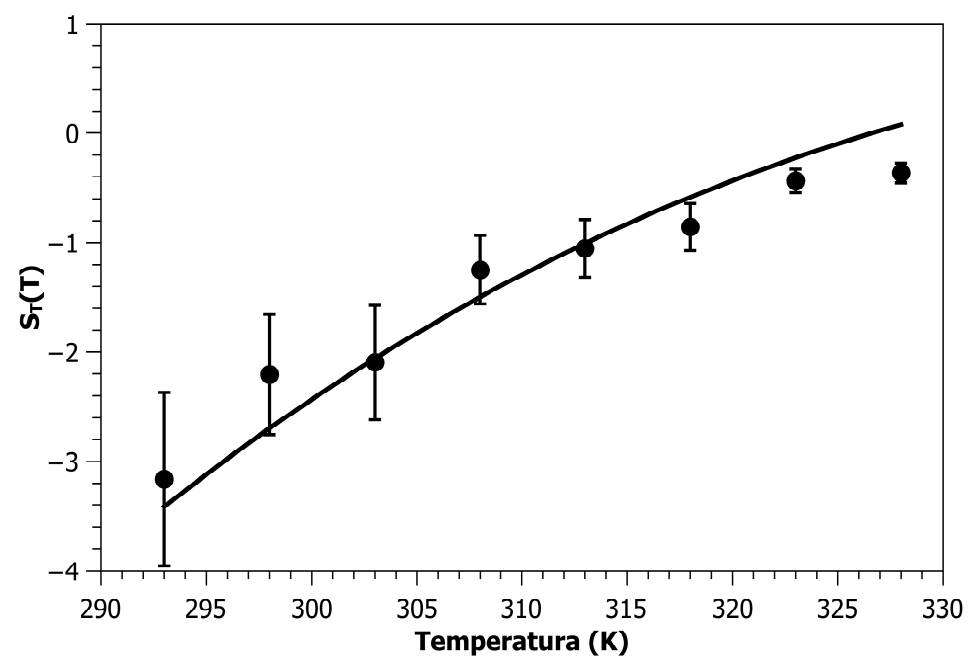

Figura 4.14: Comparação teórica com o coeficiente Soret da amostra FF1 usando o modelo de dupla camada elétrica completo com mais um termo independente.

\subsection{Conclusão - amostras em meio ácido}

A dependência com a temperatura do coeficiente Soret $S_{T}(T)$ mostrou comportamento semelhante ao observado em vários outros sistemas de partículas carregadas dispersas em solução eletrolítica aquosa. A equação fenomenológica 1.1 proposta por Iacopini [1] descreve bem os resultados, porém não representa nenhum fenômeno físico.

Os resultados experimentais apresentados neste capítulo mostram que não ocorre mudança de sinal de $S_{T}$ de negativo para positivo, como observado em muitos sistemas dispersos em água. É verificada a hipótese de que esse comportamento surge por conta do efeito dominante sobre o coeficiente Soret das nanopartículas, neste caso o efeito termoelétrico. Realizando medidas das grandezas envolvidas na difusão de nanopartículas, é verificado que a combinação dos modelos baseados na dupla camada elétrica e no coeficiente Seebeck prevê o comportamento $S_{T}(T)$ semelhante ao obtido experimentalmente.

Os valores do coeficiente Seebeck que foram utilizados nesse capítulo devem ser investigados mais a fundo, devido a seus altos valores. Uma possível origem da alta contribuição termoelétrica para o efeito Soret de nanopartículas pode ser a relação entre o coeficiente Soret iônico e a resposta termoelétrica da solução. Para isso, o coeficiente Soret iônico 
$S_{T}^{i o n}$ será determinado experimentalmente para alguns ácidos e bases e serão investigados nos próximos capítulos. Os diferentes resultados para o coeficiente Soret iônico em diferentes soluções iônicas serão verificados como a causa de diferente resposta termoelétrica no capítulo 6. Com isso, uma investigação mais completa de todos os termos da equação 2.29 pode ser realizada. O efeito da dupla camada elétrica sobre o efeito Soret das nanopartículas também será investigado para outras soluções iônicas, sendo que teoricamente esta contribuição não depende dos diferentes tipos de íons, mas apenas da concentração de íon. 


\section{Capítulo 5}

\section{Influência do Coeficiente $S_{T}^{\text {ion }}$ Sobre $S_{T}$}

A estabilização de nanopartículas de óxidos de ferro em soluções de hidróxidos pode causar a mudança de sinal do coeficiente Soret comparado com partículas em meio ácido. Essa observação já foi realizada em trabalhos anteriores, mostrando padrões de comportamento do sinal obtido para o coeficiente Soret $[19,21,28]$. Uma das questões fundamentais que permanece não resolvida é a origem microscópica do efeito causado pelo gradiente de temperatura em partículas dispersas em ácidos ou bases, carregando partículas para o lado quente ou frio. No capítulo anterior, a hipótese desenvolvida foi baseada no efeito dominante do campo termoelétrico gerado pelas cargas em solução, determinado experimentalmente. Para aprofundar a hipótese baseada na relação das respostas de íons e nanopartículas ao gradiente de temperatura, este capítulo apresenta resultados para o coeficiente Soret iônico e de nanopartículas dispersas nas soluções iônicas. Serão investigadas nanopartículas dispersas em hidróxidos, possuindo assim carga superficial negativa, e será verificado se é possível descrever os resultados utilizando as equações teóricas para $S_{T}$

Este capítulo apresenta resultados para o coeficiente Soret de hidróxidos orgânicos TMAOH (hidróxido de tetrametilamônio) e TBAOH (hidróxido de tetrabutilamônio) diluídos em água e para nanopartículas dispersas nestas soluções de hidróxidos, em função da concentração de íons e da temperatura das amostras. Também serão apresentados resultados para soluções de $\mathrm{NaOH}$ e nanopartículas dispersas em soluções de $\mathrm{NaOH}$, para investigar o papel do tipo de contra-íon (orgânico / não-orgânico). Para determinar $S_{T}^{i o n}$ 
e $S_{T}$ nestas soluções, o experimento IRTDFRS é utilizado.

Quando nanopartículas de óxido de ferro são dispersas em soluções aquosas de hidróxidos, o equilíbrio das reações de protonação/desprotonação (apresentadas no capítulo anterior para o meio ácido) gera excesso de hidróxidos na superfície. Isso confere carga superficial negativa às nanopartículas, para qualquer hidróxido utilizado [170]. Os resultados mostrarão que o sinal do coeficiente Soret não está apenas relacionado com o sinal da carga das nanopartículas, mas sim com o tipo do contra-íon.

Será mostrado que, diferente de resultados presentes na literatura para sais comuns, a descrição empírica pela equação 1.1 dos valores $S_{T}(T)$ não se aplica aos valores obtidos para o sal TBAOH. Para este sal, o valor de $S_{T}^{\text {ion }}$ diminui com o aumento de temperatura, o que pode ser explicado de maneira simples pelos valores de $D_{T}^{i o n}(T)$ e $D_{i o n}(T)$. Os resultados obtidos para o coeficiente $D_{T}^{i o n}(T)$ para íons em água são descritos teoricamente com base em uma combinação das forças termoforética devido à expansão da solução e da energia livre de solvatação (ou hidratação, neste caso).

Para o coeficiente Soret das nanopartículas será feita uma análise dos resultados $S_{T}(T)$ quando a concentração de hidróxidos aumenta em relação a uma amostra de referência, contendo pouco íon em relação à quantidade de hidróxidos posteriormente adicionada. A equação de Iacopini 1.1 não descreve empiricamente os resultados quando as partículas são dispersas em TBAOH, sendo que novamente os valores de $S_{T}$ diminuem com aumento de temperatura e sugere que existe uma relação entre os resultados para coeficiente Soret dos íons e das nanopartículas. Essa relação será quantificada em uma descrição baseada na velocidade adquirida pela nanopartícula em um gradiente de concentração iônico, equação 2.22. Quando dispersas nas soluções de TMAOH, a equação 1.1 descreve empiricamente os resultados, porém sem significado físico para os parâmetros obtidos. Pela determinação experimental do potencial- $\zeta$, será mostrado que $S_{T}(T)$ para as nanopartículas dispersas em TMAOH e TBAOH são descritos por uma combinação da teoria de dupla camada elétrica, e pelo efeito Soret iônico.

Os experimentos de IRTDFRS para determinar o coeficiente Soret nas soluções aquosas de hidróxidos e das nanopartículas quando dispersas nas mesmas foram realizados no 
centro de pesquisa em Juelich - Alemanha, durante o estágio de Doutorado Sanduíche da CAPES. A supervisão e orientação dos experimentos foi realizada pela Profa. Dra. Simone Wiegand.

\subsection{Curvas experimentais de $\zeta^{\text {het }}(t)$ para soluções iôni- cas e de nanopartículas}

O objetivo deste capítulo é verificar qual a relação entre os resultados para $S_{T}(T)$ das nanopartículas com o coeficiente Soret iônico $S_{T}^{i o n}$. Em primeiro lugar, serão apresentadas curvas experimentais características obtidas do experimento IRTDFRS para soluções iônicas e de nanopartículas em soluções iônicas. Como mostrado na figura 5.1, o tempo característico do efeito Soret em íons é mais rápido que em nanopartículas. Uma análise das curvas experimentais $\zeta^{\text {het }}(t)$ foi necessária para verificar a possibilidade de observar a grade de concentração de íons durante o mesmo experimento para induzir a grade de partículas. Caso isso ocorra, haverá duas mudanças sequentes na curva $\zeta^{\text {het }}(t)$ devido ao efeito Soret de íons e nanopartículas, separadas no tempo devido aos diferentes valores de $D$ para íons e nanopartículas. Dessa forma, a equação 3.10 deve ser usada na forma completa, com ambas amplitudes $A^{i o n}$ e $A^{N P s}$ contribuindo para o sinal total $\zeta^{\text {het }}(t)$. A figura 5.1a mostra $\zeta^{\text {het }}(t)$ para soluções aquosas de TMAOH em duas concentrações, 8 e 40 $\mathrm{mMol} / \mathrm{L}$, sem conter nanopartículas na solução. O sinal medido é normalizado para que a mudança rápida $0<\zeta^{\text {het }}(t)<1$ considere o efeito de aumento de temperatura, sendo que mudanças mais lentas são associadas ao efeito Soret. Importante observar nestas curvas que a amplitude do efeito Soret para a solução iônica de TMAOH na concentração de 8 mMol/L é muito baixa, sendo que esta é a menor concentração possível de medir $S_{T}^{\text {ion }}$ para TMAOH em água com precisão significativa. Para os experimentos contendo partículas dispersas em TMAOH, a figura 5.1b mostra $\zeta^{\text {het }}(t)$ para concentrações de 2 e $20 \mathrm{mMol} / \mathrm{L}$ de TMAOH. A evolução temporal do efeito Soret mostra um único processo difusivo, devido às nanopartículas. O gradiente de concentração dos íons não é observado neste caso, que seria uma mudança mais rápida na intensidade de $\zeta^{\text {het }}(t)$, na mesma escala de tempo 


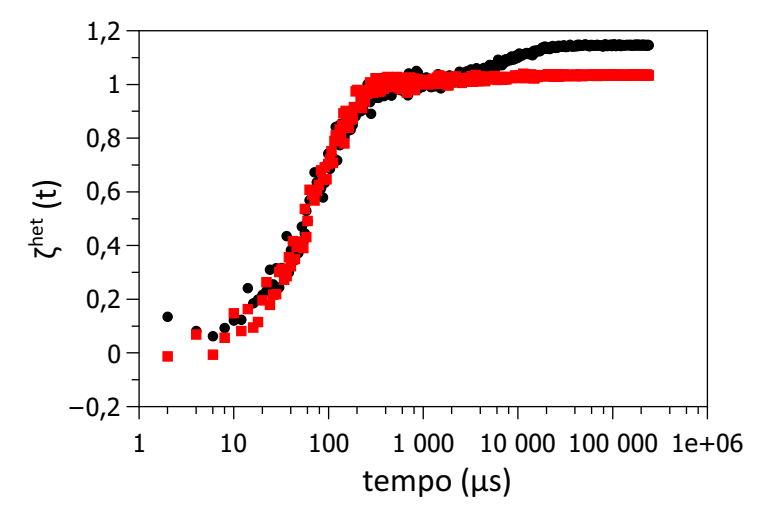

(a)

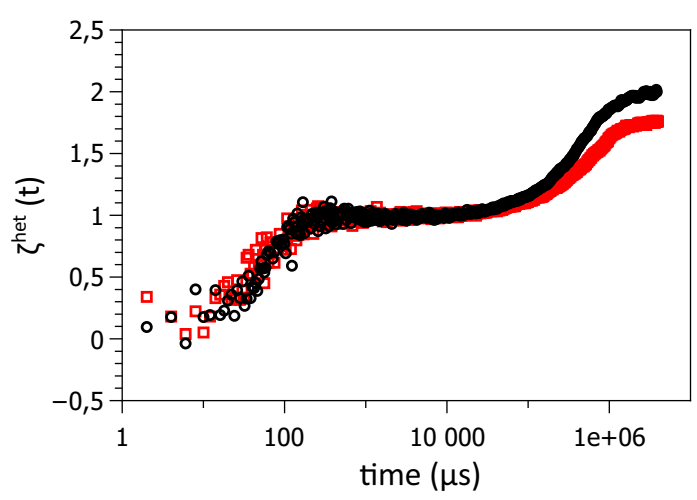

(b)

Figura 5.1: (a) Sinal medido no experimento IRTDFRS para soluções aquosas de TMAOH em duas diferentes concentrações: $8 \mathrm{mMol} / \mathrm{L}$ (quadrados vermelhos) e $40 \mathrm{mMol} / \mathrm{L}$ (círculos pretos), e (b) para nanopartículas dispersas em soluções com $2 \mathrm{mMol} / \mathrm{L}$ e $20 \mathrm{mMol} / \mathrm{L}$ de TMAOH.

observado para os resultados da figura 5.1a. Isso significa que a maior parte dos íons de hidróxidos orgânicos dispersos com as partículas pode estar na dupla camada elétrica das partículas, e uma grade de concentração de íons não é observada para concentrações de hidróxidos de até $20 \mathrm{mMol} / \mathrm{L}$. O mesmo foi observado para as soluções contendo TBAOH.

\subsection{Coeficiente Soret de íons em função da concentra- ção e temperatura}

Esta seção apresenta resultados para o coeficiente Soret de íons em função da concentração em solução e da temperatura da amostra. A influência do aumento da concentração de íons em solução sobre os valores do coeficiente Soret $S_{T}^{i o n}$ foi investigada em trabalhos anteriores para sais comuns como $\mathrm{NaCl}$ e $\mathrm{KCl}$ [163, 171] e $\mathrm{LiCl}$ [172], e também para os hidróxidos investigados neste trabalho [173].

No caso dos sais comuns, foram observados comportamentos críticos com mínimos estreitos e repentinos nos resultados $S_{T}^{\text {ion }}(c)$, em concentrações relativamente baixas (no intervalo de 0,001 a $0,1 \mathrm{~mol} / \mathrm{L}$ ), em experimentos realizados em colunas termogravitacionais [172]. As mudanças repentinas nos valores de $S_{T}^{i o n}$ foram associadas a mudanças na 
estrutura da água, principalmente nas moléculas de bulk, mais distantes dos íons, devido ao aumento da interação eletrostática com o aumento de concentração de íons. Contudo estes comportamentos críticos não foram reproduzidos experimentalmente ou previstos por dinâmica molecular em um trabalho mais recente [163]. Para os hidróxidos de tetraalkilamônio, como o TMAOH e TBAOH, nenhum comportamento crítico foi observado por Leaist and Hao [173], em experimentos realizados em células condutimétricas.

A Figura 5.2 mostra os resultados para o coeficiente Soret de TMAOH e TBAOH em água, para a mínima e a máxima temperaturas investigadas $\left(T_{\min }=293 \mathrm{~K}\right.$ e $T_{\max }=333$ $\mathrm{K}$, respectivamente).

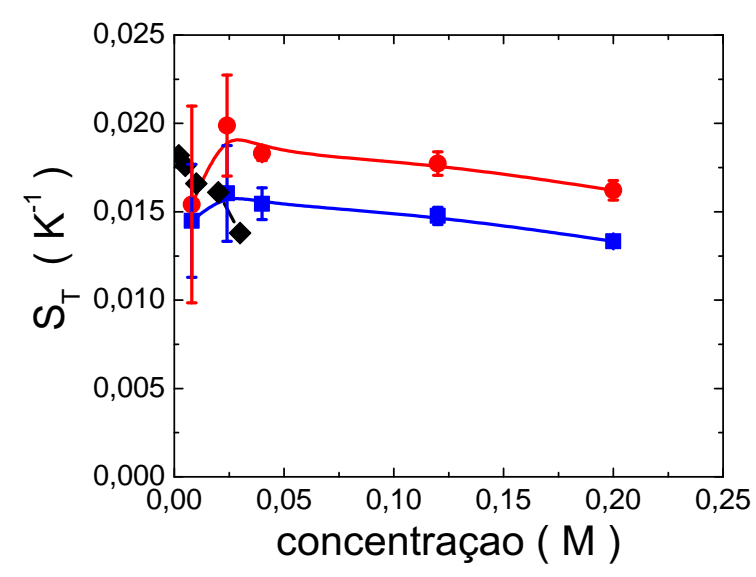

(a)

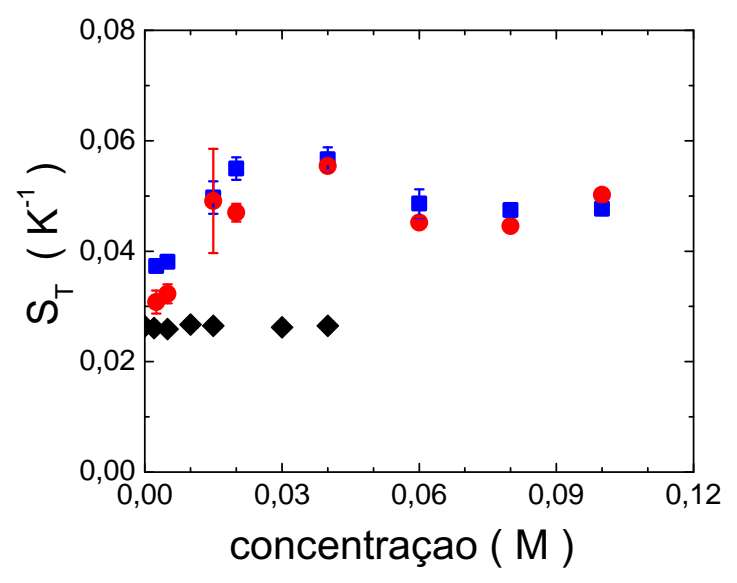

(b)

Figura 5.2: Coeficiente Soret $S_{T}^{i o n}$ em função da concentração $(\mathrm{M}=\mathrm{Mol} / \mathrm{L})$ de íons nas soluções aquosas de (a) TMAOH e (b) TBAOH nas temperaturas de $293 \mathrm{~K}$ (azul) e 333 $\mathrm{K}$ (vermelho). As linhas contínuas em (a) são guias para os olhos.

Adicionalmente foram inseridos os dados obtidos anteriormente por D. G. Leaist e L. Hao [173], e não se observa comportamento crítico dos valores de $S_{T}^{\text {ion }}$. O suave máximo sugerido pelos dados em torno de $30 \mathrm{mM}$ para TBAOH não caracteriza comportamento crítico que justifique maior atenção quando da dispersão de partículas nestas soluções. O intervalo de concentrações investigado é justificado devido à possibilidade de dispersão das nanopartículas até concentrações iônicas de 20 mM. Acima dessa concentração as partículas se tornam instáveis em solução, para a concentração de partículas utilizada neste experimento $(\Phi=0,1 \%$ vol. $)$.

Dois detalhes são importantes nestes dados: a magnitude de $S_{T}^{\text {ion }}$ é uma ordem de 


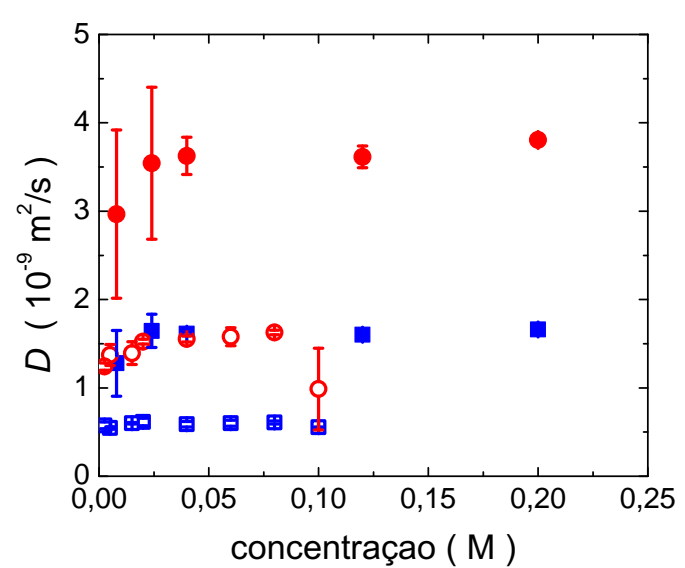

(a)

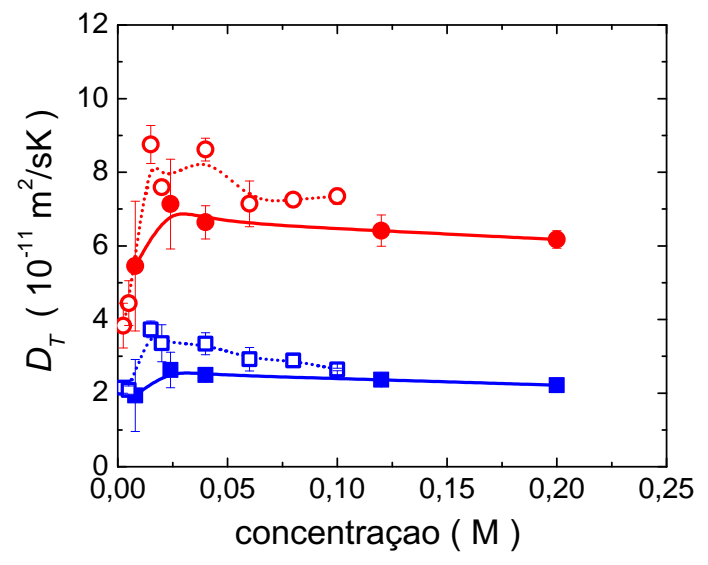

(b)

Figura 5.3: (a) Coeficiente de difusão $D_{i o n}$ e (b) coeficiente de difusão $D_{T}^{i o n}$ em função da concentração de íons nas soluções aquosas de TMAOH (símbolos fechados) e TBAOH (símbolos abertos) nas temperaturas de $293 \mathrm{~K}$ (azul) e $333 \mathrm{~K}$ (vermelho).

grandeza maior que valores geralmente encontrados para sais em água $S_{T}^{\text {ions }} \leq 0,01[142]$. Além disso, o aumento da temperatura causa aumento dos valores para TMAOH e decréscimo nos valores para TBAOH. Dado que uma das definições de $S_{T}$ é a razão $D_{T} / D$, a dependência com a concentração dos dois coeficientes deve esclarecer qual dos coeficientes gera o comportamento dos resultados para $S_{T}^{i o n}(c)$. A Figura 5.3 mostra a dependência com a concentração da constante de difusão $D_{i o n}(c)$ e da constante de difusão térmica $D_{T}^{i o n}(c)$. É possível verificar que $D_{i o n}$ é constante em todo o intervalo de concentração e que $D_{T}^{i o n}$ é responsável pelo comportamento dos valores de $S_{T}^{i o n}(c)$. Verificar que $D_{\text {ion }}$ é constante com a concentração mostra que não é necessário considerar interações íon-íon para descrever efeito Soret nestes sistemas.

Para descrever a termodifusão de íons de forma mais completa é preciso analisar os resultados em função da temperatura da amostra. Como visto no capítulo anterior para nanopartículas em meio ácido, as grandezas físicas do problema podem ter sua dependência com a temperatura conhecidas e permitir a comparação com descrições teóricas. A figura 5.4 mostra os resultados para $S_{T}^{i o n}(T)$ de TMAOH e TBAOH dispersos em água, nas concentrações de 0,024 e 0,02 mol/L, respectivamente. O resultado para TMAOH é um aumento linear com a temperatura, não sendo descrito pela equação de Iacopini, 
equação 1.1, mas tendo comportamento similar. Já os valores de $S_{T}^{i o n}(T)$ para TBAOH seguem dependência inversa, diminuindo de valor com o aumento de temperatura.

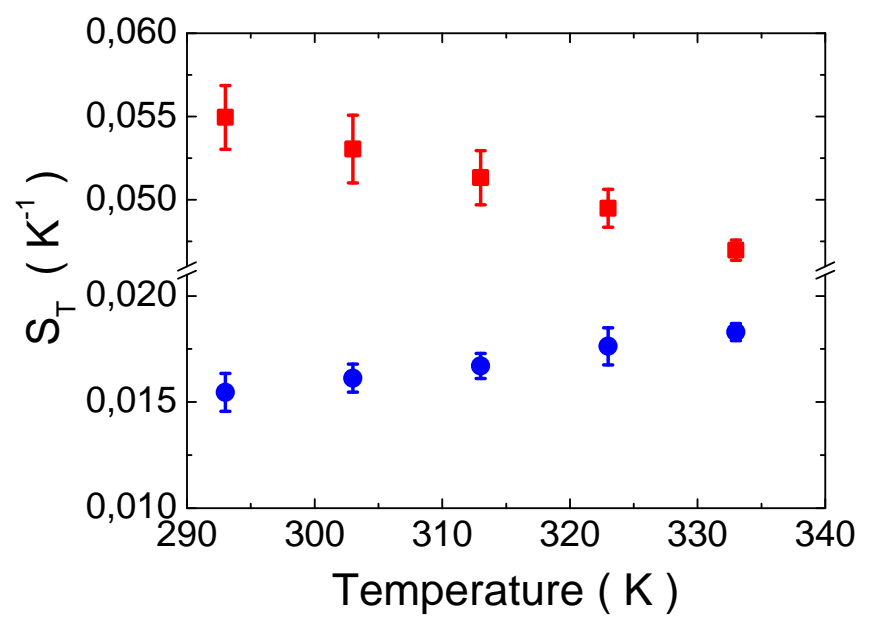

Figura 5.4: Coeficiente Soret $S_{T}^{\text {ion }}$ em função da temperatura para soluções aquosas de TMAOH (círculos azuis) e TBAOH (quadrados vermelhos), para concentrações iônicas de 0.024 e $0.02 \mathrm{~mol} / \mathrm{L}$, respectivamente.

O resultado para TBAOH não é frequentemente observado na literatura para $S_{T}(T)$ de íons e moléculas dispersos em água. Resultados deste tipo obtidos recentemente para moléculas $[174,175]$ foram associados ao crescente grau de hidrofobicidade. Uma relação empírica foi proposta recentemente entre a variação $\triangle S_{T}(T)$ em um dado intervalo de temperatura e o coeficiente de partição $P$ ( $P$ caracteriza o grau de hidrofobicidade), $\triangle S_{T}(T) \propto \log (P)$ [175]. Para entender melhor a origem das diferentes dependências de $S_{T}^{i o n}(T)$, os resultados para os coeficientes $D_{T}^{i o n}(T)$ e $D_{i o n}(T)$ são apresentados na figura 5.5. Além dos resultados para TMAOH e TBAOH, são apresentados resultados para $D_{T}^{i o n}(T)$ e $D_{\text {ion }}(T)$ obtidos para outros sais e publicados em outro trabalho [163]. Estes resultados são utilizados para a discussão geral sobre o efeito Soret em íons, realizada na próxima seção.

A Figura 5.5a mostra que $D_{i o n}(T)$ aumenta com a temperatura como esperado, devido ao aumento da energia térmica $k_{B} T$ e da menor viscosidade $\eta$ da água com o aumento de temperatura. Dentre os resultados apresentados, os valores para TBAOH são os que mais se diferenciam, sendo os valores mais baixos para $D_{i o n}(T)$ devido ao maior tamanho 


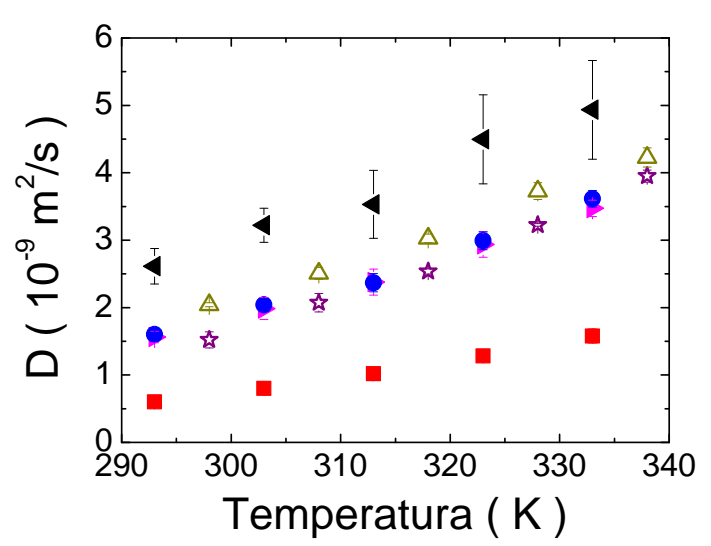

(a)

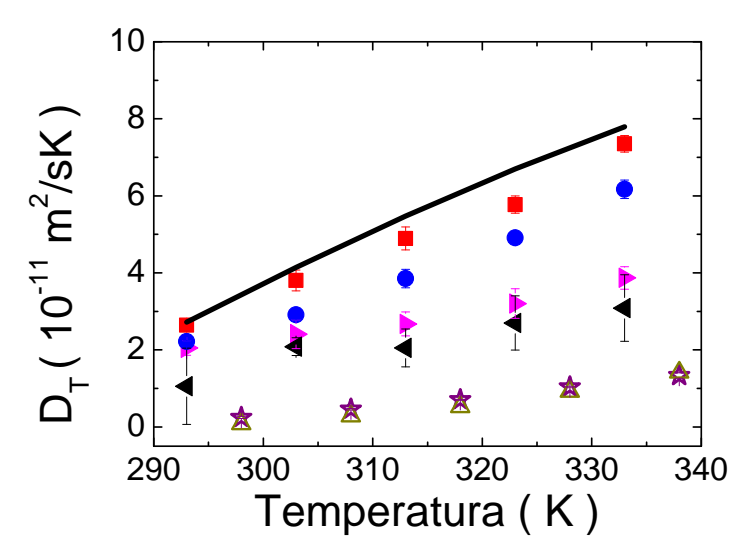

(b)

Figura 5.5: (a) Constante de difusão $D_{i o n}$ e (b) Constante de difusão térmica $D_{T}^{i o n}$ em função da temperatura para os sais investigado neste trabalho: TMAOH (círculo azul), TBAOH (quadrado vermelho), $\mathrm{NaOH}$ (triângulo rosa), $\mathrm{HNO}_{3}$ (triângulo preto), $\mathrm{NaCl}$ (estrela púrpura) e $\mathrm{KCl}$ (triângulo oliva). A linha contínua representa os valores calculados com a equação teórica $D_{T}=\beta D_{t h}$, como descrito no texto principal.

do íon $\mathrm{TBA}^{+}$. Na Figura 5.5b são apresentados os resultados para $D_{T}^{i o n}(T)$ nos mesmos sais, sendo que este coeficiente possui diferentes valores para os diferentes sais. A linha contínua representa um cálculo teórico que será discutido na próxima seção. Para TMAOH e TBAOH, os resultados experimentais apresentam comportamento similar, com os valores para TBAOH sendo sistematicamente maiores que para TMAOH. Dada essa similaridade para os resultados $D_{T}^{i o n}(T)$ e a grande diferença dos valores das curvas $D_{\text {ion }}(T)$, o motivo das diferentes dependências de $S_{T}^{\text {ion }}(T)$ para os dois sais é unicamente o maior tamanho do íon $\mathrm{TBA}^{+}$comparado com $\mathrm{TMA}^{+}$. Para quantificar a influência de $D_{\text {ion }}(T)$ sobre $S_{T}^{\text {ion }}(T)$, em $T=293 \mathrm{~K}$ temos que $D(\mathrm{TMAOH}) / D(\mathrm{TBAOH}) \approx 3$ e em $T=333 \mathrm{~K}$ essa razão é $\approx 2,4$. Logicamente, a consequência será diferente coeficiente angular $d S_{T}^{\text {ion }}(T) / d T$ para TMAOH e TBAOH, que acontece de ser negativo para TBAOH.

Na próxima seção os resultados apresentados na Figura 5.5b serão comparados com resultados teóricos, sendo que os parâmetros físicos envolvidos são conhecidos em função da temperatura. 


\subsection{Descrição teórica proposta para o efeito Soret iô- nico}

Os dados da figura 5.5b sugerem que uma descrição completa do efeito Soret em íons deve considerar a natureza específica de cada sal, dada a grande diferença nos resultados dos hidróxidos orgânicos para os sais comuns $\mathrm{NaCl} / \mathrm{KCl}$. Contudo, dado que $\mathrm{TMA}^{+}$e $\mathrm{TBA}^{+}$ possuem diferentes tamanhos e logo diferentes valores de $D_{i o n}$, mas semelhantes valores de $D_{T}$, uma primeira descrição baseada em uma "teoria geral" se justifica. Uma destas teorias foi desenvolvida por H. Brenner [176, 177], e foi baseada na expansão térmica do líquido. Verificando um conjunto de equações de mecânica dos fluidos e de transporte de calor [176], o autor mostra que uma partícula dispersa em líquido, na presença de um gradiente de temperatura, terá velocidade dada por $\vec{v} \propto-\beta D_{t h} \tilde{\nabla} T$, proporcional aos coeficientes de expansão térmica $\beta$ e difusividade térmica $D_{t h}$. Ambos coeficientes são propriedades da solução e possuem valores aproximadamente do próprio líquido dispersante quando uma pequena quantidade de partículas é dispersa. O coeficiente $D_{T}$ pode então ser definido como $D_{T}=\beta D_{t h}$. A força que causa o movimento da partícula dispersa é simplesmente $\mathrm{F}=-\beta D_{t h} \nabla T / 6 \pi \eta R$.

Considerando as dependências com a temperatura $\beta(T)$ e $D_{t h}(T)$ para a água bem definidas na literatura [178, 179], é possível estimar o coeficiente de difusão térmica $D_{T}(T)=\beta(T) D_{t h}(T)$. O cálculo usando valores para a água é mostrado na linha inserida no gráfico da figura 5.5b, e pode-se supor que a mudança desses valores para $\beta(T)$ e $D_{t h}(T)$ em cada um dos sais é desprezível. O baixo desvio relativo entre os valores calculados com os valores experimentais para TMAOH e TBAOH sugere que o efeito de expansão térmica possui uma grande contribuição no efeito Soret iônico destes sais. Já para os sais comuns $\mathrm{NaCl}$ e $\mathrm{KCl}$ o desvio relativo é alto, devido a algum efeito adicional ou outro mecanismo levando ao efeito Soret.

Para uma descrição mais completa do efeito Soret em íons, é proposto que o efeito da expansão térmica [180] seja combinado com uma descrição baseada nos princípios do modelo de Dhont et al [54, 77]. Como visto na seção 2.2.3, para nanopartículas 
eletrostaticamente carregadas o coeficiente Soret $S_{T}$ é derivado a partir da dependência com a temperatura da energia armazenada na dupla camada elétrica. No caso dos íons em alta diluição, a energia em torno de cada íon vem da interação com as moléculas do solvente, denominada energia de hidratação. O processo físico proposto para que o íon se mova em um gradiente de temperatura é ilustrado na figura 5.6. Inicialmente o íon localizado em uma dada posição possui energia de hidratação $\triangle G^{\text {hid }}(T)$. Para um gradiente de temperatura na direção $z$, o íon irá se deslocar por uma distância $\delta z$ se a energia de hidratação $\triangle G^{\text {hid }}(T+\delta T)$ for diferente de $\triangle G^{\text {hid }}(T)$. Podemos imaginar esse deslocamento com um processo intermediário, onde se remove a camada de hidratação em $z$ realizando um trabalho $W^{\text {hid }}(T)$ e reconstruindo em $\delta z$ com energia correspondente $W^{\text {hid }}(T+\delta T)$. A energia de hidratação é definida como $\triangle G^{\text {hid }}=\triangle H^{\text {hid }}-T \triangle S^{\text {hid }}$, sendo $\triangle H^{\text {hid }}$ e $\triangle S^{\text {hid }}$ a entalpia e a entropia de hidratação, respectivamente. A entalpia definida como $H=U+p V_{\text {sol }}$, sendo $U$ a energia de interação entre o íon e as moléculas de água, $p$ a pressão e $V_{\text {sol }}$ o volume da solução.

A força responsável pelo deslocamento é expressa a partir da dependência de $\triangle G^{\text {hid }}$ com a temperatura:

$$
F^{h i d}=-d\left(\triangle G^{h i d}\right) / d z=-\frac{d\left(\triangle G^{h i d}\right)}{d T} \nabla T
$$

Dado que a solução permanece em equilíbrio mecânico e que a contribuição $\triangle S^{\text {hid }}(T)$ é muito baixa quando as interações eletrostáticas são intensas, a primeira aproximação para investigar $F^{\text {hid }}$ é considerar a energia do campo eletrostático em torno do íon, a energia de Born dada por $U=e^{2} / 2 \varepsilon r$, sendo $r$ o raio do íon. A diluição de um sal em meio líquido implica em uma mudança da energia livre eletrostática, dada por

$$
\triangle G^{h i d}=\frac{e^{2}}{2}\left(\frac{1}{\varepsilon}-1\right)\left(\frac{1}{r_{+}}+\frac{1}{r_{-}}\right),
$$

e a expressão para a força sobre o íon em um gradiente de temperatura surge devido à dependência com a temperatura da constante dielétrica 


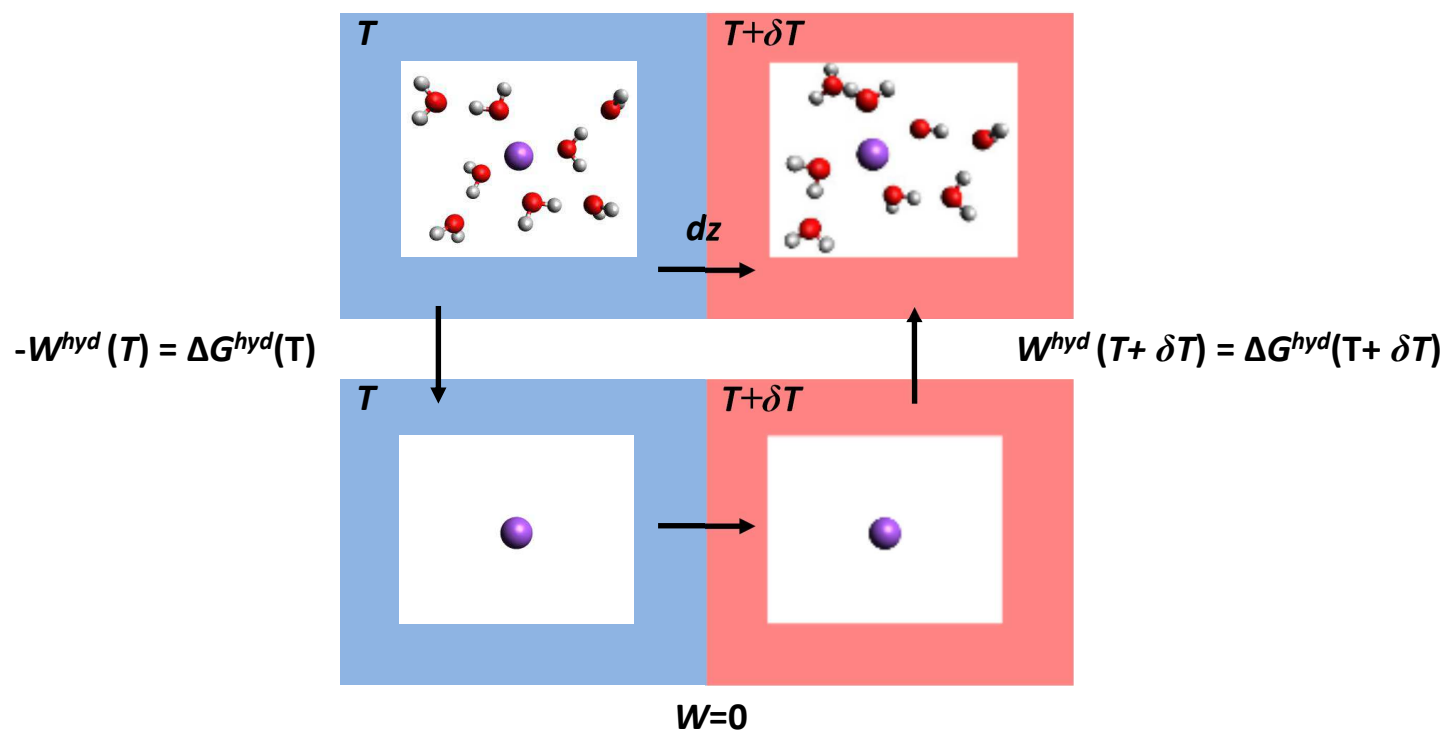

Figura 5.6: Esquema ilustrativo do deslocamento de um íon em um gradiente de temperatura. Em uma dada temperatura $T$ a energia de hidratação é dada por $\triangle G^{\text {hid }}(T)$, enquanto que a uma distância $\delta z$ e temperatura $T+\delta T$ a energia é $\triangle G^{\text {hid }}(T+\delta T)$. Sendo $\triangle G^{\text {hid }}$ associado ao trabalho $W^{\text {hid }}$ para retirar e recolocar a camada de hidratação em torno do íon, o deslocamento pode ser imaginado por um processo sem gasto de energia $W=0$. A força $F^{\text {hid }}$ move o íon para o quente (ou frio) se $\triangle G^{\text {hid }}(T)>\triangle G^{\text {hid }}(T+\delta T)$ (ou $\triangle G^{\text {hid }}(T)<\triangle G^{\text {hid }}(T+\delta T)$ ). 


$$
F^{h i d}=\frac{e^{2}}{2}\left(\frac{1}{\varepsilon^{2}} \frac{d \varepsilon}{d T}\right)\left(\frac{1}{r_{+}}+\frac{1}{r_{-}}\right) \nabla T
$$

Para dispersão dos íons em água onde $d \varepsilon / d T<0$, o íon sentirá uma força movendo-o em direção ao lado quente, e será mais intensa quanto menor o raio físico dos íons que constituem um sal. Dessa forma, supomos que a contribuição de $F^{\text {hid }}$ para os sais comuns $\mathrm{NaCl} / \mathrm{KCl}$ pode ser maior que em relação aos sais $\mathrm{TMAOH} / \mathrm{TBAOH}$. Contudo, os valores $D_{T}^{i o n}(T)$ obtidos para NaOH mostram resultados que são mais próximos aos sais orgânicos que aos inorgânicos. Sendo que o íon hidróxido $\mathrm{OH}^{-}$possui tamanho similar ao $\mathrm{Cl}^{-}$, este resultado mostra que mais efeitos além da expansão térmica e da energia de Born devem estar contribuindo para o efeito Soret em íons.

Para ilustrar a diferente interação dos íons orgânicos e monoatômicos com as moléculas de água, a figura 5.7 mostra ilustrações da minimização da energia total, eletrostática + potencial para alguns íons e moléculas de água em torno. Os íons monoatômicos interagem principalmente pelas interações eletrostáticas da carga iônica com o momento de dipolo elétrico da molécula de água, enquanto os íons orgânicos são hidrofóbicos e formam uma espécie de interface íon-água, como indicado na figura 5.7. Além disso, os íons $\mathrm{TMA}^{+} \mathrm{e}$ $\mathrm{TBA}^{+}$não formam ligações de hidrogênio com a água (apesar dos íons $\mathrm{OH}^{-}$formarem). A diferente interação de cada íon com a água é a primeira hipótese para explicar os diferentes valores de $D_{T}^{i o n}$.

Uma equação para o o coeficiente de difusão térmica de íons pode ser proposta como

$$
D_{T}=\beta D_{t h}+D_{T}^{B o r n}+D_{T}^{h i d}
$$

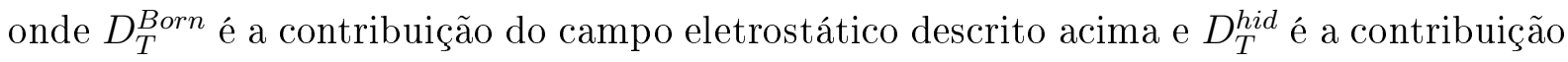
desconhecida da energia de hidratação.

Dado que o efeito Soret de íons vem sendo investigado há muito tempo, os dados apresentados para $D_{T}^{i o n}(T)$ podem ser comparados com os resultados conhecidos pela principal descrição para íons, a teoria do calor de transporte apresentada na seção 2.2.4. Naquela 

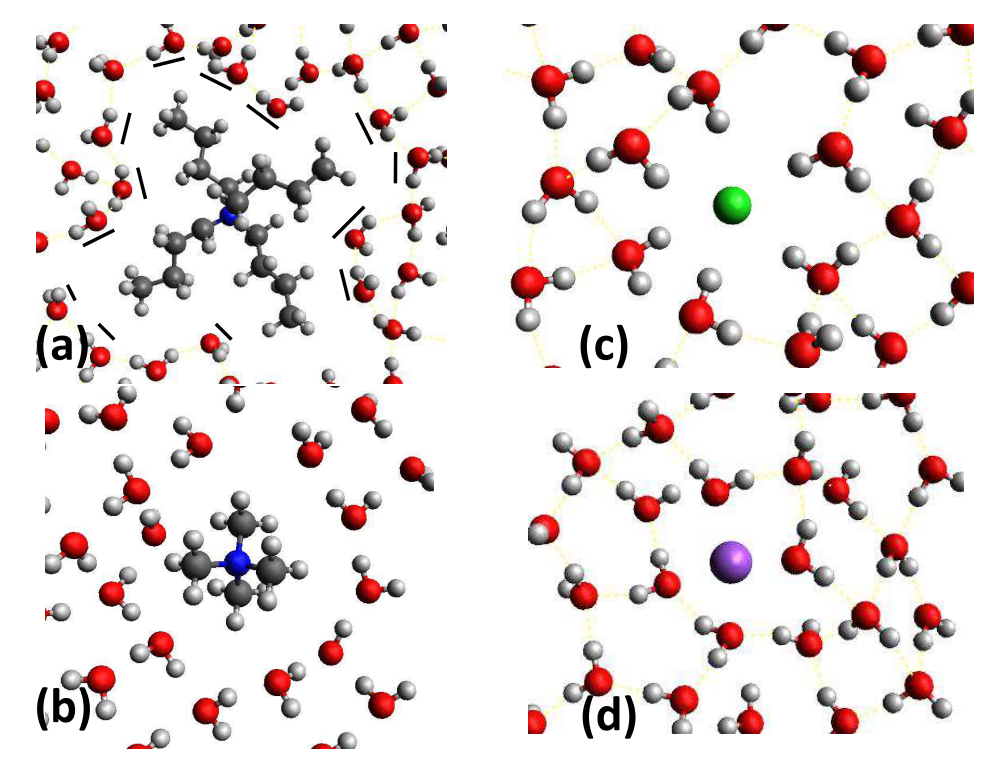

Figura 5.7: Ilustração da organização das moléculas de água em torno de diferentes íons. À esquerda, os íons utilizados neste trabalho para dispersão de nanopartículas, $\mathrm{TBA}^{+} \mathrm{e}$ $\mathrm{TMA}^{+}$, e à direita os íons monoatômicos utilizados em trabalhos anteriores para investigar o efeito Soret. Devido ao efeito hidrofóbico nos íons orgânicos, as moléculas de água próximas aos íons não demonstram a interação eletrostática íon - dipolo da água, como pode ser visualizado para os íons monoatômicos. As pequenas barras pretas paralelas a ligações O-H da água ilustram a existência de uma interface entre os íons orgânicos.

teoria, a sequência de maior para menores valores de $Q^{*}$ é a mesma para resultados de $D_{T}^{\text {ion }}(T)$ apresentados aqui [115]: $\mathrm{TBAOH}>\mathrm{TMAOH}>\mathrm{NaOH}>\mathrm{HNO}_{3}>\mathrm{NaCl}>\mathrm{KCl}$. A relação entre $S_{T}^{i o n}$ e $Q_{i}^{*}$ expressa pela equação 3.4 prevê que os valores conhecidos de $Q_{i}^{*}$ (apenas para $T=298 \mathrm{~K}$ ) forneçam valores de $S_{T}^{i o n}$ que são próximos ao que pode ser estimado para $T=298 \mathrm{~K}$ nos resultados apresentados na Figura 5.5b. Por exemplo, para $\mathrm{NaCl}$ e TMAOH os valores calculados com a equação 3.4 são $S_{T}^{\text {ion }}=0,0054$ e $0,031 \mathrm{~K}^{-1}$. Contudo, não há dados presentes na literatura para $Q_{i}^{*}(T)$ para realizar uma análise de resultados para a dependência com a temperatura de $S_{T}^{i o n}$. Dessa forma, este trabalho propõe que o efeito Soret iônico pode ser descrito de forma mais completa a partir da equação 5.4. Resultados de simulações de Monte Carlo e de Dinâmica Molecular para esclarecer o papel de $\triangle G^{\text {hid }}(T)$ podem ser usados para descrição mais completa da contribuição da energia de hidratação no efeito Soret iônico. 


\subsection{Coeficiente Soret de nanopartículas dispersas em soluções aquosas de hidróxidos orgânicos}

Esta seção apresenta os resultados obtidos para o coeficiente Soret de nanopartículas de óxido de ferro dispersas nas soluções aquosas de TMAOH e TBAOH. O objetivo é investigar qual o mecanismo físico responsável pelo efeito Soret nestas soluções, semelhante ao estudo apresentado no capítulo anterior. Para isso, serão utilizados resultados para o potencial- $\zeta$ e o coeficiente Soret iônico $S_{T}^{\text {ion }}$ para investigar as contribuições da dupla camada elétrica (equações 2.27 e 2.26 ), do campo termoelétrico (equação 2.29) e do gradiente de concentração iônico (equação 2.23). Os resultados experimentais serão comparados aos valores calculados pelas expressões teóricas e será discutido qual dos mecanismos mais influencia o efeito Soret das nanopartículas de ferrofluido.

A amostra de nanopartículas investigada neste capítulo é uma amostra comercial da empresa Chemicell (FluidMag UC/A), chamada FF3 neste trabalho, contendo originalmente nanopartículas de magnetita $\mathrm{Fe}_{3} \mathrm{O}_{4}$ dispersas em solução iônica com baixa concentração de $\mathrm{NaOH}$ livre $\left(c^{\mathrm{NaOH}} \approx 0,01 \mathrm{mM}\right)$. Dessa forma, a análise dos resultados será feita a partir do raio hidrodinâmico das nanopartículas. Isso porque as baixas concentrações de hidróxidos $\left(c^{\text {hid }} \leq 2 \mathrm{mMol} / \mathrm{L}\right)$ adicionados às nanopartículas resultam em valores para a distância de Debye $\left(\kappa^{-1} \geq 10 \mathrm{~nm}\right)$ maiores que o raio hidrodinâmico medido. Sendo que o tamanho médio do cristal sólido da nanopartícula possui em torno de $8 \mathrm{~nm}$, os valores de $\kappa R$ são $\approx 0,1$ a 0,4 , não permitindo o uso da aproximação $\kappa R \gg 1$, ou seja, a principal condição para a derivação da equação 2.27 não é respeitada. Por conta da baixa concentração de íons, o raio hidrodinâmico das nanopartículas adquire valores comparáveis $\operatorname{com} \kappa^{-1}$. Esta descrição para as nanopartículas foi proposta em uma publicação recente [114]. A figura 5.8 mostra os valores de diâmetro hidrodinâmico obtidos por DLS, e será utilizado para a descrição do coeficiente Soret.

Os resultados para os valores de $S_{T}(T)$ das nanopartículas em várias concentrações de hidróxidos TMAOH e TBAOH são mostrados na figura 5.9. A concentração volumétrica 


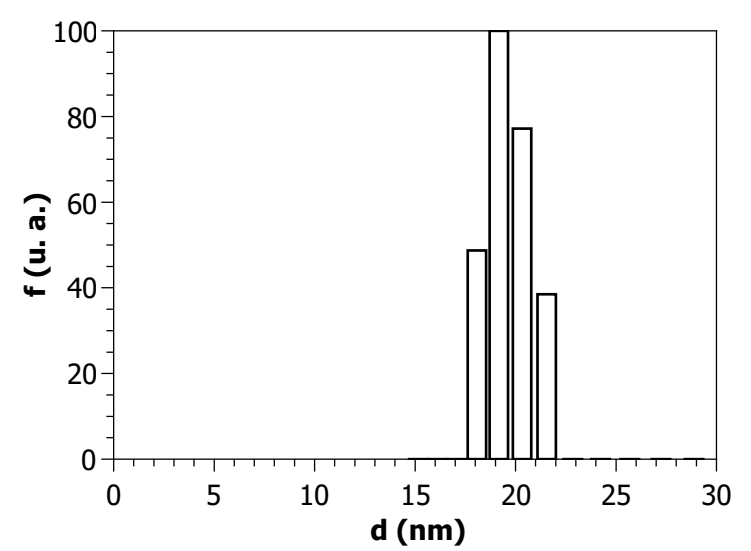

Figura 5.8: Distribuição de diâmetro hidrodinâmico $d=2 R_{h}$ para as partículas da amostra FF3 obtido por DLS.

de partículas é mantida fixa em $\Phi \approx 0,1 \%$ em todos os experimentos. Para dispersão com TMAOH, os resultados experimentais seguem o comportamento empírico proposto por Iacopini et al [1], equação 1.1. As linhas contínuas mostram o melhor ajuste da equação 1.1 para cada uma das concentrações de hidróxidos. Novamente, o único parâmetro que possui significado físico é a temperatura de inversão $T^{*}$, que diminui com o aumento de concentração de TMAOH. Para os resultados em TBAOH a situação é diferente, sendo que em concentrações $c^{T B A O H} \geq 0,5 \mathrm{mMol} / \mathrm{L}$ os valores $S_{T}(T)$ diminuem com a temperatura.

O comportamento $d S_{T} / d T<0$ para $S_{T}(T)$ quando as partículas estão dispersas em TBAOH pode ser entendido pela análise dos valores de $D_{T}(T)$ e $D(T)$ para as diferentes concentrações de TBAOH. Enquanto que para estas nanopartículas o coeficiente de difusão é definido como $D(T)=k_{b} T / 6 \eta \pi R_{h}$, a Figura 5.10 mostra os valores obtidos de $D_{T}(T)$ para as nanopartículas em diferentes concentrações de TMAOH e TBAOH. À medida que a concentração dos hidróxidos aumenta, os valores de $D_{T}(T)$ para TBAOH adicionado tendem a aumentar mais em comparação à mesma quantidade de TMAOH adicionado. Sendo que os valores para $D(T)$ das partículas em ambos sais não seguem a mesma taxa de mudança com a concentração, tendo sempre valores próximos aos correspondentes ao raio hidrodinâmico, o resultado é a mudança na inclinação $d S_{T} / d T$ das curvas $S_{T}(T)$ para dispersão em TBAOH. Isso sugere que quando os valores de $D_{T}(T)$ alcançam valores críticos, $d S_{T} / d T$ mudará de positivo para negativo. Dessa forma, os valores $S_{T}(T)$ para 


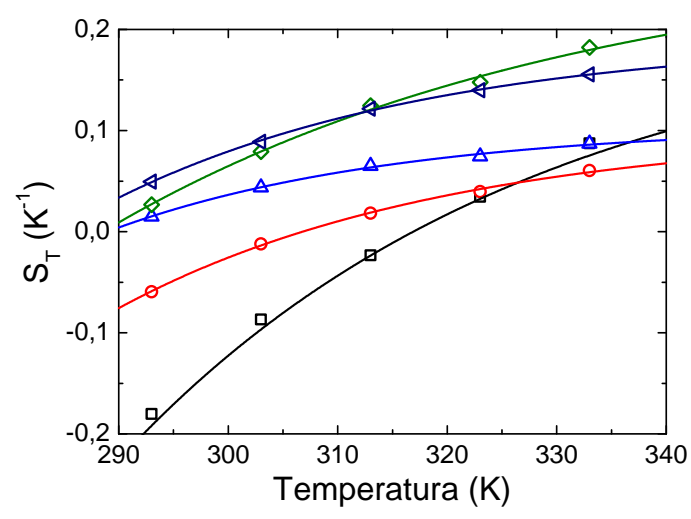

(a)

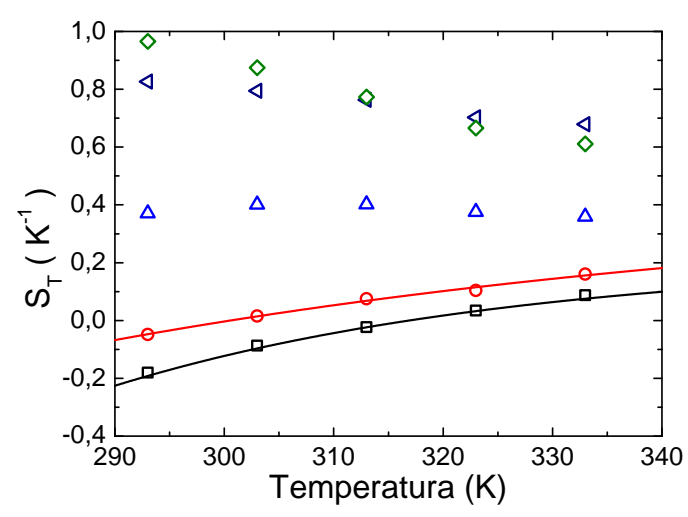

(b)

Figura 5.9: Coeficiente Soret em função da temperatura para as nanopartículas dispersas em soluções de (a) TMAOH e (b) TBAOH, nas seguintes concentrações de hidróxidos: 0 $\mathrm{mMol} / \mathrm{L}$ (quadrado preto), 0,1 mMol/L (círculo vermelho), 0,5 mMol/L (triângulo azul claro), $1 \mathrm{mMol} / \mathrm{L}$ (losango oliva) e $2 \mathrm{mMol} / \mathrm{L}$ (triângulo azul escuro). As linhas contínuas são os melhores ajustes realizados com a equação 1.1, sendo as cores das linhas correspondentes às cores dos resultados experimentais.

nanopartículas apresentam $d S_{T} / d T<0$ devido aos diferentes valores $D_{T}(T)$, enquanto que no caso dos hidróxidos em água esse comportamento ocorre para TBAOH devido aos diferentes valores de $D(T)$, como mostrado na figura 5.5 e descrito anteriormente. Considerando as observações acima, a conclusão é que o aumento de $S_{T}(T)$ deve estar relacionado com $S_{T}^{\text {ion }}$, que apresenta valores significativamente maiores para TBAOH que TMAOH como visto na figura 5.4.

O efeito do coeficiente $S_{T}^{i o n}$ sobre o coeficiente $S_{T}$ fica ainda mais evidente ao realizar a razão entre os coeficientes para a máxima e mínima temperaturas. Para os resultados com soluções contendo TBAOH, $S_{T}(293 \mathrm{~K}) / S_{T}^{\text {ion }}(293 \mathrm{~K}) \approx 17,5$ e $S_{T}(333 \mathrm{~K}) / S_{T}^{\text {ion }}(333 \mathrm{~K}) \approx$ 15 mostram valores muito próximos. Ao realizar o mesmo cálculo com as soluções contendo TMAOH, essas razões são $S_{T}(293 \mathrm{~K}) / S_{T}^{\text {ion }}(293 \mathrm{~K}) \approx 9$ e $S_{T}(333 \mathrm{~K}) / S_{T}^{\text {ion }}(333 \mathrm{~K}) \approx 2$. A maior diferença entre essas razões para soluções com TMAOH pode mostrar que o efeito de $S_{T}^{i o n}$ sobre $S_{T}$ não é dominante, como nas soluções contendo TBAOH.

Os maiores valores de $D_{T}(T)$ com o aumento de concentração dos hidróxidos indica que a resposta dos íons ao gradiente de temperatura implica no aumento da resposta das nanopartículas. Uma hipótese para esse efeito é que muitos dos íons dos hidróxidos 


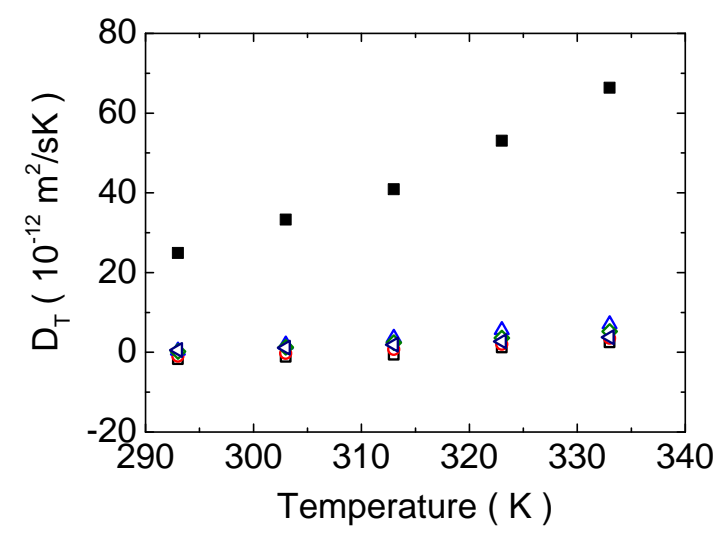

(a)

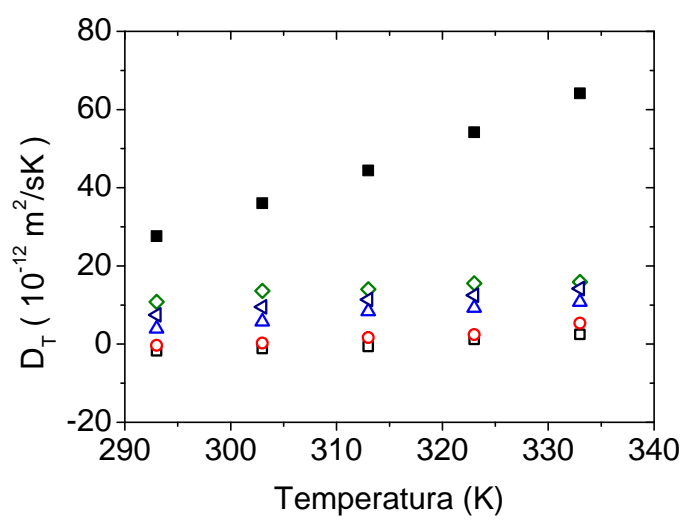

(b)

Figura 5.10: Coeficiente de difusão térmica $D_{T}$ em função da temperatura para as nanopartículas dispersas em soluções de (a) TMAOH e (b) TBAOH, nas seguintes concentrações de hidróxidos: $0 \mathrm{mMol} / \mathrm{L}$ (quadrado preto), $0,1 \mathrm{mMol} / \mathrm{L}$ (círculo vermelho), 0,5 $\mathrm{mMol} / \mathrm{L}$ (triângulo azul claro), $1 \mathrm{mMol} / \mathrm{L}$ (losango oliva) e $2 \mathrm{mMol} / \mathrm{L}$ (triângulo azul escuro). Os quadrados preenchidos mostram valores de $D_{T}$ para as soluções iônicas.

adicionados às soluções estarão na dupla camada elétrica das nanopartículas. Devido à baixa concentração de $\mathrm{NaOH}$ na solução original de ferrofluido, as superfícies das nanopartículas não estão saturadas de $\mathrm{OH}^{-}$e quando TMAOH ou TBAOH é adicionado, estes íons ocuparão sítios de pronotação e os íons orgânicos ficarão em torno das nanopartículas devido à alta densidade de carga superficial [50, 83]. Para verificar se íons estão em torno das nanopartículas, a condutividade elétrica de soluções com nanopartículas e hidróxidos é comparado com a soma dos valores da solução inicial de partículas mais os valores nas soluções apenas de hidróxidos. A figura 5.11 mostra que os valores de condutividade elétrica são menores para as soluções de nanopartículas e hidróxidos que os valores esperados pela soma da condutividade da solução inicial de partículas mais a condutividade das soluçãoes apenas de hidróxidos. Essa diferença mostra que muitos dos íons adicionados até a concentração correspondente a $1 \mathrm{mM}$ estão na dupla camada elétrica.

Apesar de serem observações importantes, os resultados das Figuras 5.10 e 5.11 não permitem uma conclusão sobre o mecanismo físico responsável pelo efeito Soret das nanopartículas. Para isso, as equações que representam os diferentes processos físicos que levam ao efeito Soret das nanopartículas são utilizadas para calcular as contribuições de 


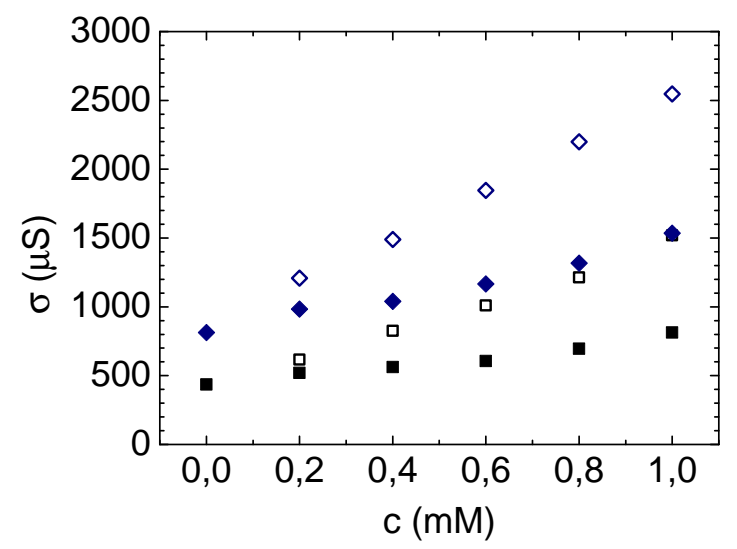

(a)

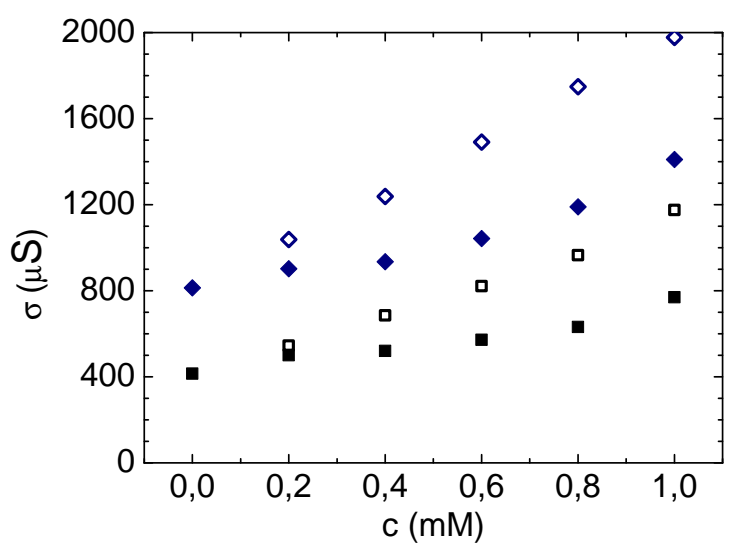

(b)

Figura 5.11: Condutividade elétrica das soluções de nanopartículas (símbolos fechados) contendo hidróxidos nas soluções indicadas, comparado com os valores esperados pela soma dos valores para solução de nanopartículas + soluções de hidróxidos medidos separadamente (símbolos abertos), em função das concentrações de (a) TMAOH e (b) TBAOH. Os símbolos quadrados são resultados para $\mathrm{T}=20{ }^{\circ} \mathrm{C}$ e losangos para $\mathrm{T}=50$ ${ }^{\circ} \mathrm{C}$.

\begin{tabular}{|c|c|c|c|c|c|}
\hline $\mathrm{T}(\mathrm{K})$ & $0 \mathrm{mM}$ & $0,5 \mathrm{mM}$ TMAOH & $1 \mathrm{mM}$ TMAOH & $0,5 \mathrm{mM}$ TBAOH & $1 \mathrm{mM}$ TBAOH \\
\hline \hline 298 & $-75 \pm 8$ & $-48 \pm 7$ & $-45 \pm 6$ & $-55 \pm 8$ & $-42 \pm 7$ \\
\hline 308 & $-70 \pm 8$ & $-44 \pm 7$ & $-41 \pm 6$ & $-47 \pm 7$ & $-39 \pm 6$ \\
\hline 318 & $-67 \pm 7$ & $-42 \pm 6$ & $-39 \pm 7$ & $-44 \pm 6$ & $-37 \pm 6$ \\
\hline 328 & $-62 \pm 7$ & $-39 \pm 5$ & $-37 \pm 5$ & $-40 \pm 6$ & $-39 \pm 6$ \\
\hline
\end{tabular}

Tabela 5.1: Valores de potencial- $\zeta$ de nanopartículas (em unidades de $\mathrm{mV}$ ) obtidos pelo experimento de espalhamento de luz eletroforético

cada efeito (equações 2.27 e 2.26 para a dupla camada elétrica, equação 2.29 para o efeito Seebeck e equação 2.23 para o efeito Soret iônico). As equações são escritas em função do potencial- $\zeta$ das nanopartículas, grandeza determinada pelo experimento de espalhamento de luz eletroforético para as soluções contendo até $1 \mathrm{mMol} / \mathrm{L}$ de hidróxidos. Acima dessa concentração, o experimento não é possível de ser realizado. A Tabela 5.1 apresenta os valores obtidos para o potencial- $\zeta$, através do experimento de luz eletroforético, que serão utlizados nos cálculos.

Para calcular teoricamente valores para $S_{T}(T)$, a dependência com a temperatura dos parâmetro $\zeta, S_{T}^{i o n}$, $\varepsilon$ e $\eta$ foi determinada por equações empíricas ajustadas aos dados para cada parâmetro. Para $\varepsilon$ e $\eta$ foram utilizados dados da literatura para água pura [69], uma 
aproximação válida dada a baixa concentração de partículas e íons em solução. Equações com dependência linear com a temperatura foram utilizadas para os dados de $\zeta(T)$ e $S_{T}^{i o n}(T)$

A máxima resposta experimental do efeito Soret, como indicado pelos valores mostrados na figura 5.9, ocorre para a concentração em torno de $1 \mathrm{mMol} / \mathrm{L}$. Dessa forma, os valores obtidos nestas amostras são os resultados mais interessantes para comparar com os cálculos a partir das equações teóricas, para entender o processo físico que leva à máxima resposta do efeito Soret.

Em primeiro lugar serão apresentados os cálculos para a contribuição teórica da dupla camada elétrica, usando as equações 2.27 e 2.26. O uso da equação 2.26 deve ser mais apropriado devido aos valores de $\kappa^{-1}>R$, com a equação 2.16 para a carga efetiva da partícula $Q_{e}$, e $\sigma_{e}=Q_{e} / 4 \pi R_{h}^{2}$. O último termo na equação 2.26 contém a dependência com a temperatura $d Q_{e} / d T$ da carga efetiva e, por isso, com o potencial- $\zeta, d \zeta / d T$. A equação final para $S_{T}$ fica extensa devido à dependência com a temperatura de $\epsilon, \kappa$ e $\zeta$, e não é escrita explicitamente como a equação 2.27 .

A figura 5.12 mostra os resultados para os cálculos de $S_{T}(T)$ usando as equações 2.27 e 2.26, para a solução sem adição de hidróxidos orgânicos $(c=0 \mathrm{mMol} / \mathrm{L})$ e para as soluções nas quais são adicionados $1 \mathrm{mMol} / \mathrm{L}$ de TMAOH e TBAOH. Como as equações utilizadas possuem todos os parâmetros conhecidos, nenhum ajuste das equações é realizado aos dados experimentais. Para $c=0 \mathrm{mMol} / \mathrm{L}$ os valores calculados pela equação 2.27 são deslocados para valores menores se comparados com os resultados experimentais, enquanto que a equação 2.26 resulta em $S_{T}(T)>0$. Na adição de $1 \mathrm{mMol} / \mathrm{L}$ de TMAOH e TBAOH, o cálculo teórico não segue a mudança de valores observada experimentalmente para ambas equações, sugerindo que o mecanismo físico responsável pelo efeito Soret das nanopartículas na adição dos hidróxidos orgânicos seja diferente.

Os valores obtidos para a carga efetiva $Q_{e}$ calculada pela equação 2.16 são apresentados na figura 5.13. A carga efetiva total $Q_{e}=-N e$ tende a diminuir com a temperatura e, os valores na faixa de 55 a 25 cargas elementares são valores tipicamente encontrados como 


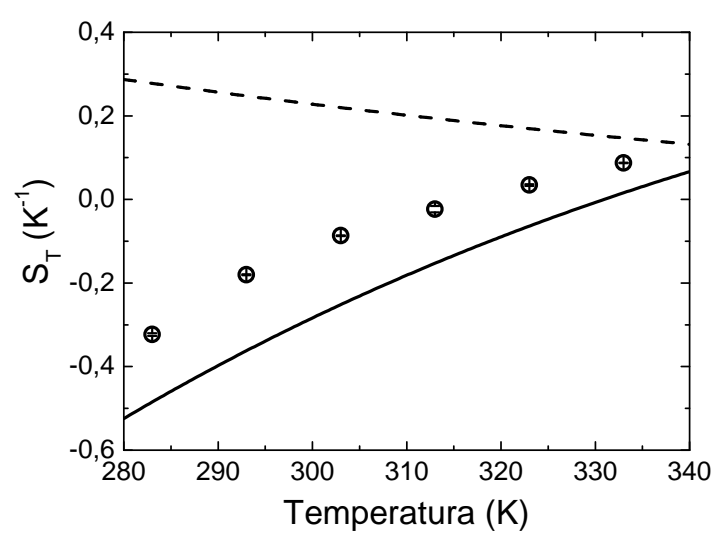

(a)

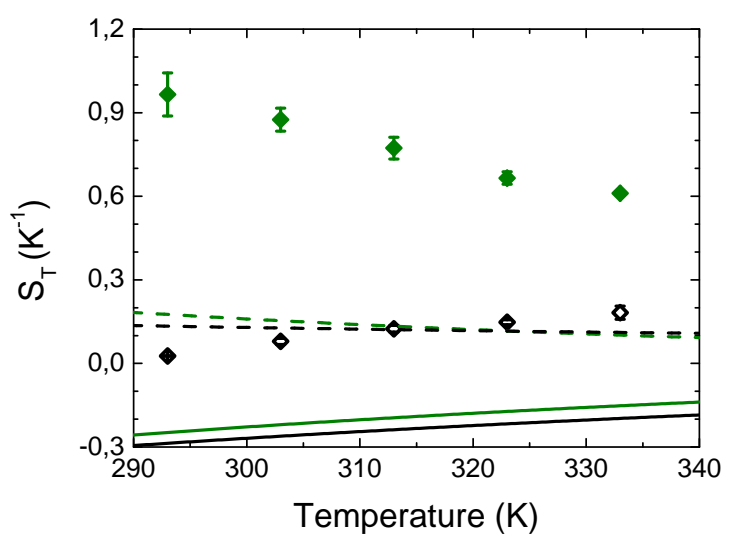

(b)

Figura 5.12: Linhas contínuas mostram resultados dos cálculos realizados com equação 2.27 e as linhas tracejadas os cálculos da equação 2.26, mostrando a influência da dependência com a temperatura da energia na dupla camada elétrica para (a) solução inicial $c^{\mathrm{NaOH}} \leq 0,01 \mathrm{mMol} / \mathrm{L}$ e (b) $1 \mathrm{mMol} / \mathrm{L}$ de $\mathrm{TMAOH}$ (cor preta) e TBAOH (cor verde).

carga efetiva de nanopartículas [99].

Um mecanismo que pode levar à mudança de $S_{T}$ é o efeito Seebeck dos íons considerado na equação 2.29 [55]. A Figura 5.14 mostra os cálculos obtidos e comparados com os resultados experimentais, considerando os valores para o calor de transporte de cada íon obtidos pela teoria de Agar et al [115]. O calor de transporte é conhecido para os íons utilizados neste trabalho, porém apenas para a temperatura $T=298 \mathrm{~K}$. Dessa forma, a comparação dos cálculos com a equação é incompleta e mais confiável em torno de $T=$ 298 K. Os valores dos cálculos referentes à dispersão em TMAOH mostram sinal negativo, devido ao sinal negativo to coeficiente Seebeck $S \propto Q_{+}^{*}-Q_{-}^{*}<0$, e é o termo dominante na equação 2.29. Em TBAOH $S \propto Q_{+}^{*}-Q_{-}^{*}>0$ e o resultado do cálculo também mostra $S_{T}>0$, concordando qualitativamente com o experimento, porém com amplitude muito menor. Uma hipótese é a de que, de forma semelhante ao que ocorreu em meio ácido, o coeficiente Seebeck real da amostra seja maior que o previsto pela diferença de calor de transporte. Isso poderia explicar os resultados para a dispersão em TBAOH, e em TMAOH apenas se o sinal do coeficiente Seebeck medido for contrário ao previsto pela diferença $\Delta Q_{i}^{*}$, além de maior amplitude. Contudo, fica evidente pelos resultados nas figuras 5.12 e 5.14 que apenas as contribuições da dupla camada elétrica e do efeito 


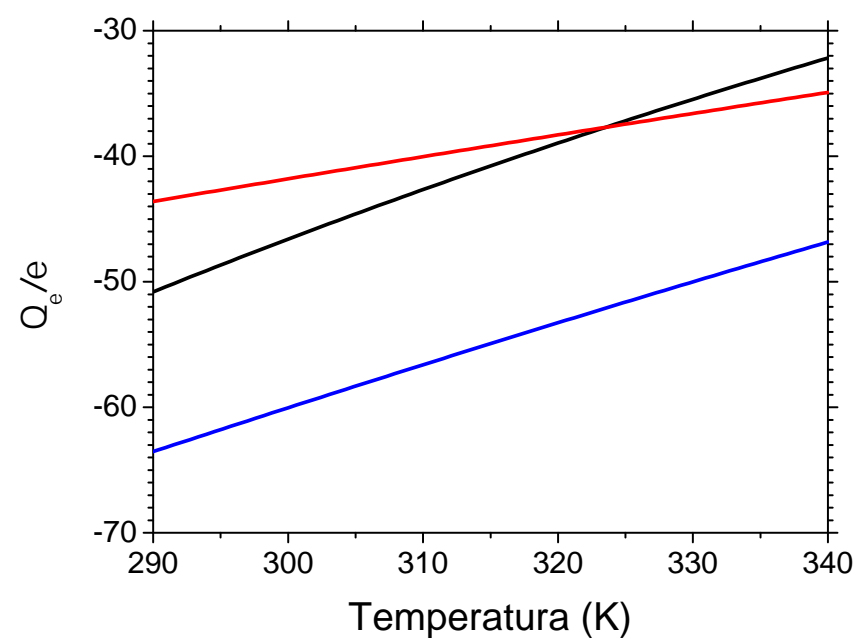

Figura 5.13: Carga efetiva $Q_{e}$ das nanopartículas em função da temperatura, calculada pela equação 2.16 sem adição de hidróxidos (azul) e adição de $1 \mathrm{mMol} / \mathrm{L}$ de TMAOH (vermelho) e TBAOH (preto).

Seebeck combinadas não descrevem os resultados obtidos.

As semelhanças entre as dependências com $T$ para $S_{T}^{i o n}(T)$ (figura 5.4) e $S_{T}(T)$ em concentrações de 1mM de hidróxidos para nanopartículas sugerem que estas podem sentir forte influência do gradiente de concentração iônico. A equação 2.23 permite calcular a amplitude dessa influência. Os valores calculados são mostrados na figura 5.15 e mostram que quando as partículas estão em TBAOH este é o mecanismo físico predominante dada a semelhança do cálculo teórico e o resultado experimental. Em TMAOH a equação 2.23 resulta em valores aproximadamente constantes enquanto o resultado experimental parece refletir a dependência devida ao efeito da dupla camada elétrica.

Ao realizar a soma dos valores calculados com as equações 2.27 e 2.23, os valores resultantes se aproximam muito dos valores experimentais, como mostrado pela linha oliva na figura 5.15. Dessa forma, o efeito Soret destas nanopartículas pode ser descrito como uma combinação dos efeitos da dupla camada elétrica e do gradiente de concentração de íons, mesmo considerando aproximações na derivação da equação 2.27 que não são respeitadas nas amostras investigadas.

No capítulo anterior os resultados obtidos para nanopartículas dispersas em $\mathrm{HNO}_{3}$ 


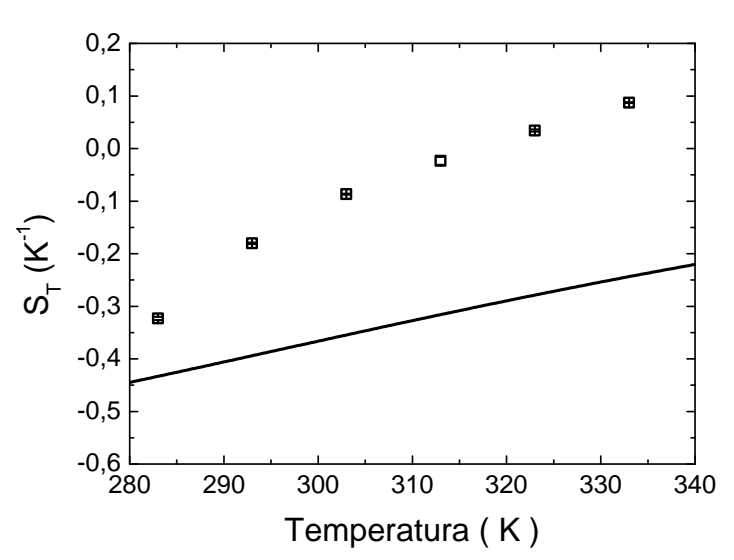

(a)

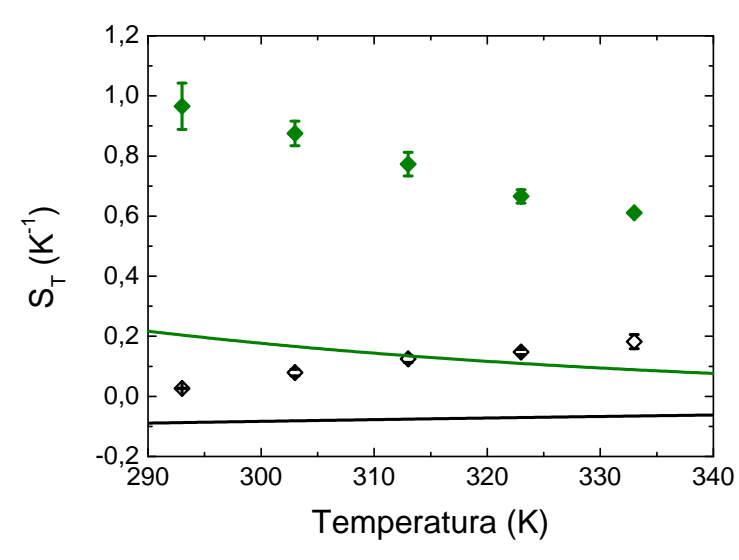

(b)

Figura 5.14: Linhas contínuas mostram resultados dos cálculos realizados com equação 2.29 mostrando a influência do efeito Seebeck para (a) solução inicial $c^{\mathrm{NaOH}} \leq 0,01$ $\mathrm{mMol} / \mathrm{L}$ e (b) $1 \mathrm{mMol} / \mathrm{L}$ de TMAOH (linha preta) e TBAOH (linha oliva).

foram descritos como a combinação dos efeitos de dupla camada elétrica e do coeficiente Seebeck $S$. Este último foi determinado por experimentos na célula termoelétrica, $S=\triangle V / \triangle T$, sendo uma ordem de grandeza maior que o esperado pela equação $S=k_{B}\left(Q_{+}^{*}-Q_{-}^{*}\right) / e$, sendo $Q^{*}$ conhecido na literatura. Neste capítulo os resultados foram descritos como combinação dos efeitos da dupla camada elétrica e do efeito Soret iônico, sendo que novamente o cálculo teórico considerando os calores de transporte conhecidos na literatura resulta em baixa contribuição para $S_{T}(T)$ quando as nanopartículas estão dispersas em TMAOH e TBAOH. No próximo capítulo serão analisados resultados para $S=\triangle V / \triangle T$ obtidos para as soluções de sais investigados neste capítulo (figura 5.5). Será investigada a relação entre as grandezas $S$ e $S_{T}^{i o n}$, sendo que nos resultados do experimento da célula termoelétrica deve estar presente a contribuição de um termo de campo elétrico presente na equação $2.23(\propto \beta \zeta)$. A observação experimental dessa contribuição deverá levar à conclusão sobre qual fenômeno microscópico melhor descreve os resultados experimentais obtidos para $S_{T}$. 


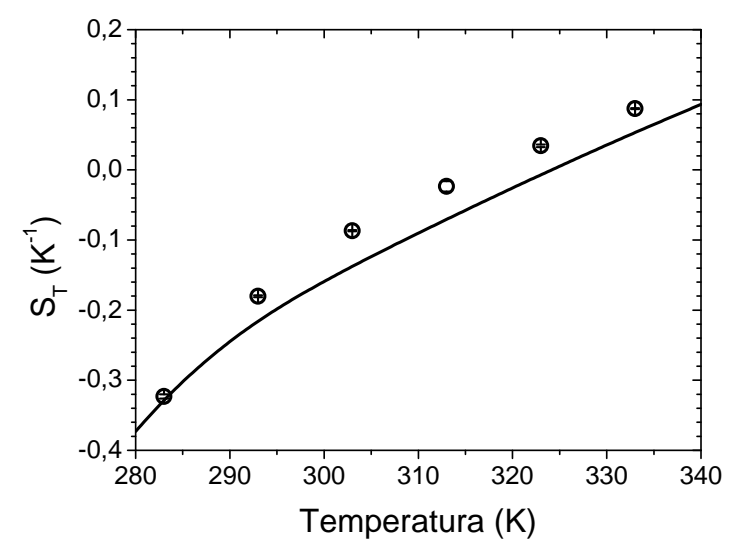

(a)

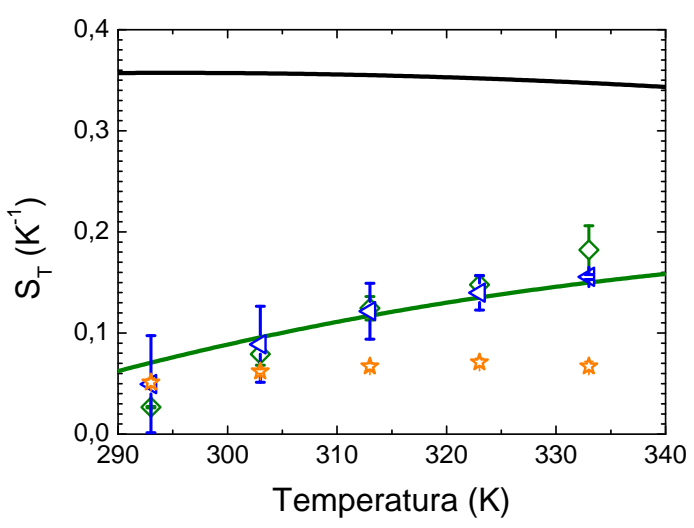

(b)

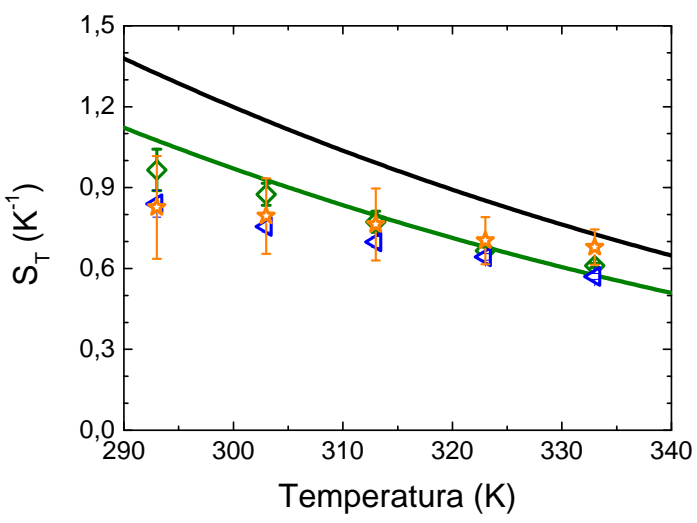

(c)

Figura 5.15: Descrição mais provável do efeito Soret como a combinação das influências da dupla camada elétrica e do gradiente de concentração iônico. (a) Linha contínua é a soma dos valores com as equações 2.27 e 2.23 para a solução inicial $c^{\mathrm{NaOH}} \approx 0,01 \mathrm{mMol} / \mathrm{L}$. Em (b) (partículas com TMAOH) e (c) (partículas com TBAOH) as linhas pretas são os valores obtidos pela equação 2.23 e linhas oliva representam a soma das equações 2.27 e 2.23. Além dos dados para $1 \mathrm{mMol} / \mathrm{L}$ (losango oliva) e para $2 \mathrm{mMol} / \mathrm{L}$, são adicionados dados para $20 \mathrm{mMol} / \mathrm{L}$ de hidróxidos adicionados às nanopartículas. 


\section{Capítulo 6}

\section{Relação entre $S$ e $S_{T}^{\text {ion }}$ na célula termoelétrica}

No Capítulo 4 os dados experimentais resultando em $S_{T}(T)<0$ obtidos para nanopartículas em meio ácido foram descritos pelos valores medidos do coeficiente Seebeck $S(T)$, enquanto que no Capítulo 5 é sugerido que o efeito Soret $S_{T}(T)>0$ das nanopartículas em hidróxidos pode ser descrito efeito Soret iônico $S_{T}^{i o n}$. Apesar de serem duas descrições diferentes, elas possuem alguma relação devido ao termo de campo elétrico presente na equação 2.22 e pelo fato de também ocorrer o efeito Soret de íons no experimento para obter $S$ na célula termoelétrica. Dessa forma, a equação $S=k_{B}\left(Q_{+}^{*}-Q_{-}^{*}\right) / e$ parece ser insuficiente por não conter uma relação entre $S$ e $S_{T}^{i o n}$.

Neste Capítulo serão analisados resultados obtidos para o coeficiente Seebeck através do experimento na célula termoelétrica nos diferentes sais investigados no capítulo 5 . Os resultados para $S=\triangle V(t \rightarrow \infty) / \triangle T$ serão comparados com duas equações diferentes para $S$. A primeira é a equação utilizada anteriormente, $S=k_{B}\left(Q_{+}^{*}-Q_{-}^{*}\right) / e$, que é a equação resultante quando se considera o fluxo de íons no estado estacionário $\mathbf{J}_{ \pm}=0$. Já uma condição mais restritiva para o estado estacionário é considerar $\sum_{i} z_{i} e \mathbf{J}_{i}=0$, de forma semelhante à derivação da equação 2.22, porém com a inclusão do termo para o coeficiente Soret em $\mathbf{J}_{ \pm}$. Dessa forma, a segunda equação para $S$ será dependente da diferença das constantes de difusão e do coeficiente Soret iônico $S_{T}^{i o n}$, além de um termo 
semelhante à primeira equação.

De forma inédita, será descrito como aparecem diferentes respostas características nos resultados de $S(t)=\triangle V(t) / \triangle T$, devido à separação temporal de várias ordens de grandeza dos diferentes efeitos ocorrendo na célula. Um dos efeitos é devido à diferença de coeficiente Soret de ânions e cátions, e ocorre muito rápido para os parâmetros físicos dos experimentos. O outro efeito que contribui para a mudança de $\triangle V(t)$ ocorre em uma escala de tempo muito maior, sendo da ordem de grandeza da constante de difusão de íons $D_{i o n}$. As amplitudes de $S$ para diferentes sais seguem a mesma ordem sequencial obtida para $S_{T}^{\text {ion }}$ no capítulo anterior, além de também apresentarem o mesmo sinal de $\triangle V$, da mesma forma que $S_{T}^{i o n}>0$ para todos os sais.

\subsection{Resultados experimentais para soluções eletrolíti-}

\section{cas}

Alguns resultados obtidos para $\triangle V(t)$ nas soluções eletrolíticas são mostrados como exemplo na figura 6.1. É possível notar que antes de surgir diferença de temperatura entre os eletrodos $(t \rightarrow 0)$ existe $\triangle V_{0} \neq 0$, como discutido nos procedimentos experimentais. A solução completa para o problema teórico da equação 3.6 é inexistente na literatura, não sendo possível estimar as contribuições eletroforéticas e termodifusivas separadamente.

Ao estabelecer uma diferença de temperatura $\triangle T$ entre os eletrodos, a diferença de potencial muda de $\triangle V_{0}$ para um novo valor $\triangle V_{0}^{\prime}$ que pode ser determinado quando $\triangle T$ estabiliza. Os resultados mostram que isso ocorre em todos os experimentos, sendo que a mudança para maior ou menor valor de $\triangle V$ depende do tipo de sal. Após essa mudança rápida o efeito Soret induz mudança lenta de $\triangle V$, com tempo característico da ordem de milhares de segundos. Ao retirar a diferença de temperatura entre os eletrodos, os valores de $\triangle V$ retornam a valores próximos ao do ínício dos experimentos, mostrando que o efeito é reversível como esperado para o efeito Soret. A amplitude do coeficiente Seebeck é calculada com a média de no mínimo 3 ciclos como aqueles da Figura 6.1. Os 


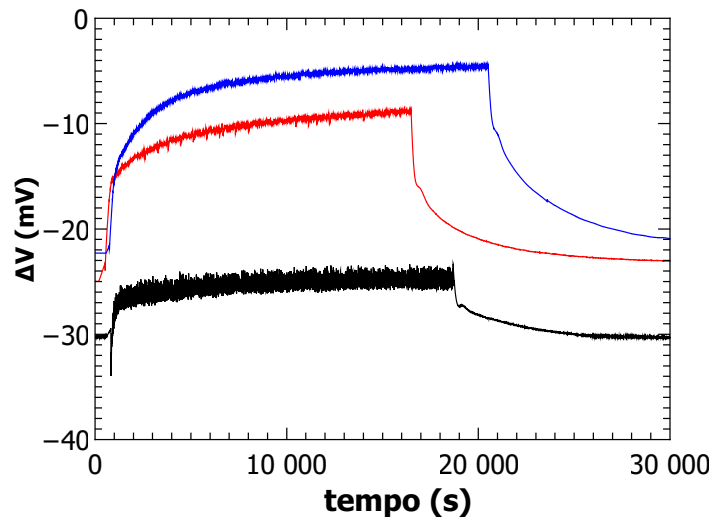

(a)

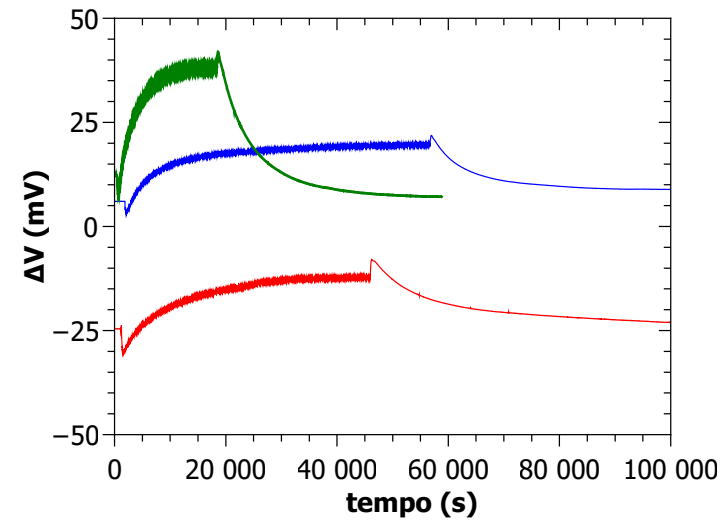

(b)

Figura 6.1: Curvas experimentais para $\triangle V(t)$ obtidos para os experimentos na célula termoelétrica para sais diluídos em água, sendo a separação dos eletrodos $l=11 \mathrm{~mm}$ e $\Delta T=10 \mathrm{~K}$ e temperatura média da célula $\mathrm{T}=298 \mathrm{~K}$. (a) $\mathrm{HCl}$ (azul), HNO3 (vermelho) e $\mathrm{LiCl}$ (preto) e (b) $\mathrm{NaOH}$ (azul), TMAOH (vermelho) e TBAOH (verde).

tempos experimentais refletindo a dinâmica das cargas são analisados a seguir.

Algumas observações são importantes a partir dos dados. Primeiro, o alto valor de $S$ para soluções de hidróxidos, comparado com os ácidos e sais comuns, sugerindo que não há uma relação clara entre os valores de $\Delta Q_{i}^{*}$. Isso porque os valores tabelados para $Q_{i}^{*}$ são maiores para $\mathrm{H}^{+}$e $\mathrm{OH}^{-}$que os contraíons, o que implica em contribuição de sinal contrário para a amplitude de $S$ e sugerindo que a resposta rápida pode estar associada a $\Delta Q_{i}^{*}$. Além disso, o tempo mais longo para atingir o estado estacionário termodifusivo (refletido em um valor de saturação de $\triangle V$ ) para hidróxidos mostra que o transiente não possui uma dependência clara da constante de difusão $D_{i o n}$, ao contrário dos resultados para IR-TDFRS apresentados no capítulo 5. Finalmente, a sequência dos maiores valores obtidos para $S$ segue a mesma sequência obtida para $S_{T}^{i o n}$ indicando uma relação entre estes parâmetros.

\subsubsection{Mudança rápida de $\Delta V(t)$, separação de cargas na camada difusa.}

Os resultados obtidos são analisados a partir dos resultados teóricos previstos por Stout e Khair [181]. As equações para o fluxo de íons (equação 2.28), a equação da continuidade, 
a equação de Poisson e a equação do calor são resolvidas com condições de contorno apropriadas para a célula termoelétrica. A solução desse conjunto de equações fornece valores para a concentração de íons $c$, da densidade de cargas $\rho$ e do potencial eletrostático $\phi$ em toda a célula, e do potencial $V_{T}$ em cada eletrodo em relação ao meio da solução. As expressões resultantes não são analíticas, dificultando a comparação com resultados experimentais. Usando aproximações, os autores mostram que é possível obter as seguintes expressões para as grandezas físicas em um eletrodo:

$$
\begin{gathered}
c(-l, t) \sim \frac{c_{0}\left(Q_{+}^{*}+Q_{-}^{*}\right)}{4 k_{B} T}\left(1-e^{-t / \tau_{c}}\right), \\
\rho(-l, t) \sim \frac{c_{0}\left(Q_{+}^{*}-Q_{-}^{*}\right)}{4 k_{B} T} \frac{\tanh (\kappa l)}{\kappa l}\left(1-e^{-t / \tau_{\rho}}\right), \\
V_{T}(-l, t) \sim-\frac{k_{B} \Delta T\left(Q_{+}^{*}-Q_{-}^{*}\right)}{2 e z k_{B} T}\left(1-\frac{\tanh (\kappa l)}{\kappa l}\right)\left(1-e^{-t / \tau_{\phi}}\right),
\end{gathered}
$$

sendo que as constantes de tempo $\tau$ são dadas por:

$$
\begin{gathered}
\tau_{c}=\frac{l^{2}}{3 D_{\text {ion }}}, \\
\tau_{\rho}=\frac{1}{2 D_{\text {ion }} \kappa^{2}}\left(1-\frac{2 \kappa l}{\sinh (2 \kappa l)}\right), \\
\tau_{\phi}=\frac{1}{2 D_{\text {ion }} \kappa^{2}} \frac{3 \tanh (\kappa l)+\kappa l\left(\tanh ^{2}(\kappa l)-3\right)}{\tanh (\kappa l)-\kappa l},
\end{gathered}
$$

onde $D_{i o n}$ é a constante de difusão dos íons, igual para cátions e ânions no cálculo. Um detalhe importante é notar que $\tau_{\phi}$ é da ordem de $\tau_{\rho}$, e ambos diferem de $\tau_{c}$ por um fator multiplicativo $l^{2} \kappa^{2}$. Isso indica que o efeito Soret do sal neutro por toda a célula ocorre após a rápida separação de carga na camada difusa. Usando valores para as grandezas experimentais características deste trabalho $\left(D \sim 10^{-9} \mathrm{~m}^{2} / \mathrm{s}, l=0.011 \mathrm{~m} \mathrm{e} \kappa^{-1} \sim 5 \times 10^{-9}\right.$ $\mathrm{m})$, a equação 6.6 fornece um valor surpreendente $\tau_{\phi} \sim 10^{-8} \mathrm{~s}$. Isso significa que o 
potencial $V_{T}$ muda praticamente no mesmo instante em que a diferença de temperatura é estabelecida entre os eletrodos. Além disso, quando $t \rightarrow \infty$ e $\kappa l \gg 1$ a expressão para $V_{T}$ se reduz àquela obtida anteriormente $S=V_{T} / \triangle T=k_{B}\left(Q_{+}^{*}-Q_{-}^{*}\right) / e$. Por conta dessa dinâmica das cargas descrita apenas recentemente, a mudança de diferença de potencial rápida ao estabelecer a diferença de temperatura é associada ao rápido efeito Soret na camada difusa.

O coeficiente Seebeck pode ser escrito como dois termos $S=S_{\triangle Q}+S_{\nabla c}$, sendo $S_{\triangle Q}$ o efeito rápido relacionado a $V_{T}$ e $S_{\nabla c}$ associado à mudança lenta de $\Delta V$. Para verificar uma relação entre os valores observados para $\triangle V_{0}-\triangle V_{0}^{\prime}$ e $\Delta Q_{\text {Agar }}^{*}$, as amplitudes observadas para $\left(\triangle V_{0}-\triangle V_{0}^{\prime}\right) / \triangle T=S_{\triangle Q}$ são mostradas na tabela 6.1. Os maiores valores de $S_{\triangle Q}$ são realmente observados para os ácidos que possuem maiores valores de $\Delta Q_{\text {Agar }}^{*}$, enquanto que $S_{\triangle Q}<0$ para TMAOH e $\mathrm{NaOH}$, com $\Delta Q_{\text {Agar }}^{*}<0$, sendo o caso do TBAOH descrito adiante. Dessa forma verificamos que a mudaça rápida de $\Delta V$ realmente pode ser associada ao efeito Soret iônico na camada difusa, ou seja ao potencial $V_{T}$ na equação 6.3 , gerando um pequeno acúmulo líquido de cargas na superfície dos eletrodos, sem modificar a distribuição dos íons além da distância de Debye $\kappa^{-1}$ a partir dos eletrodos. Contudo vale destacar que ao estabelecer diferentes temperaturas nos dois eletrodos, o gradiente de temperatura leva um tempo característico da equação do calor $t_{\text {térmico }}=l^{2} / \pi D_{t h} \sim 600$ s para estabilizar em toda a amostra. Portanto a amplitude $S_{\triangle Q}$ é obtida após o estado estacionário de $\triangle T(z, t)$ ser alcançado.

Pela análise acima, as expressões obtidas por Stout e Khair [181] resultando na equação 6.3 para o potencial termoelétrico não prevêem contribuição devido ao efeito Soret do sal, referente ao coeficiente Soret $S_{T}^{i o n}$ determinado por IR-TDFRS. A equação 6.1 para o perfil de concentração de sal na célula possui dependência temporal $\tau_{c} \propto l^{2} / D_{\text {ion }}$, semelhante aos tempos para o efeito Soret nos experimentos de IR-TDFRS. Para os nossos experimentos, $\tau_{c} \sim 10^{4}$ segundos, que é a ordem de tempo da observação da mudança lenta de $\Delta V$, como mostra a figura 6.1. A origem da mudança de $\Delta V$ em um tempo muito longo deve, então, estar associada à difusão do sal para o frio ou quente. Tal mudança poderia ser esperada devido aos resultados apresentados no capítulo anterior, onde o coeficiente Soret 
das partículas carregadas tem forte dependência com o gradiente de concentração iônico, sendo que o primeiro termo da equação 2.22 possui dimensão física de campo elétrico. Na sequência, o efeito lento será descrito com base na derivação da equação 2.23 de forma semelhante à descrição feita por D. C. Prieve et al [108].

\subsubsection{Difusão de íons no bulk, descrição da mudança lenta de $\Delta V(t)$.}

Considerando os íons dispersos no bulk da solução, isto é, desprezando as interfaces, a análise do problema começa de forma diferente à desenvolvida por Stout e Khair [181] para a célula termoelétrica. No estado estacionário de difusão de íons, $\mathbf{J}_{ \pm}=0$ e a corrente total na solução é nula $I=\sum_{i} e z_{i} \mathbf{J}_{i}$, ou $z_{+} \mathbf{J}_{+}+z_{-} \mathbf{J}_{-}=0$. É considerado como bulk todo o volume além da camada difusa $\left(\kappa^{-1} \sim 5 \times 10^{-9}\right.$ m neste trabalho, $\left.l \gg \kappa^{-1}\right)$, sendo que em todo o bulk não ocorre acúmulo de carga total devido a $\Delta Q^{*}$ e as concentrações de cada íon são dadas por $c_{+}=c_{-}=c_{0} / 2$. Essa condição implica que o coeficiente Soret iônico é igual para ânions e cátions no bulk, e portanto $\alpha_{+}=\alpha_{-}=S_{T}^{i o n}$. A partir das equações 2.28, e rearranjo dos termos, obtém-se a seguinte expressão para o gradiente de potencial

$$
\nabla V=\frac{k_{B} T}{e} \frac{\left(z_{-} D_{-}-z_{+} D_{+}\right)}{\left(z_{-}^{2} D_{-}+z_{+}^{2} D_{+}\right)} \frac{\nabla c_{0}}{c_{0}}+\frac{2 k_{B}}{e} \frac{\left(z_{-} \alpha_{-} D_{-}-z_{+} \alpha_{+} D_{+}\right)}{\left(z_{-}^{2} D_{-}+z_{+}^{2} D_{+}\right)} \nabla T,
$$

e usando as definições para o coeficiente Seebeck $S=-\nabla V / \nabla T$ e o coeficiente Soret iônico $S_{T}^{i o n}=\nabla c_{0} /\left(c_{0} \nabla T\right)$, a equação para o coeficiente Seebeck devido à difusão lenta do sal é dado por

$$
S_{\nabla c}^{\text {teo }} \sim \frac{k_{B} T}{e} \frac{\left(z_{+} D_{+}-z_{-} D_{-}\right)}{\left(z_{-}^{2} D_{-}+z_{+}^{2} D_{+}\right)} S_{T}^{i o n}
$$

sendo que o termo $\nabla V \propto T$ é $T / 2$ maior que o segundo e pode ser desprezado na equação 6.7. O coeficiente Seebeck teórico devido à dependência com o coeficiente Soret iônico foi definido como $S_{\nabla c}^{t e o}$. Para sais monovalentes $z_{+}=-z_{-}=1$, e sendo que a equação 6.8 é

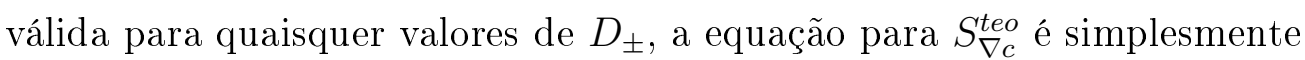




\begin{tabular}{|c|c|c|c|c|c|}
\hline sal & $\mathrm{c}(\mathrm{mM})$ & $\Delta Q_{i}^{*}(\mathrm{~kJ} / \mathrm{mol})$ & $S_{\triangle Q}^{\exp }$ & $S_{\nabla c}^{\text {exp }}$ & $S_{T}^{\text {ion }}\left(\mathrm{K}^{-1}\right)$ \\
\hline \hline TBAOH & 4,4 & 3,79 & $-0,2 \pm 0,1$ & $3,8 \pm 0,3$ & 0,14 \\
\hline TMAOH & 2,8 & $-7,2$ & $-0,5 \pm 0,1$ & $1,7 \pm 0,2$ & 0,066 \\
\hline $\mathrm{NaOH}$ & 2,0 & $-9,84$ & $-0,3 \pm 0,1$ & $1,4 \pm 0,2$ & 0,054 \\
\hline $\mathrm{HNO}_{3}$ & 1,0 & 13,93 & $0,85 \pm 0,15$ & $0,55 \pm 0,15$ & 0,021 \\
\hline $\mathrm{HCl}$ & 2,0 & 12,77 & $0,9 \pm 0,1$ & $1,1 \pm 0,1$ & 0,042 \\
\hline $\mathrm{LiCl}$ & 10,0 & 0 & $0,12 \pm 0,07$ & $0,18 \pm 0,11$ & 0,007 \\
\hline $\mathrm{NH}_{4} \mathrm{I}$ & 10,0 & 3,28 & $0,5 \pm 0,1$ & $0,7 \pm 0,2$ & 0,027 \\
\hline $\mathrm{KCl}$ & 10,0 & 2,06 & $0,3 \pm 0,1$ & $0,2 \pm 0,1$ & 0,008 \\
\hline
\end{tabular}

Tabela 6.1: Tabela com valores obtidos para as duas diferentes contribuições do coeficiente Seebeck na célula termoelétrica, para os diferentes sais e a concentração utilizada. Os valores de $S$ são dados em $\mathrm{mV} / \mathrm{K}$. O sinal de $\Delta Q_{i}^{*}$ concorda com o de $S_{\triangle Q}^{\exp }$, a não ser para TBAOH.

$$
S_{\nabla c}^{t e o} \sim \frac{k_{B} T}{e} S_{T}^{i o n}
$$

Essa relação mostra que é possível prever a contribuição do efeito Soret iônico para o coeficiente Seebeck se o coeficiente Soret $S_{T}^{i o n}$ é conhecido. Usando agora a definição para o coeficiente experimental $S_{\nabla c}^{e x p}=-\triangle V_{\nabla c}^{e x p} / \triangle T$, a única grandeza desconhecida na equação 6.8 em um experimento da célula termoelétrica é o coeficiente Soret iônico $S_{T}^{\text {ion }}$. Além disso, a equação 6.8 mostra que os valores observados experimentalmente para $\triangle V_{\nabla c}^{e x p}$ devem alterar os valores medidos $\Delta V(t)$ sempre para o mesmo sentido, sendo que todo sal apresenta $S_{T}^{i o n}>0$. Isso explica porque todos os resultados na figura 6.1 mostram aumento nos valores $V(t)$ em um tempo muito lento.

A tabela 6.1 mostra valores para as grandezas acima, sendo que os valores de $Q_{i}^{*}$ obtidos por Agar et al [115] são utilizados como referência para comparação.

A tabela mostra que o sal TBAOH possui valor de referência [115] para $\Delta Q_{\text {Agar }}^{*}$ positivo, o que implicaria em $V_{T}$ com mesmo sinal para os ácidos. Contudo, os resultados experimentais da figura 6.1 mostram que $V_{T}$ possui mesmo sinal para todos os hidróxidos, diminuindo o valor de $V(t)$ ao estabelecer a diferença de temperatura. Os ácidos e sais comuns possuem sinal de acordo com $\Delta Q_{\text {Agar }}^{*}$, aumentando $\Delta V(t)$. A discrepância do sinal para TBAOH pode ser explicada pela energia de hidratação de cada íon em função 
da temperatura, proposta no capítulo anterior. Se o íon $\mathrm{OH}^{-}$possui a maior variação de $\triangle G^{\text {hid }}$ com a temperatura, seu coeficiente de transporte $D_{T}^{i o n}$ ou $Q^{*}$ deve ter maior valor comparado aos contra-íons. Assim, a observação experimental de $V_{T}$ deve seguir o mesmo comportamento em todos os hidróxidos, como observado experimentalmente. A menor amplitude de $V_{T}$ observada experimentalmente é para o sal $\mathrm{LiCl}$, que possui valores de referência $Q_{i}^{*}$ iguais para os dois íons. Já a menor amplitude para o efeito Soret lento ocorre para o sal $\mathrm{KCl}$, que possui valores de referência $D_{i}$ iguais.

As descrições acima demonstram o acordo qualitativo entre os resultados da célula termoelétrica e as equações mais recentes para descrever a dinâmica das cargas na solução. Os altos valores experimentais obtidos para $S_{T}^{i o n}$ neste experimento em comparação ao IRTDFRS podem ter duas explicações. A primeira é a de possíveis contribuições para o coeficiente Seebeck que não aparecem no experimento óptico, como o efeito eletroforético produzido pela diferença de potencial inicial, ou a polarização térmica da água, como sugerido recentemente [182]. A outra possibilidade é a de que os valores de $Q_{i}^{*}$ obtidos por Agar et al [115] sejam diferentes na realidade. Recentes resultados usando simulações de dinâmica molecular indicam diferentes valores de $Q_{i}^{*}$ para alguns sais [183].

\subsection{Coeficiente Seebeck na presença de nanopartículas}

Ao realizar experimentos na célula termoelétrica com soluções de nanopartículas de ferrofluidos é novamente observado que os resultados fornecem o mesmo comportamento das curvas para ácidos e bases, a menos da mudança rápida durante a estabilização de $\triangle T$. O efeito Soret iônico ocorre de forma semelhante ao apresentado na figura 6.1, na mesma escala de tempo e amplitudes similares. Se a diferença de temperatura é mantida durante uma escala de tempo ainda maior, correspondente ao tempo de difusão das nanopartículas $\tau_{N P s} \propto l^{2} / D_{N P s}$, o valor de $\Delta V(t)$ irá se alterar novamente devido ao efeito Soret das nanopartículas, sendo $D \approx 100 D_{\text {ion }}$. Os resultados nas figuras 6.2 e 6.3 mostram que a mudança observada em $\Delta V(t)$ quando nanopartículas estão dispersas com TMAOH e TBAOH são ainda mais lentas que o efeito Soret iônico, e sempre diminui a amplitude do coeficiente Seebeck na célula. 


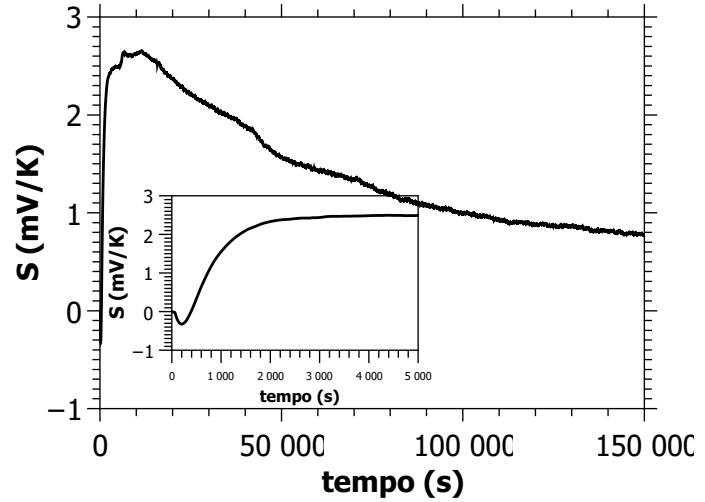

(a)

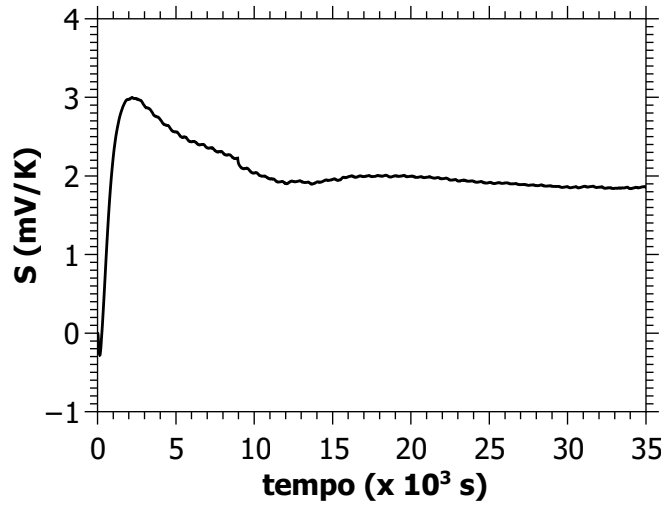

(b)

Figura 6.2: Coeficiente Seebeck $S$ em função do tempo para nanopartículas da amostra FF4, dispersas em TMAOH. (a) Temperatura média da célula $\mathrm{T}=298 \mathrm{~K}$; o inset na figura mostra que o potencial $V_{T}$ surge durante a estabilização de $\triangle T$, e que o tempo para o máximo do efeito Soret iônico é menor em relação aos resultados obtidos nas soluções iônicas sem nanopartículas. (b) Resultado para a temperatura média da célula $\mathrm{T}=328$ $\mathrm{K}$, mostrando que a mudança de $\Delta V$ é mais rápida para ambos os efeitos em comparação com (a), devido ao aumento de temperatura.

Considerando que o coeficiente Seebeck devido ao efeito Soret iônico em solução possui o mesmo sinal para os diferentes sais, o valor de $\Delta V(t)$ devido ao efeito Soret das nanopartículas irá diminuir quando partículas de carga positiva dispersas em ácidos migram para o lado quente e partículas negativas dispersas em hidróxidos migram para o lado frio. Isso ocorre porque o campo elétrico gerado pelo efeito Soret iônico tem o mesmo sentido (do frio para o quente) para os diferentes sais investigados, como sugerido pela equação 6.7. A equação para a corrente de partículas no interior da célula termoelétrica é

$$
\mathbf{J}=-D \nabla \Phi-\Phi D_{T} \nabla T+\Phi \mu_{e l} \mathbf{E}
$$

sendo $\mu_{e l}$ a mobilidade da partícula, $\mu_{e l}=\epsilon \zeta / \eta$ para $\kappa R \ll 1$ ou $\mu_{e l}=2 \epsilon \zeta / 3 \eta$ para $\kappa R \gg$ 1. Resolvendo as equações para o estado estacionário do fluxo de íons e de partículas, Majee e Würger [82] obtiveram uma expressão para o potencial termoelétrico gerado pela presença de nanopartículas, correspondente ao potencial $V_{T}$ acima. A teoria não considera a contribuição devida ao efeito Soret iônico lento, e uma descrição teórica completa se faz 


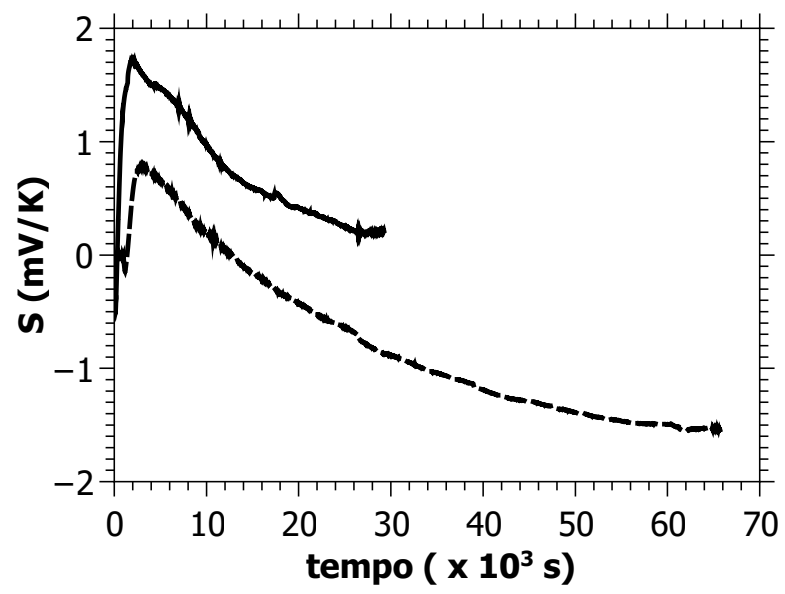

Figura 6.3: Coeficiente Seebeck em função do tempo para nanopartículas da amostra FF5, dispersas com TBAOH, mostrando o efeito da temperatura média na célula $\mathrm{T}=$ $298 \mathrm{~K}$ (linha tracejada) e $\mathrm{T}=323 \mathrm{~K}$ (linha contínua).

necessária. Contudo, uma simples análise da equação 6.10 quando $|\mathbf{J}|=0$ leva à conclusão de que $\mathbf{E}$ (ou seja, a contribuição do fluxo de partículas para a amplitude final de $\mathbf{E}$ ) possui o mesmo sentido no interior da célula para as combinações $D_{T}<0, \zeta>0$ e $D_{T}>0, \zeta<$ 0. Combinado com o fato de que todos os sais possuem $S_{T}^{\text {ion }}>0$, também originando uma contribuição para $\mathbf{E}$ sempre no mesmo sentido, temos a explicação completa de como o efeito Soret de íons e partículas originam o mesmo resultado qualitativo na célula termoelétrica para partículas dispersas em ácidos ou hidróxidos, a menos do potencial $V_{T}$, que gera $\Delta V$ de sinais opostos na estabilização de $\Delta T$.

Estes resultados comprovam as hipóteses feitas nos capítulos anteriores para a descrição do efeito Soret de nanopartículas. No capítulo 4, a amplitude total do coeficiente Seebeck medido na célula termoelétrica foi utilizada para a descrição do coeficiente Soret das nanopartículas. Os experimentos foram realizados com a separação entre os eletrodos $l=2 \mathrm{~mm}$, o que não permitiu uma clara separação temporal entre as duas contribuições para $\Delta V, V_{T}$ e $S_{T}^{i o n}$. A boa descrição dos resultados experimentais a partir do coeficiente Seebeck não foi por acaso, já que Majee e Würger [81] mostraram teoricamente que no experimento de Lente de Matéria a contribuição para $S_{T}$ correspondente a $V_{T}$ está presente. Os valores de $S$ medidos também incorporam a contribuição devida a $S_{T}^{i o n}$, indicando ser uma descrição quase completa do efeito devido à relação entre $S$ e $S_{T}^{\text {ion }}$ dada pela equação 6.8. A equação 6.8 também indica que a descrição feita no capítulo 5 para 
CAPÍTULO 6. RELAÇÃO ENTRE S E $S_{T}^{I O N}$ NA CÉLULA TERMOELÉTRICA 114

partículas dispersas com TMAOH e TBAOH, utilizando a equação 2.23 que relaciona $S_{T}$ e $S_{T}^{i o n}$, é quase equivalente à descrição do capítulo 4 utilizando a relação entre $S_{T}$ e $S$, porque a contribuição de $V_{T}$ é muito baixa para o caso dos hidróxidos orgânicos. Dessa forma, os resultados e a descrição física apresentados neste capítulo fornecem fundamentos necessários para as hipóteses deste trabalho. 


\section{Capítulo 7}

\section{Conclusões e Perspectivas}

O coeficiente Soret de nanopartículas de óxidos de ferro, constituintes de ferrofluidos, foi investigado através dos experimentos ópticos de Lente de Matéria e IRTDFRS. Ambos experimentos demonstraram ser equivalentes para a determinação de $S_{T}$, sendo o efeito observado em tempos experimentais equivalentes $t_{\text {Soret }} \propto l^{2} / D$, onde $l$ o raio do feixe Gaussiano no experimento de Lente de Matéria ou a periodicidade da grade de intensidade no IRTDFRS.

O experimento de Lente de Matéria foi utilizado para determinar experimentalmente a dependência de $S_{T}$ com a temperatura da amostra para nanopartículas dispersas em soluções ácidas. Os experimentos em meio ácido foram realizados com quantidade de ácido suficiente para saturar a superfície das partículas de sítios protonados, e observamos que, em todo o intervalo de temperatura investigado, as partículas migram para o lado quente do gradiente de temperatura. Determinando o potencial- $\zeta$ e o coeficiente Seebeck em função da temperatura, mostramos que o campo termoelétrico, que surge devido aos diferentes coeficientes Soret de íons positivos e negativos, é a principal causa da migração das nanopartículas para a região de mais alta temperatura do líquido. Os valores de coeficiente Seebeck medidos experimentalmente são maiores que os previstos teoricamente a partir de valores conhecidos para o calor de transporte de cada íon, resultado que foi necessário para descrever os valores obtidos para $S_{T}(T)$.

A hipótese de que o efeito termoelétrico gerado pelos íons é a principal contribuição para o efeito Soret de nanopartículas eletrostaticamente carregadas foi também investi- 
gada para a dispersão das nanopartículas em hidróxidos. Verificamos que, com a adição de hidróxidos de contraíons orgânicos, TMAOH e TBAOH, o campo termoelétrico esperado pela diferença de calor de transporte entre os íons novamente não foi suficiente para descrever os resultados obtidos pelo experimento IRTDFRS para $S_{T}(T)$ das nanopartículas. Utilizando o mesmo experimento, o coeficiente Soret iônico $S_{T}^{i o n}$ foi determinado, e uma equação relacionando $S_{T}$ e $S_{T}^{i o n}$, proposta pela primeira vez, resultou na melhor descrição obtida para $S_{T}(T)$.

Os resultados obtidos para $S_{T}^{i o n}(T)$ foram descritos fisicamente a partir dos coeficientes $D_{T}^{i o n}(T)$ e $D^{i o n}(T)$. A principal razão para diferentes resultados de $S_{T}^{i o n}(T)$ para diferentes íons é a diferença nos valores de $D_{T}^{i o n}(T)$. Os valores experimentais desta grandeza foram comparados com o resultado teórico baseado na expansão térmica da solução líquida, e mostraram bom acordo com os resultados experimentais para TMAOH e TBAOH. Por outro lado, os resultados experimentais para sais comuns apresentam alto desvio relativo em relação ao cálculo teórico. A hipótese formulada neste trabalho é a de que diferentes resultados para $D_{T}^{i o n}(T)$ estão relacionados com diferenças na energia de interação entre íons e moléculas de água, especificamente na dependência com a temperatura da energia de hidratação $\Delta G^{\text {hid }}$.

Ao realizar o experimento na célula termoelétrica para determinar o potencial termoelétrico em soluções dos diferentes sais, a amplitude da diferença de potencial gerada pela diferença de temperatura mostrou seguir a mesma sequência de valores obtida no experimento IRTDFRS para $S_{T}^{\text {ion }}(T)$ dos diferentes sais. A descrição dos resultados demonstra que o coeficiente Seebeck das soluções é, na verdade, relacionado com o coeficiente Soret iônico, $S \propto S_{T}^{\text {ion }}(T)$. Além disso, os dados demonstraram que, de acordo com uma recente teoria para dinâmica de cargas na célula termoelétrica, uma rápida mudança de potencial entre os eletrodos ocorre devido à diferença de efeito Soret dos íons positivo e negativo. A mudança de potencial devido ao efeito Soret ocorre em escala de tempo muito maior, e o efeito Seebeck total medido na célula termoelétrica explica os valores $S_{T}<0$ de nanopartículas em meio ácido e $S_{T}>0$ em solução de hidróxidos de TMAOH e TBAOH. O resultado para as nanopartículas em $\mathrm{NaOH}$, hidróxido que possui baixo valor 
de $S_{T}^{\text {ion }}(T)$ e o maior valor de $\Delta Q_{i}^{*}$ entre os hidróxidos (o que implicaria em efeito semelhante à dispersão em ácidos), mostrou valores de $S_{T}(T)$ intermediários entre os extremos que ocorrem para ácidos e os hidróxidos orgânicos.

Os experimentos ópticos para determinar o coeficiente Soret de nanopartículas e íons demonstraram que é possível identificar claramente o sinal característico do efeito Soret ao alterar alguma característica da solução, como a mudança do íon dispersante. Esse efeito físico pode ser utilizado para, através da observação da resposta característica do efeito Soret em uma amostra complexa, identificar a presença de um constituinte específico, através de um experimento simples como o de Lente de Matéria, por exemplo. Além disso, o experimento com a célula termoelétrica também reflete a resposta característica do efeito Soret quando cargas iônicas estão presentes em solução e seu uso pode se aplicar além de apenas investigar geração de termoeletricidade. A vantagem da célula termoelétrica em relação aos experimentos ópticos é a possibilidade de seu uso para maiores intervalos de concentrações de íons e partículas.

Este trabalho se fez necessário para a compreensão dos mecanismos físicos que levam ao efeito termodifusivo em nanopartículas que constituem ferrofluidos a base de água. A relação entre os coeficientes Soret das nanopartículas e de íons dispersantes foi esclarecida, e isso permite que trabalhos futuros possam utilizar estas informações para controlar ou descrever o acúmulo de partículas carregadas em uma região mais fria ou mais quente de líquidos. Apesar de verificar que a termodifusão das nanopartículas de óxido de ferro, muito mais lenta que a termodifusão dos íons, diminui a intensidade do campo termoelétrico iônico no interior da solução, outras propriedades das partículas podem ser utilizadas para amplificar o efeito termoelétrico. Uma delas é a aplicação de campo magnético, gerando estruturas a partir do acoplamento magnético das nanopartículas e induzindo efeito de confinamento da solução iônica, o que pode amplificar a resposta termoelétrica dos íons.

Os efeitos descritos neste trabalho podem se aplicar também ao estudo de biomoléculas em geral. O efeito termodifusivo vem sendo utilizado como um meio de identificar respostas específicas de proteínas, DNA, RNA entre outros [61, 65, 184, 185, 186]. Muitas destas moléculas são dispersas em água e alguma quantidade de sal, o que permitiria 
a investigação dos efeitos termodifusivos pelo uso de laser infravermelho (Lente de Matéria, IRTDFRS, Microscopia) ou pela resposta termoelétrica. A vantagem de realizar experimentos em célula termoelétrica é a possibilidade de usar soluções com baixas concentrações de soluto, sendo que experimentos ópticos são realizados em concentrações relativamente mais altas. Assim, o experimento na célula termoelétrica pode ser muito explorado em trabalhos futuros, baseado na dinâmica da resposta termodifusiva descrita experimentalmente neste trabalho.

Dessa forma, a principal contribuição desse trabalho foi mostrar que o mecanismo físico que controla o efeito Soret das nanopartículas de óxidos de ferro está relacionado com o coeficiente Soret dos íons que estão presentes na solução. A hipótese feita para descrever o efeito Soret iônico é baseada em um modelo para a dependência com a temperatura das interações em torno da partícula, no caso dos íons da interação dos íons com as moléculas vizinhas. Essa hipótese poderá ser melhor fundamentada em trabalhos futuros com o uso de simulações computacionais. 


\section{Referências Bibliográficas}

[1] S. Iacopini, R. Rusconi, and R. Piazza, Eur Phys J E Soft Matter 19, 59 (2006).

[2] P. Polyakov, Study of the thermal diffusion behavior of simple binary mixtures, Phd thesis, University of Twente (2008).

[3] S. Kim, K.-S. Lee, M. R. Zachariah, and D. Lee, Journal of Colloid and Interface Science 344, 353 (2010).

[4] D. Lee, J.-W. Kim, and B. G. Kim, J. Phys. Chem. B 110, 4323 (2006).

[5] F. A. Tourinho, R. Franck, and R. Massart, Journal of Materials Science 25, 3249 (1990).

[6] C. Scherer and A. Figueiredo, Brazilian Journal of Physics 35, 718 (2005).

[7] J. A. Gomes, M. H. Sousa, F. A. Tourinho, R. Aquino, G. J. d. Silva, J. Depeyrot, E. Dubois, and R. Perzynski, J. Phys. Chem. C 112 (2008).

[8] R. E. Rosensweig, Ferrohydrodynamics, 1st ed. (Dover Publications, 1997).

[9] M. Strömberg, K. Gunnarsson, S. Valizadeh, P. Svedlindh, and M. Stromme, Journal of Applied Physics 101 (2007).

[10] J. Lim, S. P. Yeap, H. X. Che, and S. C. Low, Nanoscale Research Letters 8, 381 (2013).

[11] M. Shinkai, Journal of Bioscience and Bioengineering 94, 606 (2002).

[12] J. C. Bacri, R. Perzynski, D. Salin, V. Cabuil, and R. Massart, Journal of Magnetism and Magnetic Materials 85, 27 (1990). 
[13] V. Bustos and M. Mayorga, J. Non-Equilib. Thermodyn. 35, 35 (2010).

[14] E. Dubois, V. Cabuil, F. Boué, and R. Perzynski, J. Chem. Phys. 111, 7147 (1999).

[15] J. Dobson, nature nanotechnology 3, 139 (2008).

[16] J. Dobson, Nanomedicine 1, 31 (2006).

[17] J. Lenglet, A. Bourdon, J. C. Bacri, and G. Demouchy, Phys Rev E 65, 031408 (2002).

[18] B. T. Huang, M. Roger, M. Bonetti, T. J. Salez, C. Wiertel-Gasquet, E. Dubois, R. C. Gomes, G. Demouchy, G. Mériguet, V. Peyre, M. Kouyaté, C. L. Filomeno, J. Depeyrot, F. A. Tourinho, R. Perzynski, and S. Nakamae., J. Chem. Phys. 143, 054902 (2015).

[19] S. Alves, G. Demouchy, A. Bee, D. Talbot, A. Bourdon, and A. M. Figueiredo Neto, Philosophical Magazine 83, 2059 (2003).

[20] S. Alves, A. Bourdon, and A. M. F. Neto, J. Opt. Soc. Am. B 20, 713 (2003).

[21] G. Meriguet, G. Demouchy, E. Dubois, R. Perzynski, and A. Bourdon, Journal of Non-Equilibrium Thermodynamics 32, 271 (2007).

[22] G. Demouchy, A. Mezulis, A. Bee, D. Talbot, J. C. Bacri, and A. Bourdon, J. Phys. D: Appl. Phys. 37 (2004).

[23] L. Sprenger, A. Lange, and S. Odenbach, Phys. Fluids 25, 122002 (2013).

[24] K. Morozov, Journal of Magnetism and Magnetic Materials 201, 248 (1999).

[25] K. I. Morozov, "On the theory of soret effect in colloids," in Thermal nonequilibrium phenomena in fluid mixtures, Vol. 584 (Springer-Verlag Berlin Heidelberg, 2002) Book section 4.

[26] K. I. Morozov, Soviet Journal of Experimental and Theoretical Physics 88, 944 (1999). 
[27] A. Mezulis, M. Maiorov, and E. Blums, Journal of Magnetism and Magnetic Materials 252, 221 (2002).

[28] A. Mezulis, M. Maiorov, and O. Petricenko, Central European Journal of Physics 10, 989 (2012).

[29] E. Blums, S. Odenbach, A. Mezulis, and M. Maiorov, Phys. Fluids 10, 2155 (1998).

[30] L. Sprenger, A. Lange, and S. Odenbach, Physics of Fluids 26, 022001 (2014).

[31] A. L. Sehnem, R. Aquino, A. F. C. Campos, F. A. Tourinho, J. Depeyrot, and A. M. F. Neto, Physical Review E 89, 032308 (2014).

[32] A. L. Sehnem, Investigação da influência do tamanho de partícula na termodifusao de colóides magnéticos positivamente carregados, Master's thesis, Universidade de São Paulo (2014).

[33] S. Chapman, Proceedings of the Physical Society 72, 353 (1958).

[34] H. Brenner, Phys. Rev. E 82, 036325 (2010).

[35] W. Köhler and K. I. Morozov, Journal of Non-Equilibrium Thermodynamics 41, 151 (2016).

[36] T. G. Anderson and F. H. Horne, J. Chem. Phys. 55, 2831 (1971).

[37] M. Giglio and A. Vendramini, Appl. Phys. Lett. 25 (1974).

[38] S. Semenov and M. Schimpf, Phys Rev E 72, 041202 (2005).

[39] M. Giglio and A. Vendramini, Phys. Rev. Lett 38, 26 (1977).

[40] B.-J. d. Gans, R. Kita, S. Wiegand, and J. Luettmer-Strathmann, Phys. Rev. Lett. 91, 245501 (2003).

[41] S. Wiegand, J. Phys.: Condens. Matter 16, R357 (2004).

[42] L. Talbot, R. K. Cheng, R. W. Schefer, and D. R. Willis, Journal of Fluid Mechanics 101, $737(1980)$. 
[43] S. L. Goren, Journal of Colloid and Interface Science 61, 77 (1977).

[44] F. Zheng, Advances in Colloid and Interface Science 97, 255 (2002).

[45] B. Rauch and G. Meyerhoff, J. Phys. Chem 67, 946 (1963).

[46] G. S. McNab and A. Meisen, J. Coll. Inter. Sci. 44, 339 (1973).

[47] C. Ludwig, Sitzungsber. Adad. Wiss. Wien 20, 539 (1856).

[48] C. Soret, Arch. Sci. Phys. Nat. Geneve 3, 48 (1879).

[49] C. Soret, C. R. Acad Sci. Paris . 91, 289 (1880).

[50] F. Tourinho, A. Campos, R. Aquino, M. Lara, G. J. Silva, and J. Depeyrot, Braz. J. Phys. 32, 501 (2002).

[51] R. Aquino, F. Tourinho, R. Itri, M. d. Lara, and J. Depeyrot, Journal of Magnetism and Magnetic Materials 252, 23 (2002).

[52] W. B. Russel, D. A. Saville, and W. R. Schowalter, Colloidal Dispersions (Cambridge University Press, Cambridge, UK, 1989).

[53] R. J. Hunter, Zeta Potential in Colloid Science (Academic Press, 1981).

[54] J. K. Dhont, S. Wiegand, S. Duhr, and D. Braun, Langmuir 23, 1674 (2007).

[55] A. Würger, Rep. Prog. Phys. 73, 126601 (2010).

[56] E. D. Eastman, Journal of the American Chemical Society 50, 283 (1928).

[57] J. N. Agar, Thermogalvanic Cells, in Advances in Electrochemistry and Electrochemical Engineering, pp. 31-121, edited by P. Delahay, Advances in Electrochemistry and Electrochemical Engineering, pp. 31-121 (Interscience New York, 1963).

[58] R. Piazza, J. Phys.: Condens. Matter 16 (2004).

[59] S. A. Putnam, D. G. Cahill, and G. C. Wong, Langmuir 23, 9221 (2007). 
[60] M. Bonetti, S. Nakamae, B. T. Huang, T. J. Salez, C. Wiertel-Gasquet, and M. Roger, The Journal of Chemical Physics 142, 244708 (2015).

[61] M. Reichl, M. Herzog, A. Götz, and D. Braun, Phys. Rev. Lett. 112 (2014).

[62] Y. Kishikawa, H. Shinohara, K. Maeda, Y. Nakamura, S. Wiegand, and R. Kita, Phys. Chem. Chem. Phys. 14, 10147 (2012).

[63] Z. Wang, H. Kriegs, and S. Wiegand, J. Phys. Chem. B 116, 7463 (2012).

[64] K. A. Eslahian, A. Majee, M. Maskos, and A. Würger, Soft Matter 10, 1931 (2014).

[65] M. Reichl, M. Herzog, F. Greiss, M. Wolff, and D. Braun, Phys. Rev. E 91, 062709 (2015).

[66] S. A. Putnam and D. G. Cahill, Langmuir 21, 5317 (2005).

[67] K. A. Eslahian and M. Maskos, Colloids and Surfaces A: Physicochemical and Engineering Aspects 413, 65 (2012).

[68] R. Rusconi, L. Isa, and R. Piazza, J. Opt. Soc. Am. B 21 (2004).

[69] A. L. Sehnem, A. M. Figueiredo Neto, R. Aquino, A. F. C. Campos, F. A. Tourinho, and J. Depeyrot, Phys. Rev. E 92, 042311 (2015).

[70] S. Wiegand, H. Ning, and H. Kriegs, J. Phys. Chem. 111, 14169 (2007).

[71] J. K. G. Dhont, An Introduction to Dynamics of Colloids (Elsevier Science, 1996).

[72] A. F. C. Campos, E. P. Marinho, M. d. A. Ferreira, F. A. Tourinho, F. L. d. O. Paula, and J. Depeyrot, Braz. J. Phys. 39, 230 (2009).

[73] A. Campos, F. Tourinho, G. J. d. Silva, and J. Depeyrot, Journal of Magnetism and Magnetic Materials 289, 171 (2005).

[74] R. W. O’Brien and L. R. White, J. Chem. Soc., Faraday Trans. 2 74, 1607 (1978).

[75] C. Sestier, M. F. Da-Silva, D. Sabolovic, J. Roger, and J. N. Pons, Electrophoresis 19, 1220 (1998). 
[76] J. Lim, C. Lanni, E. R. Evarts, F. Lanni, R. D. Tilton, and S. A. Majetich, ACS Nano 5, 217 (2011).

[77] J. K. G. Dhont and W. J. Briels, Eur Phys J E Soft Matter 25, 61 (2008).

[78] E. Bringuier and A. Bourdon, Phys. Rev. E 67, 011404 (2003).

[79] A. Würger, Phys. Rev. Lett 101 (2008).

[80] D. Vigolo, S. Buzzaccaro, and R. Piazza, Langmuir 26, 7792 (2010).

[81] A. Majee and A. Würger, Soft Matter 9, 2145 (2013).

[82] A. Majee and A. Wurger, Phys Rev E Stat Nonlin Soft Matter Phys 83, 061403 (2011).

[83] A. Campos, F. Tourinho, G. d. Silva, M. Lara, and J. Depeyrot, Eur. Phys. J. E 6, 29 (2001).

[84] A. F. C. Campos, R. Aquino, F. A. Tourinho, F. L. O. Paula, and J. Depeyrot, Eur. Phys. J. E 36 (2013).

[85] J. A. Davis and J. O. Leckie, J. Coll. Inter. Sci. 67, 90 (1978).

[86] J. A. Davis and J. O. Leckie, J. Coll. Inter. Sci. 74, 32 (1980).

[87] O. Stern, Z. Elektrochem. 30, 508 (1924).

[88] D. C. Grahame, Chem. Rev. 41, 441 (1947).

[89] R. J. Hunter, Foundations of Colloid Science (Oxford University Press, 2001).

[90] J. Duval, J. Lyklema, J. M. Kleijn, and H. P. van Leeuwen, Langmuir 17, 7573 (2001).

[91] A. L. Loeb, J. Overbeek, and P. H. Wiersema, The electrical Double-Layer Around a Spherical Colloid Particle (MIT Press, 1961).

[92] A. B. Glendinning and W. B. Russel, J. Coll. Inter. Sci. 93, 95 (1983). 
[93] G. M. Bell, S. Levine, and McCartney, J. Coll. Inter. Sci. 33, 335 (1970).

[94] J. N. Israelachvili, Intermolecular and Surface Forces (Academic Press, 1985).

[95] V. S. Mendelev and A. O. Ivanov, Phys. Rev. E 70, 051502 (2004).

[96] D. Heinrich, A. R. Goni, and C. Thomsen, The Journal of Chemical Physics 126, 124701 (2007).

[97] Y. Zhao, C. Zhao, J. He, Y. Zhou, and C. Yang, Soft Matter 9, 7726 (2013).

[98] A. V. Delgado, F. González-Caballero, R. J. Hunter, L. K. Koopal, and J. Lyklema, J. Coll. Inter. Sci. 309, 194 (2007).

[99] T. L. Doane, C.-H. Chuang, R. J. Hill, , and C. Burda, Acc. Chem. Res. 45, 317 (2012).

[100] B. R. Ware, Adv. Colloid interface Sci. 4, 1 (1974).

[101] A. S. Dukhin and P. J. Goetz, Characterization of Liquids, Nano- and Microparticles, and Porous Bodies Using Ultrasound (Elsevier, 2002).

[102] M. Siebentritt, P. Volovitch, K. Oglea, and G. Lefévre, Colloids and Surfaces A: Physicochemical and Engineering Aspects 443, 338 (2014).

[103] S. R. d. Groot and P. Mazur, Non-Equilibrium Thermodynamics (North-Holland, Amsterdam, 1962).

[104] S. Kjelstrup and D. Bedeaux, Non-Equilibrium Thermodynamics of Heterogeneous Systems (World Scientific, 2008).

[105] L. Onsager, Phys. Rev. 37, 405 (1931).

[106] E. Ruckenstein, Journal of Colloid and Interface Science 83, 77 (1981).

[107] J. L. Anderson, Annual Review of Fluid Mechanics 21, 61 (1989).

[108] D. C. Prieve, J. L. Anderson, J. P. Ebel, and M. E. Lowell, Journal of Fluid Mechanics 148, 247 (1984). 
[109] R. Piazza and A. Guarino, Phys. Rev. Lett. 88 (2002).

[110] S. Duhr and D. Braun, Proc. Nat. Acad. Sci. 103, 19678 (2006).

[111] Z. Wang, H. Kriegs, J. Buitenhuis, J. K. G. Dhont, and S. Wiegand, Soft Matter 9, $8697(2013)$.

[112] H. Ning, J. K. Dhont, and S. Wiegand, Langmuir 24, 2426 (2008).

[113] O. Syshchyk, D. Afanasenkau, Z. Wang, H. Kriegs, J. Buitenhuis, and S. Wiegand, The European Physical Journal E 39, 129 (2016).

[114] F. Batalioto, G. Barbero, A. L. Sehnem, and A. M. F. Neto, Journal of Applied Physics 120, 054304 (2016).

[115] J. N. Agar, C. Y. Mou, and J. L. Lin, J. Phys. Chem 93, 2079 (1989).

[116] E. D. Eastman, Journal of the American Chemical Society 49, 794 (1927).

[117] E. Helfand and J. G. Kirkwood, The Journal of Chemical Physics 32, 857 (1960).

[118] H. Sugioka, Langmuir 30, 8621 (2014), pMID: 25003210.

[119] I. Chikina, V. Shikin, and A. A. Varlamov, Phys. Rev. E 86, 011505 (2012).

[120] A. Majee and A. Würger, Phys. Rev. Lett. 108, 118301 (2012).

[121] Y.-L. Chen, C.-X. Yang, and H.-R. Jiang, Scientific Reports 8, 5945 (2018).

[122] K. Touati, M. Depriester, M. Kuriakose, and A. H. Sahraoui, Review of Scientific Instruments 86, 094901 (2015).

[123] M. Bonetti, S. Nakamae, M. Roger, and P. Guenoun, J Chem Phys 134, 114513 (2011).

[124] T. J. Salez, B. T. Huang, M. Rietjens, M. Bonetti, C. Wiertel-Gasquet, M. Roger, C. L. Filomeno, E. Dubois, R. Perzynski, and S. Nakamae, Phys. Chem. Chem. Phys. 19, 9409 (2017). 
[125] H. Im, T. Kim, H. Song, J. Choi, J. S. Park, R. Ovalle-Robles, H. D. Yang, K. D. Kihm, R. H. Baughman, H. H. Lee, T. J. Kang, and Y. H. Kim, Nature Communications 7, 10600 (2016).

[126] D. Zhao, H. Wang, Z. U. Khan, J. C. Chen, R. Gabrielsson, M. P. Jonsson, M. Berggren, and X. Crispin, Energy Environ. Sci. 9, 1450 (2016).

[127] A. Al-zubaidi, X. Ji, and J. Yu, Sustainable Energy Fuels 1, 1457 (2017).

[128] L. Zhang, T. Kim, N. Li, T. J. Kang, J. Chen, J. M. Pringle, M. Zhang, A. H. Kazim, S. Fang, C. Haines, D. Al-Masri, B. A. Cola, J. M. Razal, J. Di, S. Beirne, D. R. MacFarlane, A. Gonzalez-Martin, S. Mathew, Y. H. Kim, G. Wallace, and R. H. Baughman, Advanced Materials 29, 1605652 (2017).

[129] A. Ly, A. Majee, and A. Würger, New Journal of Physics 20, 025001 (2018).

[130] R. J. Bearman and V. S. Vaidhyanathan, The Journal of Chemical Physics 39, 3411 (1963).

[131] R. J. Bearman, J. G. Kirkwood, and M. Fixman, "Statistical mechanical theory of transport processes. x. the heat of transport in binary liquid solutions," in Advances in Chemical Physics (Wiley-Blackwell, 1958) pp. 1-13.

[132] K. G. Denbigh, The Thermodynamics of the Steady State (Methuen and Co. Ltd., 1964).

[133] P. Y. Kahana and J. long Lin, The Journal of Chemical Physics 75, 5043 (1981).

[134] P. Y. Kahana and J. long Lin, The Journal of Chemical Physics 74, 2993 (1981).

[135] A. F. C. Campos, Contribuição ao estudo da densidade superficial de carga na estabilidade de coloides magnéticos: uma abordagem eletroquimica, Thesis, Universidade de Brasília (2005).

[136] J. de Andrade Gomes, Estudo das propriedades estruturais locais de fluidos magnéticos: da nanopartícula `a dispersão, Ph.D. thesis, Universidade de Brasília (2007). 
[137] O. Glatter, Journal of Applied Crystallography 10, 415 (1977).

[138] O. Glatter, Journal of Applied Crystallography 13, 7 (1980).

[139] A. S. Dukhin, V. N. Shilov, H. Ohshima, and P. J. Goetz, Langmuir 15, 6692 (1999).

[140] R. W. O’Brien, J. Fluid Mech. 190, 71 (1988).

[141] I. Lucas, S. Durand-Vidal, O. Bernard, V.Dahirel, E. Dubois, J.F.Dufrêche, S. Gourdin-Bertin, M. Jardat, G. Meriguet, and G. Roger, Molecular Physics 112, 1463 (2014).

[142] J. N. Agar and J. C. R. Turner, Proc. R. Soc. Lond. A 255, 307 (1960).

[143] J. N. Agar and W. G. Breck, Trans. Faraday Soc. 53, 167 (1957).

[144] J. A. Bierlein, The Journal of Chemical Physics 23, 10 (1955).

[145] N. Ghofraniha, G. Ruocco, and C. Conti, Langmuir 25, 12495 (2009), pMID: 19817352.

[146] M. Dietzel and S. Hardt, Phys. Rev. Lett. 116, 225901 (2016).

[147] M. Dietzel and S. Hardt, Journal of Fluid Mechanics 813, 1060 (2017).

[148] A. M. Benneker, H. D. Wendt, R. G. H. Lammertink, and J. A. Wood, Phys. Chem. Chem. Phys. 19, 28232 (2017).

[149] J. P. Gordon, R. C. C. Leite, R. S. Moore, S. P. S. Porto, and J. R. Whinnery, Journal of Applied Physics 36, 3 (1965).

[150] S. Bialkowski, Photothermal spectroscopy methods for chemical analysis (John Wiley \& Sons, 1988).

[151] H. S. Carslaw and J. C. Jaeger, Operational methods in applied mathematics (Dover Publications, EUA, 1963). 
[152] P. R. dos Santos, Caracterização estrutural e óptica de lipoproteínas humanas nativa e oxidadas, Ph.D. thesis, Universidade de Sao Paulo (2013).

[153] R. Vyas and R. Gupta, Appl Opt 27, 4701 (1988).

[154] H. L. Fang and R. L. Swofford, J. Appl. Phys. 50, 6609 (1979).

[155] H. L. Fang and R. L. Swofford, Ultrasensitive Laser Spectroscopy, ch. 3, edited by D. Klieger (Academic Press, 1983).

[156] A. Yariv, Quantum Electronics (John Wiley \& Sons, 1988).

[157] W. Köhler, C. Rosenauer, and P. Rossmanith, International Journal of Thermophysics 16, 11 (1995).

[158] A. L. Sehnem, D. Espinosa, E. S. Gonçalves, and A. M. Figueiredo Neto, Brazilian Journal of Physics 46, 547 (2016).

[159] W. Köhler, J Chem Phys 98, 660 (1993).

[160] W. Köhler, C. Rosenauer, and P. Rossmanith, International Journal of Thermophy$\operatorname{sics} \mathbf{1 6}, 11(1995)$.

[161] W. Köhler and P. Rossmanith, J Chem Phys 99, 5838 (1995).

[162] R. Kita, P. Polyakov, and S. Wiegand, Macromolecules 40, 1638 (2007).

[163] F. Römer, Z. Wang, S. Wiegand, and F. Bresme, The Journal of Physical Chemistry B 117, 8209 (2013).

[164] R. Kita, S. Wiegand, and J. Luettmer-Strathmann, J. Chem. Phys. 121 (2004).

[165] W. R. Bousfield, Journal of the Chemical Society Transactions 107, 1781 (1915).

[166] M. Laliberté, Journal of Chemical \& Engineering Data 54, 1725 (2009).

[167] E. K. Goharshadi, H. Ahmadzadeh, S. Samiee, and M. Hadadian, Phys. Chem. Res. 1, 1 (2013). 
[168] J. Philip and P. D. Shima, Advances in Colloid and Interface Science 183-184, 30 (2012).

[169] J. C. Bacri, A. Cebers, A. Bourdon, G. Demouchy, B. M. Heegaard, and R. Perzynski, Phys. Rev. Lett. 74, 5032 (1995).

[170] C. L. Filomeno, M. Kouyatè, V. Peyre, G. Demouchy, A. F. C. Campos, R. Perzynsky, F. A. Tourinho, and E. Dubois, The Journal of Physical Chemistry C 121, 5539 (2017).

[171] F. S. Gaeta, G. Perna, G. Scala, and F. Bellucci, The Jornal of Physical Chemistry 66, 2967 (1982).

[172] J. Colombani, J. Bert, and J. Dupuy-Philon, Journal of Chemical Physics 110, 8622 (1999).

[173] D. G. Leaist and L. Hao, J. Chem. Soc., Faraday Trans. 90, 1223 (1994).

[174] K. Eguchi, D. Niether, S. Wiegand, and R. Kita, Eur Phys J E Soft Matter 39, 86 (2016).

[175] D. Niether, T. Kawaguchi, J. Hovancová, K. Eguchi, J. K. G. Dhont, R. Kita, and S. Wiegand, Langmuir 33, 8483 (2017).

[176] H. Brenner, Phys. Rev. E 70, 061201 (2004).

[177] J. R. Bielenberg and H. Brenner, Physica A 356, 279 (2005).

[178] G. S. Kell, Journal of Chemical \& Engineering Data 20, 97 (1975).

[179] J. Blumm and A. Lindemann, High Temperatures - High Pressures 35 - 36, 627 (2003).

[180] A. L. Sehnem, D. Niether, S. Wiegand, and A. M. Figueiredo Neto, The Journal of Physical Chemistry B 122, 4093 (2018).

[181] R. F. Stout and A. S. Khair, Phys. Rev. E 96, 022604 (2017). 
[182] S. Di Lecce and F. Bresme, The Journal of Physical Chemistry B 122, 1662 (2018), pMID: 29293343.

[183] S. Di Lecce, T. Albrecht, and F. Bresme, Scientific Reports 7, 44833 (2017).

[184] M. Wolff, J. J. Mittag, T. W. Herling, E. D. Genst, C. M. Dobson, T. P. J. Knowles, D. Braun, and A. K. Buell, Scientific Reports 6, 22829 (2016).

[185] S. A. Seidel, P. M. Dijkman, W. A. Lea, G. van den Bogaart, M. Jerabek-Willemsen, A. Lazic, J. S. Joseph, P. Srinivasan, P. Baaske, A. Simeonov, I. Katritch, F. A. Melo, J. E. Ladbury, G. Schreiber, A. Watts, D. Braun, and S. Duhr, Methods 59, 301 (2013), biophysical Methods for the Study of Protein Interactions.

[186] M. Jerabek-Willemsen, C. J. Wienken, D. Braun, P. Baaske, and S. Duhr, ASSAY and Drug Development Technologies 9, 342 (2011). 